Rodrigo Xavier das Neves

\title{
INFLAMAÇÃO E ALTERAÇÃO METABÓLICA NA CAQUEXIA: PAPEL DOS ADIPÓCITOS, DO FÍGADO E DA MODULAÇÃO OFERECIDA PELA MICROBIOTA INTESTINAL
}

Tese apresentada ao programa de Pós-Graduação em Biologia Celular e Tecidual do Instituto de Ciências Biomédicas da Universidade de São Paulo, para obtenção do Título de Doutor em Ciências. 
Rodrigo Xavier das Neves

\section{INFLAMAÇÃO E ALTERAÇÃO METABÓLICA NA CAQUEXIA: PAPEL DOS ADIPÓCITOS, DO FÍGADO E DA MODULAÇÃO OFERECIDA PELA MICROBIOTA INTESTINAL}

Tese apresentada ao Departamento de Biologia Celular e do Desenvolvimento do Instituto de Ciências Biomédicas da Universidade de São Paulo, para obtenção do Título de Doutor em Ciências.

Área de concentração: Biologia Celular e Tecidual

Orientadora: Profa. Dra. Marília Cerqueira Leite Seelaender

Versão corrigida. A versão original eletrônica encontra-se disponível tanto na biblioteca do ICB quanto na biblioteca Digital de Teses e Dissertações da USP (BDTD)

São Paulo, SP

2016 
DADOS DE CATALOGAClO NA FUBLICAClO (CP)

Serviço de Elbiloteca e informaçbo Elomedica do

Inettuto de Cienclas Blomedicas do Univeraldade de 8So Paulo

O ieproductio teta

Neves, Rodrigo Xavier das.

Inflamaçáo e alteraçáo matebolca na caquexia: papel dos adpocitos, no figado é da modulaçáso oferecida pela microbiota Intestinal / Rodrigo Xavier das Neves. - Săo Paulo, 2016.

Orlentador: Profa. Dra. Marlla Cerquelra Leite Seelaender.

Tese (Doutorado) - Unlversidade de Sto Paulo. Insthuto de Clencias Blomedicas. Departamento de Blologla Celular e do Desenvolvimento. Avea de concentraçálo: Blologla Celular e Tecidual. Linha de pesquisa: Metabolismo do tecido adlposo associado a caquexia.

Versto do thitu para o ingles: Cancer cachexia Inflammation and metabolk: contribution of afpocyle, of the liver and modulation by intestinal microblota.

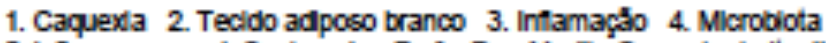
5. Inthamassoma L. Seelaender, Profa. Dra Marlla Cerquelra Lelte II. Universidade de Sáo Paulo. Instututo de Clenclas Blomedlcas.

Programa de Pos-Graduaç5̃o em Blologla Celular e Tecldual III. Titulo. 
UNIVERSIDADE DE SÅO PAULO

INSTITUTO DE CIÉNCIAS BIOMÉDICAS

\section{Candidato(a): \\ Rodrigo Xavier das Neves. \\ Titulo da Tese: \\ Inflamação e alteração matebólica na caquexia: papel dos adipócitos, no figado e da modulação oferecida pela microbiota intestinal.}

Orientador(a):

Profa. Dra. Marilia Cerqueira Leite Seelaender.

A Comissão Julgadora dos trabalhos de Defesa da Tese de Doutorado, em sessäo

pública realizada a

J considerou

( ) Aprovado(a) ( ) Reprovado(a)

$\begin{array}{ll}\text { Examinador(a): } & \begin{array}{l}\text { Assinatura: } \\ \text { Nome: } \\ \text { Instituição: }\end{array} \\ \text { Examinador(a): } & \begin{array}{l}\text { Assinatura: } \\ \text { Nome: } \\ \text { Instituiçăo: }\end{array} \\ \text { Examinador(a): } \quad \begin{array}{l}\text { Assinatura: } \\ \text { Nome: } \\ \text { Instituiçăo: }\end{array} & \begin{array}{l}\text { Assinatura: } \\ \text { Nome: } \\ \text { Instituiçăo: }\end{array} \\ \text { Assinatura: } & \begin{array}{l}\text { Nome: } \\ \text { Instituiçăo: }\end{array}\end{array}$


"Embora ninguém possa voltar atrás e fazer um novo começo, qualquer um pode começar agora e fazer um novo fim."

Chico Xavier 


\section{CERTIFICADO}

Certificamos que o protocolo registrado sob $n^{6} 050$ nas ils. 102 do livro 02 para uso de animais em experimentaçato, sob a responsabilidade do Profial Dr|ał) Marilia Cerqueira teite Seelaender, Coordenadorla) da Linha de pesquisa "Alteraçōes metabolicas e monfofuncionais mediadas pela atividade fisica e supfementaçăo nuericional em ratos caqueticos" do qual participam c'sl alunos Fernando de Oliveira Rosa, Rodolfo Gonzales Camargo, Henrique Quintas Riheiro, Luana Sabetay Oliveira Levy, Renata Silvério, Patricia Esther Rocha, Luiz Carlos Carnevali, Lucas Maceratesi Enjiu, felipe fedrizzi Donatto, Michele Joana Alves, Paulo Rogério, Felipe Capel D'Ambrosio, Adriana Jaime Sbampato Assad, Marcos Pisiotano, Rodrigo Xavier das Neves, Julia Laurindo Giacomini e a pesquisadara Anelisa Magalhães, está de acordo com os Principios Éticos de Experimentaçăo Animal adotado pela Sociedade Brasileira de Ciencia de Animais de Labocatório (SBCAL) e fai aprowado pela COMISSÄO DE ÉTICA NO USO DE ANMMAIS [CEUA] em 19.04.2011, com validade de 3 anos.

\section{Lr xum}

Prof.DT.WOTHMN TAVARES DE LIMA Cocrdenador CEUA - ICBNUSP
Sâa Pauls, 20 de abril te 2011.

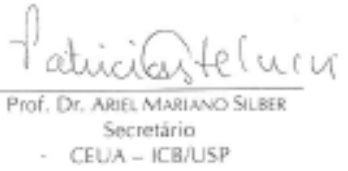




\section{Modification Review Submission Form (Animal Studies Only)-Version 2.0}

1. Modífication Review Submizaion Form

(version 1.2 2-5-2012)

1.1 Protocol Number:

LEl-008-9

1.2 Protocol Title:

Besic Research Protsed immunoenobuaton and immuncherapy in neive and tumor bearifg mice

$1.3^{*}$ Principal Investigator Information

Pindiped imestgetsc

Corgo Trinctieri MO, MD

Pindipel Investgetse E-Mal Addrum.

tinctiogriaidinth gor

Pindipel imestogtse Buldine Roordusc:

37/4186AV4182

Pindipel imvestgetse Primary Phore Number.

301.808.1203

Pindiped imvesboetse Fe:

301-206-0734

1.4 Instructions:

Al charges mux, isidete io a previoualy approved proposal.

$1.5 *$ Proposal modifications include: (chock all that apply)

\begin{tabular}{|c|c|c|c|}
\hline$\nabla$ & 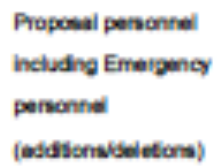 & $\square$ New arimel & 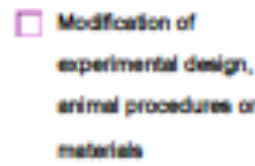 \\
\hline C & Hazardous agertb & 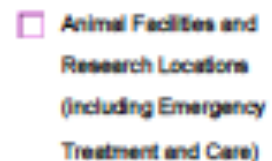 & \\
\hline
\end{tabular}

\section{Key Study Personnel Changes}

2.1 Additions/Deletions of individuals authorizod to conduct procedures involving animals under this proposal:

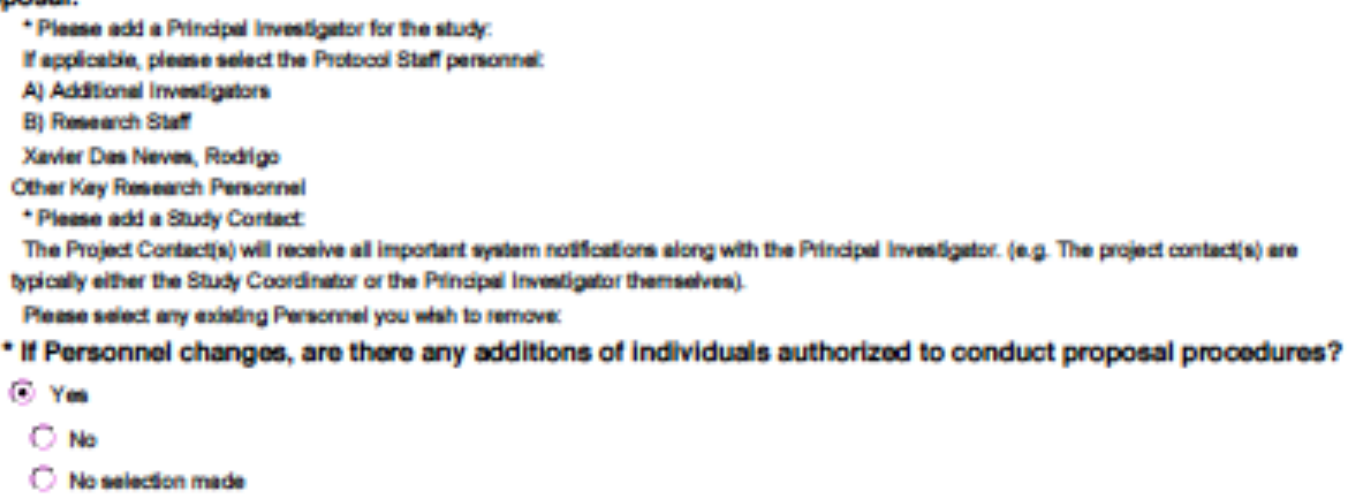

2.3 List the names of authorizod individuals (including PI, and Co-PI) who will conduct procedures involving animals under this proposal.

For individuals not proticient in performing the procedures list the name of the person who will provide their training. 


\begin{tabular}{|c|c|c|c|c|}
\hline Name & 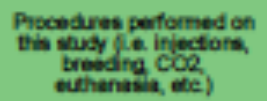 & $\begin{array}{l}\text { Experiencas in Parforming } \\
\text { Proposed Proceditus (2) of } \\
\text { years) }\end{array}$ & 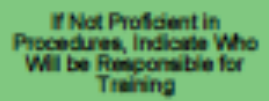 & $\begin{array}{l}\text { Penform Radieton } \\
\text { Procistures }\end{array}$ \\
\hline $\begin{array}{l}\text { Fondigo Xavier Das } \\
\text { Neves }\end{array}$ & 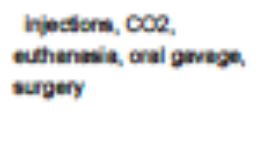 & 5 years & mene? & $\begin{array}{l}O \mathrm{Yes} \\
(6 \mathrm{No} \\
\mathrm{O} \text { No selection made }\end{array}$ \\
\hline
\end{tabular}

3. Rationale for Modifications

3.1 * Provide rationale for the modifications: incuring new persornel to the lab

4. Submission Attachments

4.1 * Attachments include: (chock all that apply)

\begin{tabular}{|c|c|c|c|c|}
\hline $\begin{array}{l}\nabla \text { No athactiment } \\
\text { necinsary }\end{array}$ & $\square$ & 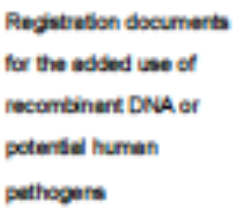 & प usds & $\square$ Prebleaton \\
\hline [ IBC documertubion & $\square$ & $\begin{array}{l}\text { Reievent } \\
\text { corrimpendence }\end{array}$ & [ RB docummitaton & $\square$ MBTM lest ienuls \\
\hline 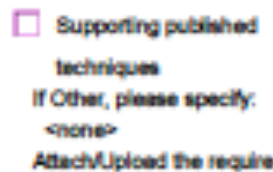 & & $\begin{array}{l}\text { Cether approved ASP (is } \\
\text { reflerincte) }\end{array}$ & $\square$ sop & $\square$ one \\
\hline
\end{tabular}

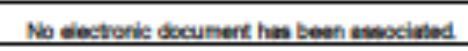

4.2 Submission Routing Instructions:

Provie tox

ค

Added Propes ad Persornel (f appleable) 


\section{DEDICATÓRIA}

Dedico esta Tese a todos que acreditaram que eu seria capaz de conseguir vencer mais esta batalha, em especial minha mãe Joana que sempre esteve do meu lado nos momentos que eu sempre necessitei, a minha noiva Daniela que me aturou com muita paciência e amor, a minha irmã Luana que me ajudou sempre que eu precisei e ao meu pai Geraldo por todos os momentos. 


\section{AGRADECIMENTO}

Primeiramente agradeço a Deus por te me dado saúde para poder chegar ao fím desta luta.

A Minha orientadora, Prof. Dra. Marília C L Seelaender que perdeu horas de sua vida me ensinando tanto técnicas laboratoriais quanto ser um homem comprometido com os meus compromissos e a confiança que depositou em meu trabalho.

A todos os colegas de laboratório, em especial Daniela Riccardi, Emídio Matos, Raquel Galvão, Katrin Radloff, Michele Alves, Rodolfo Camargo, Daniela Caetano e Joanna Carola, também aos não do laboratório, como Dr. Alex, Edson, Alexandre, Loreana, Dra. Patrícia e Dr. Thiago, Felipe Henriques, que ajudaram de alguma forma para a conclusão desta Tese. À Emília Ribeiro, pelo excelente suporte técnico, aos profissionais da Biblioteca que sempre estiveram à disposição para ajudar no que fosse necessário.

Aos Professores do ICB em especial o Dr. José Cesar Neto, o Dr. Willian, Dr. Emer, Dra. Alison, Dra. Edna, Dra. Marinilce e Dr. Niels e também os não associados ao ICB, como Dr. Miguel e Dr. Fábio aos demais que me ajudaram muito na minha formação como aluno e me preparando para a vida profissional.

A todos da secretaria, em especial à Regina, que sempre me orientou sobre todos os procedimentos necessários e sempre ajudou no que foi preciso durante todo o Doutorado.

Ao Professor M.D. Giorgio Thrinchieri, por me dar uma excelente oportunidade de trabalhar em seu laboratório durante 10 meses e todo o seu tempo com conversas para uma melhor compreensão do projeto. Sua equipe que foi maravilhosa, Robin, Cheryl, Ming, Sharon, Rosi, Amiran, Roy, Ernesto, Barbara, Bathay, Arsa, April and Loretta.

Ao NIH pelo apoio financeiro durante o meu estágio no exterior

A minha mãe, Joana Cele Xavier das Neves, meu pai, Geraldo Moreira das Neves, minha irmã, Luana Xavier das Neves, minha afilhada, Pietra e a minha noiva, Daniela M R Riccardi, por todos os meus bons e ruins momentos, pois sempre estiveram ao meu lado.

Aos meus avós (Francisco e Efigênia; Antônio e Laura) que nunca deixaram de torcer por mim, mesmo estando onde eles estão.

A Coordenação de aperfeiçoamento de Pessoal de Nível Superior (CAPES) pelo apoio financeiro desenvolvido no Brasil e no exterior. 


\title{
RESUMO
}

\author{
NEVES, R X. das Inflamação e alteração metabólica na caquexia: papel dos \\ adipócitos, do fígado e da modulação oferecida pela microbiota intestinal. \\ 2016. f. 109. Tese (Doutorado em Biologia Celular e Tecidual) - Instituto de \\ Ciências Biomédicas, Universidade de São Paulo, São Paulo, 2016.
}

A caquexia associada ao câncer é uma síndrome complexa caracterizada pela diminuição do peso corporal, depleção dos estoques de gordura, diminuição da massa muscular, anorexia, astenia e distúrbios metabólicos. Utilizando modelo animal, estudamos a participação dos adipócitos, do fígado e da microbiota intestinal para a inflamação sistêmica crônica associada aos sintomas do quadro. Os principais aspectos avaliados foram aumento dos fatores inflamatórios, alteração da via do NF- $\kappa \mathrm{B}$ e do inflamassoma, modulação pela microbiota durante progressão da caquexia. Para verificar o comportamento dos adipócitos e do fígado utilizamos ratos Wistar macho de 8 semanas, divididos em dois grupos principais: i) controle; ii) tumor. Este último foi subdividido em 2 grupos: a) $7^{\circ}$ e b) $14^{\circ \cdot}$ dia após a inoculação das células tumorais do carcinoma de Walker 256, inoculadas subcutâneamente $\left(2 \times 10^{7}\right.$ de células em 1,0 mL). Para avaliar o comportamento da microbiota durante o quadro de caquexia utilizamos camundongos C57Bl/6, convencionais e Germ free de 8-10 semanas, os quais dividimos em quatro grupos: i) Convencional controle; ii) Germ Free controle; iii) Convencional tumor; iv) Germ Free tumor. A linhagem tumoral usada para esse modelo foi Lewis Lung Carcinoma (LLC), inoculadas subcutâneamente $\left(4 \times 10^{6}\right.$ de células em 0,2 mL). Houve uma indução da via inflamassoma na fase terminal da caquexia e com aumento da expressão proteica de IL-1 $\beta$ clivada tanto local, adipócitos isolados do tecido adiposo branco (TAB) mesentérico (MEa) e fígado, quanto sistêmica. Quanto à relação da microbiota com a caquexia, observamos que a doença é exacerbada nos camundongos Germ Free, pois verificamos que a via da lipólise esta mais ativa no tecido adiposo epididimal, comparado aos camundongos do grupo convencional tumor. Em conclusão, os adipócitos isolados do TAB mesentérico e o fígado desempenham um papel importante no estabelecimento da inflamação, por meio de ativação das vias do NF- $\mathrm{BB}$ e do inflamassoma enquanto; que a simbiose a integridade da microbiota parece ser essencial para combater a redução do tecido adiposo imposta pela caquexia.

Palavras-chave: Caquexia. Tecido adiposo branco. Inflamação. Microbiota. Inflamassoma. 


\begin{abstract}
NEVES, $\mathrm{R} X$. das Cancer cachexia inflammation and metabolic: contribution of adipocyte, of the liver and modulation by intestinal microbiota. 2016. p. 109. PhD Thesis (Tissue and Celular Biology) - Instituto de Ciências Biomédicas, Universidade de São Paulo, São Paulo, 2016.

Cancer-cachexia is a complex syndrome characterized by decreased body weight, depletion of fat stores, decreased muscle mass, anorexia, asthenia and metabolic disorders. Employing animal models, we studied the role of adipocytes and liver inflammation and what would be the role of microbiota along the progression of cachexia associated with cancer. The main aspects evaluated were inflammation, modulation of NF- $\kappa \mathrm{B}$ and the inflammasome, and importance of the microbiota during the progression of cachexia. To asses the contribution of adipocytes and the liver. Eight weeks-old male rats, divided into two main groups: i) control; ii) tumor were studied. The latter was divided into 2 groups: a) $7^{\circ \cdot}$ and b) $14^{\circ}$ day after tumor cell inoculation Walker 256, which was injected subcutaneously $\left(2 \times 10^{7}\right.$ cells in $\left.1.0 \mathrm{~mL}\right)$. To assess microbial relevance during the development of cachexia, C57BL/6 conventional mice and Germ Free 8-10 weeks, were studied and divided into four groups: i) Conventional control; ii) Germ Free control; iii) Conventional tumor; iv) Germ Free tumor. The tumor cell linage employed in this model was the Lewis Lung Carcinoma (LLC), which was injected subcutaneously $\left(4 \times 10^{6}\right.$ cells in $\left.0.2 \mathrm{~mL}\right)$. Adipocytes isolated from white adipose tissue mesentericTAB, mesenteric and the liver, showed inflammasome active in the terminal phase of cachexia, when an increase in expression of cleaved IL-1 $\beta$ protein was observed. As for the relationship of the microbiota with cachexia, the establishment of the syndrome was quickly in the Germ Free mice, as lipolysis was more active in epididymal adipose tissue compared to conventional tumor mice. In conclusion, adipocytes isolated from the mesenteric depot and liver seem to play a relevant role in the establishment of inflammation, through the activation of the NF- $\kappa \mathrm{B}$ and inflammasome pathways. Microbiota integrity seems to be essential for preventing adipose tissue of lipolysis generated by cancer-cachexia.
\end{abstract}

Keywords: Cachexia. White adipose tissue. Inflammation. Microbiota. Inflammasome. 


\section{LISTA DE FIGURAS}

Figura 1 - Estágios da caquexia associada ao câncer.

Figura 2 - Ligação e subsequente ativação da via do inflamassoma por amiloide e agregado de proteínas mal formadas.

Figura 3 - Expressão gênica e proteica de citocinas inflamatórias no tecido adiposo branco durante a progressão da caquexia.

Figura 4 - Expressão gênica e proteica de citocinas inflamatórias em células adiposas isoladas durante a progressão da caquexia.

Figura 5 - Expressão gênica dos fatores de transcrição envolvidos na vias inflamatórias em células adiposas isoladas durante a progressão da caquexia.

Figura 6 - Expressão de citocinas inflamatórias no fígado durante a progressão da caquexia.

Figura 7 - Expressão gênica da via do inflamassoma em células adiposas isoladas durante a progressão da caquexia.

Figura 8 - Expressão de citocinas inflamatórias no fígado durante a progressão da caquexia.

Figura 9 - Imunohistoquímica para CD68

Figura 10 - Expressão gênica dos fatores de transcrição envolvidos na via inflamatória no fígado durante a progressão da caquexia.

Figura 11 - Expressão proteica de fatores inflamatórios no fígado durante a progressão da caquexia.

Figura 11 - Expressão gênica da via do inflamassoma em células adiposas isoladas durante a progressão da caquexia

Figura 12 - Expressão gênica da via do inflamassoma no fígado durante a progressão da caquexia

Figura 13 - IL-1 $\beta$ sérica durante na fase terminal da caquexia.

Figura 14 - Perda de peso e peso dos tecidos dos grupos Convencionais e Germ Free, com e sem caquexia

Figura 15 - Expressão gênica no $\mathrm{TAB}$ epididimal, durante a progressão da caquexia.

Figura 16 - Imunohistoquímica para UCP-1

Figura 17 - Expressão proteica de proteínas da via da lipólise no TAB epididimal, durante a progressão da caquexia 
LISTA DE TABELAS

Tabela 1 - Lista de Primers ..................................................................................... 33

Tabela 2 - Peso corporal e dos tecidos dos grupos Controle (C) e Caquéticos (TB)....... 40

Tabela 3 - Perfil lipídico durante a progressão da caquexia........................................ 40 


\section{LISTA DE ABREVIATURAS E SIGLAS}

ACC: Acetil-CoA Carboxilase

CEBP $\alpha$ : CCAAT-Enhancer Binding Protein Alpha

CPT: Carnetina Palmiotransferase

FABP: Proteína Ligadora de Ácido Graxo

FAS: Ácido Graxo Sintase

HSL: Lípase de Hormônio Sensivo

IL-1: Interleucina 1

IL-10: Interleucina 10

IL-1 $\beta$ : Interleucina 1 beta

IL-6: Interleucina 6

IL-8: Interleucina 8

INF- $\gamma$ : Interferon gamma

JNK: Jun-Kinase

LPL: Lípase Lipoproteíca

MAPK: Mitogen activated Protein Kinase

MCP-1: Monocyte Chemotactic Protein

MIF: Fator Mobilizador de Lipídios

mRNA: Ácido Ribonucleico Mensageiro

TAG: Triacilglicerol

PIF: Fator indutor de Proteólise

PPAR $\gamma$ : Peroxisome Proliferator-Activeted Recptor gamma

SDC-1: Estearoil CoA Desnaturase 1

SREBP 1C: Sterol Regulatory Element Binding Protein

TAB: Tecido Adiposo Branco

TAE: Tecido Adiposo Epididimal

TAM: Tecido Adiposo Marrom

TAME: Tecido Adiposo Mesentérico

TARP: Tecido Adiposo Retroperitoneal

TNFR1: Receptor Fator de Necrose Tumoral

TNF- $\alpha$ : Fator de Necrose Tumoral Alfa 


\section{SUMÁRIO}

1 INTRODUÇÃO

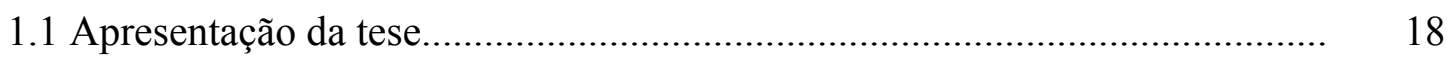

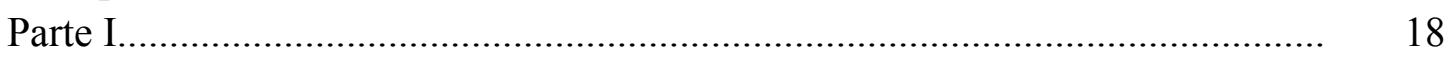

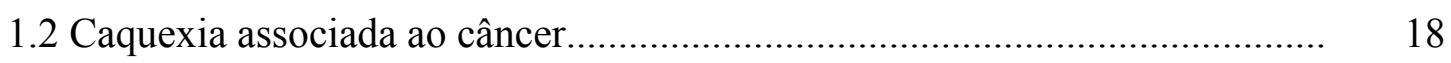

1.3 Caquexia e resposta do hospedeiro............................................................... 20

1.4 Vias inflamatórias.................................................................................. 22

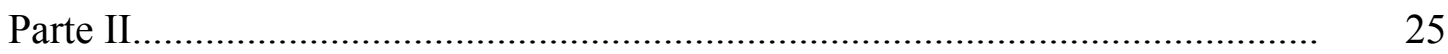

$1.5 \mathrm{O}$ estudo da microbiota e a relação com o desenvolvimento da caquexia

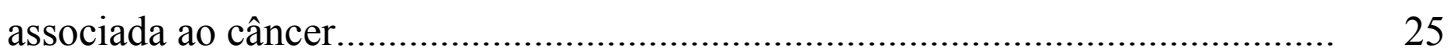

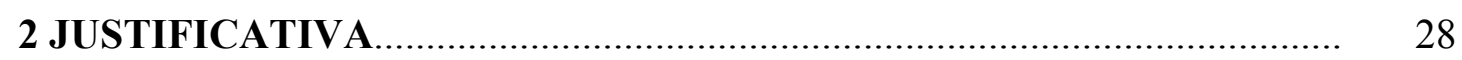

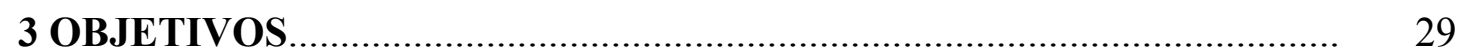

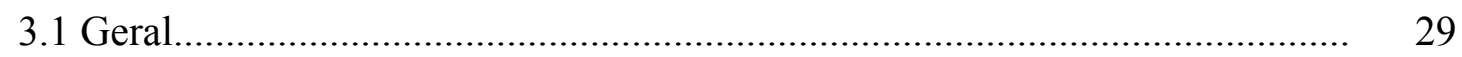

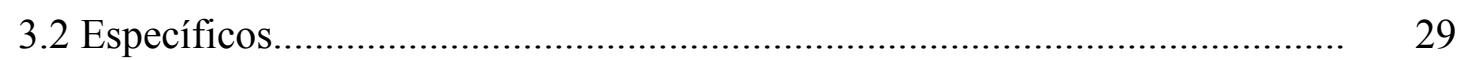

4 MATERIAL E MÉTODO........................................................................... 30

4.1 Determinação gerais.................................................................................... $\quad 30$

4.1.1 Animais............................................................................... 30

4.1.2 Desenho experimental......................................................................... $\quad 30$

4.1.3 Inoculação do tumor Walker 256........................................................... $\quad 30$

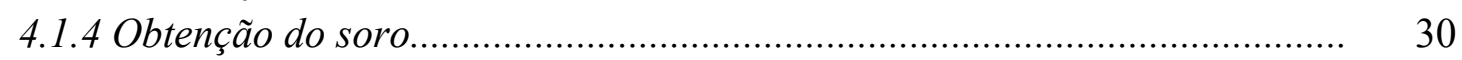

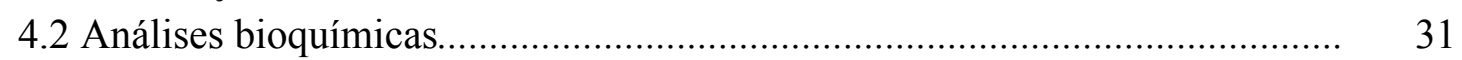

4.2.1 Determinações séricas................................................................................ 31

4.3 Análise histológica....................................................................................... 31

4.3.1 Obtenção e processamento do tecido......................................................... 31

4.4 Isolamento de células adiposas....................................................................... 31

4.5 Análise da expressão gênica por qRT-PCR.................................................... 32

4.5.1 Extração do RNA total........................................................................ 32

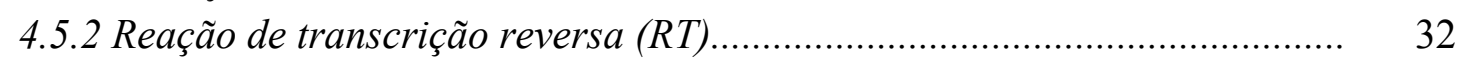

4.5.3 Seleção dos primers.............................................................................. 32

4.5.4 Reação em cadeia polimerase em tempo real (qRT-PCR)........................... 34

4.6 Análise da expressão protéica - Western bloting............................................. 34

4.6.1 Extração proteica ................................................................................... 34

4.6.2 Eletroforese SDS-PAGE .................................................................... 35

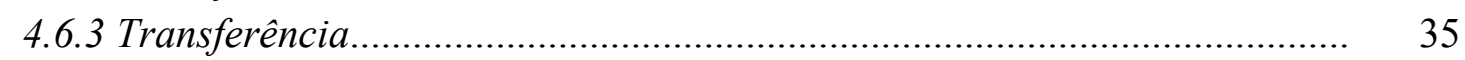

4.6.4 Bloqueio e incubação............................................................................... $\quad 35$

4.6.5 Exposição e desenvolvimento do filme.................................................... 36

4.7 Enzyme-linked immunoabsorbent assay (ELISA) ......................................... 36

4.8 Parte II - Referente ao estudo da microbiota................................................ 36

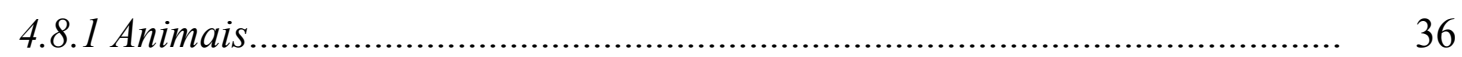

4.8.2 Desenho experimental e implantação das células tumorais......................... 37

4.8.3 Variação do peso corporal e obtenção dos tecidos...................................... 37 


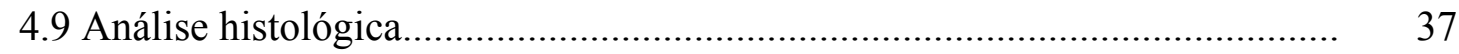

4.9.1 Obtenção e processamento do tecido........................................................ 37

4.9.2 Desparafinização/Hidratação.................................................................. 38

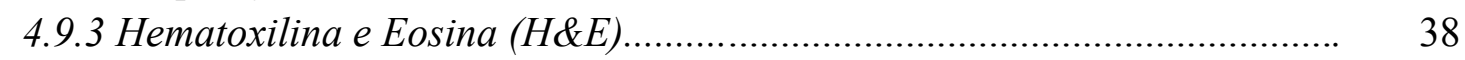

4.9.4 Imunohoistoquímica.......................................................................... 38

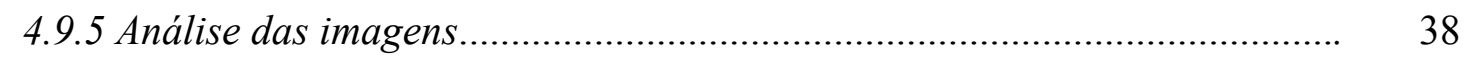

4.10 qPCR RT e Western blot....................................................................... 38

4.11 Análise estatística............................................................................. 39

5 RESULTADOS ................................................................................ 40

5.1 Parâmetros de validação da caquexia............................................................. 40

5.2 Inflamação durante a caquexia associada ao câncer....................................... 40

5.3 Estudo dos adipócitos durante o desenvolvimento da caquexia associada ao câncer.................................................................................................... 42

5.4 Estudo do fígado durante o desenvolvimento da caquexia associada ao câncer................................................................................................ 46

5.5 Contribuição do tecido adiposo e fígado para o desenvolvimento da caquexia associada ao câncer............................................................................. 51

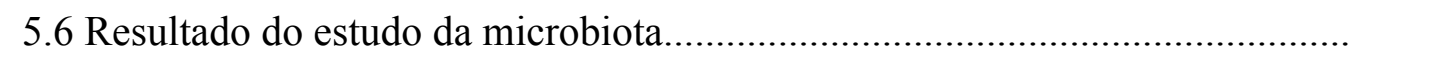

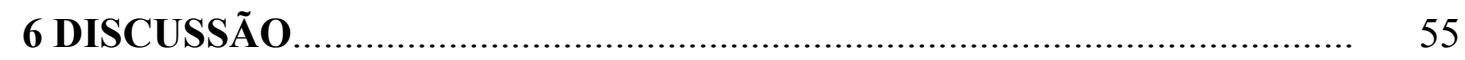

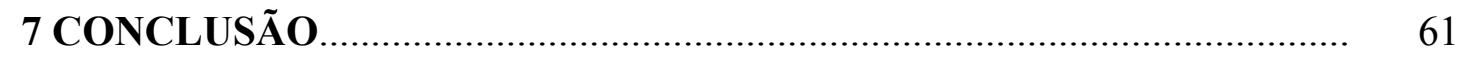

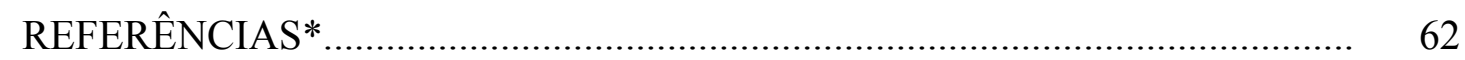

ANEXO 1 - Artigo publicado............................................................................ $\quad 72$

ANEXO 2 - Artigo enviado a publicação........................................................... 84 


\section{INTRODUÇÃO}

\subsection{Apresentação da tese}

A tese está elaborada em dois capítulos. O primeiro é composto por resultados realizados no Brasil, sob a orientação da Professora Dra. Marília Seelaender; parte desses resultados publicamos em artigo (Anexo-1) (Journal of Cachexia, Sarcopenia and Muscle White adipose tissue cells and the progression of cachexia: Inflammatory pathways); da outra parte dos resultados, escrevemos um segundo artigo "Cachexia causes time-dependent activation of the inflammasome in the liver", que foi enviado para publicação. O segundo capítulo da tese é composto por resultados obtidos nos Estados Unidos da América, em colaboração com o Professor M. D. Giorgio Trinchieri, atualmente, diretor do programa "Cancer and inflammation Program" no "National Health Institute" (NCI-NIH). Nesse estudo, abordamos a modulação exercida pela microbiota ao longo da progressão da caquexia associada ao câncer com enfoque no tecido adiposo.

Parte I

\subsection{Caquexia associada ao câncer}

A palavra caquexia tem origem grega: "kakos" significa má e "hexis" significa condição (TISDALE, 1997). Este quadro foi descrito há mais de 2.000 anos, sendo evidente em alguns tipos de cânceres, não estando, contudo, restrito somente a essa doença. A caquexia aparece associada à síndrome da imunedeficiência adquirida (AIDS), aos grandes traumas, às moléstias digestivas, à insuficiência renal, à doença respiratória, à artrite reumatoide, à insuficiência cardíaca, entre outras (TISDALE, 1997; TODOROV et al., 1996; ZEYDA e STULNIG, 2007).

Trata-se de uma síndrome de etiologia complexa e causa desconhecida, que está associada à redução de efeitos terapêuticos, como quimioterapia e radioterapia, e à qualidade de vida (ARGILÉS et al., 2010; TISDALE et al., 1996). Os principais sintomas são diminuição do peso corporal, com depleção do TAB e do músculo estriado esquelético, além da redução do apetite e da albumina sérica, aumento dos níveis de citocinas inflamatórias, alterações do perfil lipídico e incremento constante da proteína C-reativa no soro (EVANS et al., 2008; TISDALE, 1997). 
Recentemente, propôs-se que a síndrome da caquexia seja dividida em três estágios (pré-caquexia, caquexia e caquexia refratária); o primeiro estágio é descrito por alterações metabólicas e redução da massa corporal $(<5 \%)$, enquanto, no segundo estágio, o paciente é diagnosticado com redução de $5 \%$ ou mais da massa corporal, seguido por anorexia e inflamação sistêmica. No último estágio, o paciente não responde mais aos tratamentos anticâncer e a expectativa de vida não excede mais que 3 meses (FEARON et al., 2011; MUSCARITOLI et al., 2010). A figura 1 explica como são definidas as fases da caquexia.

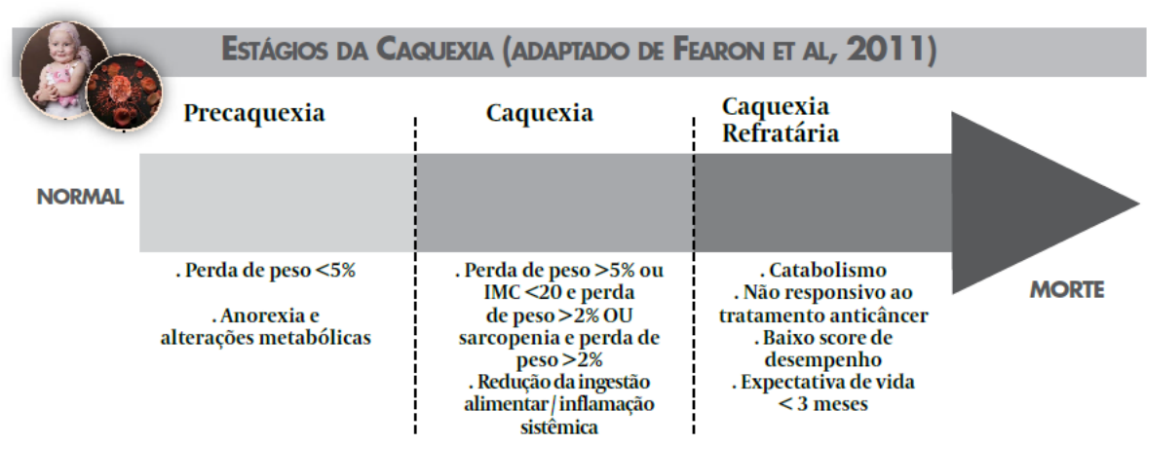

Figura 1- Estágios da Caquexia associada ao câncer. Fonte: Consenso Brasileiro de Caquexia e Anorexia (2011).

A redução da massa corpórea é considerada como o principal marcador clínico para a caquexia. No entanto, para o diagnóstico mais preciso, outros sinais devem ser considerados, tais como marcadores bioquímicos plasmáticos (hipertrigliceremia, hipercolesterolemia e aumento de citocinas pró-inflamatórias), anorexia e anemia (ARGILÉS; ALVAREZ; LÓPEZSORIANO, 1997; FEARON; MOSES, 2002; INUI, 2002). Sugere-se, ainda, que a caquexia esteja relacionada com o consumo e o gasto de energia, pois pacientes com câncer relatam saciedade durante o desenvolvimento da caquexia, diminuindo seu consumo energético (TISDALE, 1997). Em modelos animais de caquexia induzida por tumor, em geral, os animais tornam-se anoréxicos somente no período terminal (BING; TRAYHURN, 2008). Entretanto, a perda de massa corporal de animais caquéticos não pode ser explicada somente pela redução do apetite (BING et al., 2000).

Muitos pesquisadores propõem que, na etiologia e na progressão do quadro de caquexia (ARGILÉS et al., 2003, 2005), há desequilíbrio homeostático de fatores prócaquéticos no organismo (fator de necrose tumoral- $\alpha$ - TNF- $\alpha$; interleucina-6 - IL-6; interleucina-1 - IL-1 $\beta$, interferon- $\gamma$ - INF- $\gamma$; fator neurotrófico ciliar; fator inibitório de leucemia) e anticaquéticos (receptor solúvel de TNF- $\alpha$ - sTNFR; receptor solúvel de IL-6 sIL-6R; receptor antagonista da IL-1 - IL-1ra; IL-4; IL-10; IL-15), em concomitância à presença de produtos secretados pelo tumor. Entre estes, estão o Fator Mobilizador de 
Lipídios (LMF), que atua na lipólise do tecido adiposo branco, e o Fator Indutor de Proteólise (PIF), que gera a degradação proteica exacerbada. Consequentemente, tanto o organismo hospedeiro como o tumor contribuem para a progressão da síndrome (TISDALE, 2005).

1.3 Caquexia e resposta do organismo

Como visto, a relação do hospedeiro e do tumor na progressão da caquexia associada ao câncer pressupõe que os vários compartimentos do organismo não são apenas alvos da síndrome, mas sim importantes contribuintes para sua progressão. Um compartimento em especial parece ter relevante papel: o tecido adiposo branco (TAB). Nos últimos anos, esse tecido tem sido associado à secreção de grande gama de peptídeos com propriedades inflamatórias (BATISTA, M. L. et al., 2012; NEVES et al., 2015).

Atualmente, sabe-se que o TAB apresenta uma variedade de funções, tal como secreção de adipocinas, as quais podem influenciar diretamente o quadro da obesidade e conduzir ao quadro de diabete Melittus tipo 2 e/ou aterosclerose (SKURK et al., 2005).

Tradicionalmente, o TAB era considerado apenas um sítio de estoque de lipídios e, consequentemente, de reserva energética. A partir de 2004, com a descoberta da leptina pelo grupo do Dr. Friedman, da Universidade Columbia de Nova York (ZHANG et al., 1994), e da adiponectina, em 1995 (SCHERER et al., 1995), ambas conhecidas como adipocinas, o TAB passou a ser considerado um órgão endócrino, com capacidade não só de secretar as adipocinas supracitadas, mas também de expressar resistina, TNF, IL-6, IL-10, IL-1b, IL-1a, entre outras diversas citocinas e quimiocinas (BERG; COMBS; SCHERER, 2002; BING et al., 2004). As adipocinas, além de regularem o metabolismo do adipócito, também possuem ação endócrina e auxiliam na regulação da homeostase energética e de diversos parâmetros fisiológicos (BERG; COMBS; SCHERER, 2002; BING et al., 2004).

Em pacientes obesos, foi observado aumento na circulação sanguínea da proteína MCP-1 (proteína-1 quiomioatraente de monócito) (BRUUN et al., 2005). Este quiomioatraente tem como função recrutar monócitos para o sítio de inflamação. Em outro estudo, também realizado com pacientes obesos, verificou-se que o TAB era capaz de grande expressão do gene MCP-1 e que a mesma estava correlacionada positivamente com o aumento do número de macrófagos infiltrados no tecido (WEISBERG et al., 2003).

$\mathrm{A}$ composição do $\mathrm{TAB}$ não é restrita às células adiposas, mas também inclui células imunológicas, que compõem a fração vascular estromal (FVE), além de nervos e vasos (HAUSMAN et al., 2001). A relevância e a proporção relativa dessas populações celulares são variáveis, de acordo com o sítio anatômico de depósito adiposo analisado 
(DIGIROLAMO et al., 1998; DIGIROLAMO; FINE, 2001; HAUSMAN et al., 2001; HAUSMAN et al., 2003). Estudos publicados pelo nosso grupo, realizados em modelos animais, relatam diferenças entre os depósitos viscerais (características morfológicas e bioquímicas) durante a progressão da síndrome de caquexia (BATISTA, M. L., Jr. et al., 2012; MACHADO; COSTA ROSA; SEELAENDER, 2004).

Dois importantes processos no TAB durante a vigência da caquexia têm sido alvo de interesse: a lipólise e o browning. A lipólise é processo no qual enzimas denominadas lipolíticas "removem" ácidos graxos da gotícula lipídica por meio da quebra do triacilglicerol (LASS, 2011). As principais enzimas envolvidas nesse processo são a lipase do tecido adiposo (ATGL), a lipase hormônio sensível (HSL) e a lipase monoacilglicerol (MGL), que são estimuladas pela ligação de fatores a receptores de membrana, como o receptor adrenérgico beta, então fosforiladas e em sequência, ativadas, iniciando o processo de quebra do triacilglicerol em ácidos graxos livres. Por sua vez, o browning é um processo distinto, que induz o perfil de adipócitos marrom, com indução de proteínas típicas do mesmo, como UCP1, PGC-1 $\alpha$, PPAR $\alpha$, CIDEA, entre outros (PORPORATO, 2016). Ambos os processos estão relacionados com a redução do TAB na progressão da caquexia (AGUSTSSON et al., 2007; BING; TRAYHURN, 2009; KIR et al., 2016).

Outro órgão com capacidade de induzir e manter a inflamação sistêmica durante o quadro de caquexia é o fígado (MARTIGNONI et al., 2009). O fígado é a maior glândula e o segundo maior órgão do corpo humano, apresentando papel importante no organismo, como órgão central no controle de vias metabólicas. O fígado age também como um depósito, armazenando água, ferro, cobre e as vitaminas A, D e complexo B (MADRIGAL-MATUTE; CUERVO, 2016). Uma das mais relevantes proteínas secretadas pelo fígado, na físiologia, e cuja redução é marcador importante no diagnóstico de caquexia associada ao câncer, é a albumina (EVANS et al., 2008).

Estudos têm mostrado que a redução da albumina está correlacionada com o surgimento da caquexia em pacientes com câncer (CAMARGO et al., 2015). Durante a caquexia associada ao câncer, o fígado contribui para progressão da doença, tornando-se incapaz de sanar o desequilíbrio energético imposto pelo ciclo de Cori frente à incapacidade hepática do organismo caquético em realizar processos oxidativos (SEELAENDER et al., 1996). Ademais, o fígado, na vigência da síndrome, secreta fatores inflamatórios, como citocinas e eicosanoides (SEELAENDER et al., 1996; DUMAS et al., 2011; KAZANTZIS; SEELAENDER, 2005; MARTIGNONI et al., 2009; NARSALE et al., 2015). 
As principais células presentes no fígado são hepatócitos, células epiteliais biliares, células sinusoidais e células do sistema imunológico. As células imunológicas são representadas, principalmente, pelos macrófagos residentes, conhecidos como células de Kupffer, que somam por volta de $10 \%$ do total de células hepáticas (SEELAENDER; KAZANTZIS; COSTA ROSA, 1999). De acordo com (MARTIGNONI et al., 2009), foi observado que a proteína CD68, uma proteína importante para reconhecimento das células da linhagem mieloide (macrófago, monócitos e células dendríticas), está aumentada no fígado de pacientes caquéticos associado ao câncer, comparado aos não caquéticos; tal achado esteve correlacionado com a maior agressividade do tumor.

\section{4 vias inflamatórias}

Uma vez que é incontestável, na literatura, que a caquexia esteja associada com a inflamação sistêmica crônica, iremos discutir as vias participantes no processo inflamatório durante o quadro de caquexia associada ao câncer.

As citocinas, como TNFa, IL-6, IL-1beta, entre outras, apresentam indução de síntese através da atividade da via do Nuclear factor of Kappa light polypeptide gene enhancer in B-

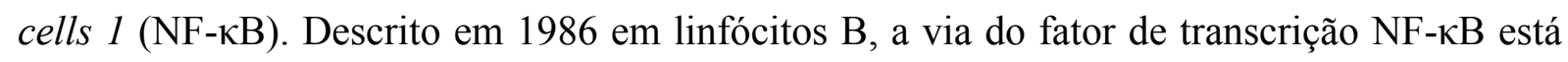
presente em muitas diferentes células do organismo, não estando restrita somente às células do sistema imunológico (BAEUERLE; BALTIMORE, 1996). Muitos estudos têm relatado a superativação da via em doenças como obesidade, diabetes e câncer (BATISTA, M. L. et al., 2012; NEVES et al., 2015; RIUS et al., 2008; YIN, PENG, et al., 2014).

O complexo proteico NF-אB é composto por 5 proteínas: p65 (RelA), p50, p52, c-Rel e RelB (RIUS et al., 2008). O homo ou heterodímero deixa o citoplasma, em direção ao núcleo, onde se liga em região alvo no DNA. A forma mais estudada de ligação ao DNA é o heterodímero p65-p50, que desencadeia a síntese de citocinas ou quimiocinas próinflamatórias (BAEUERLE; BALTIMORE, 1996; MOHAMED; MCFADDEN, 2009; WANG; CASSIDY, 2003). No entanto, um estudo mostra que o heterodímero p50-p52, ao ligar-se ao DNA no mesmo sítio de ligação do heterodímero p65-p50, é capaz de inibir a atividade do mesmo (NOLAN et al., 1993). As proteínas p50 e p52 são sintetizadas como moléculas precursoras inativas, p100 e p105, respectivamente (NOLAN et al., 1993).

A translocação do heterodímero p65-p50 do citoplasma para o núcleo ocorre quando o complexo inibitório ligado ao heterodímero no citoplasma é fosforilado, consequentemente recebendo a adição de ubiquitina e sendo conduzido à degradação no proteassomo $26 \mathrm{~S}$ (MAGNANI et al., 2000). O complexo inibitório é formado pela família do nuclear factor of 
kappa light polypeptide gene enhancer in B-cells inhibitor $(\mathrm{I} \kappa \mathrm{B} \alpha, \beta$ e $\varepsilon)$ e é fosforilado pela quinase Chuk conservada hélice-laço-hélice de quinase ubíqua (IKK), quando um estímulo é transduzido a ele (BATISTA, M. L. et al., 2012; MAGNANI et al., 2000).

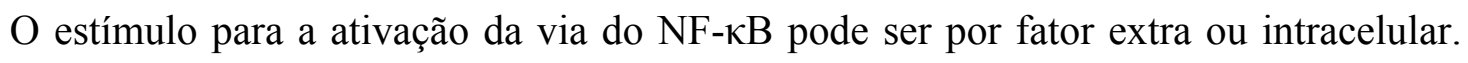
Os receptores da família Toll like receptor (TLR) podem desencadear essa ativação (MITCHELL; VARGAS; HOFFMANN, 2016). Por exemplo: o TLR4, ao receber a ligação de lipossacarídeo em sua porção extracelular, gera sinais intracelulares que desencadeiam a ativação de segundos mensageiros, TNF receptor associated factor (TRAF6) e Myeloid differentiation primary response gene 88 (MYD88); em seguida, a mensagem é transduzida à quinase inhibitor of nuclear factor kappa-B kinase (IKK) e, consequentemente, ocorre a liberação do heterodímero p65-p50 para translocação nuclear e ligação no DNA (MITCHELL; VARGAS; HOFFMANN, 2016; VERSTREPEN et al., 2008;). No entanto, o estímulo pode ocorrer também por ativação intracelular; por exemplo, os TLR7 e 9, quando estimulados por RNA ou DNA viral, respectivamente, induzem segundos mensageiros da via de ativação do TLR4, como o recrutamento das proteínas, TRAF6 e MYD88, ativadoras da quinase IKK (BERNARD; O'NEILL, 2013; KRIEG, 2002; SUZUKI; SAITO, 2006).

Estudos em pacientes obesos mostram aumento da atividade da via do NF- $\kappa$ B em tecido adiposo e, consequentemente, inflamação local (GUILHERME et al., 2008). Nosso grupo tem relatado que a atividade da via do NF- $\mathrm{B}$, no tecido adiposo branco de pacientes caquéticos associados ao câncer ou em células adiposas isoladas de ratos com caquexia, apresenta-se elevada (BATISTA, M. L. et al., 2012; BATISTA et al., 2013; CAMARGO et al., 2015; NEVES et al., 2015).

Recentemente, foi descrita uma família de receptores da imunidade inata que tem ganhado muita atenção no estudo das doenças inflamatórias. Trata-se da família do complexo inflamassoma, conhecida como Nod Like Receptors (NLR), pois algumas citocinas necessitam, além da transcrição e da tradução, passar por passo de ativação, por meio da clivagem em regiões específicas, permitindo-lhes desenvolver sua capacidade de modulação biológica (JO et al., 2016; LAPPAS, 2014). A clivagem das citocinas, por exemplo, de IL-1 $\beta$ e IL-18, somente ocorre quando o complexo do inflamassoma é ativo (JO et al., 2016). Diferentemente dos receptores TLR, os NLR consistem em proteínas solúveis que são encontradas no citoplasma e sinalizam em resposta a patógenos intracelulares (GUO; CALLAWAY; TING, 2015).

O inflamassoma é composto por dois compartimentos proteicos, o NOD-like receptor (NLR) family (NLRP1, NLRP2, NLRP3, NLRP6, NLRC4, and NLRP12) e o haematopoietic 
interferon-inducible nuclear antigens domain-containing protein (PYHIN) family (SCHRODER; TSCHOPP, 2010). Sua principal função é ativar as citocinas inflamatórias prémaduras, IL-1 $\beta$ e IL-18, nas formas maduras. Após a ativação, as mesmas são secretadas, tanto local quanto sistemicamente (LAPPAS, 2014; LATZ, 2010).

Entre as proteínas do complexo inflamassoma, o NLRP3 é o mais bem estudado, devido à sua associação com importantes doenças metabólicas e inflamatórias crônicas, tais como Alzheimer, diabetes e obesidade (WEN; TING; O'NEILL, 2012). Considera-se que a ativação do NLRP3 seja gerada por perturbações no citoplasma, que podem ser causadas por pathogen-associated molecular patterns (PAMP), tais como LPS, RNA bacteriano e viral, ou por damage-associated molecular patterns (DAMP), tais como ATP extracelular, cristais de ácido úrico ou de colesterol, hiperglicemia, amianto, sílica, asbesto e radiação UV (MARTINON; MAYOR; TSCHOPP, 2009). Em estudos realizados com modelos knockout tanto para NLPR3 quanto para Caspase-1, os camundongos mostraram-se resistentes a desenvolver obesidade e resistência à insulina, quando submetidos à dieta rica em gordura (STIENSTRA et al., 2010; VANDANMAGSAR et al., 2011).

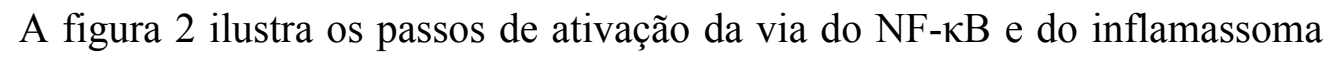
na produção de IL-1 $\beta$ total (pré-madura) e sua ativação (madura).

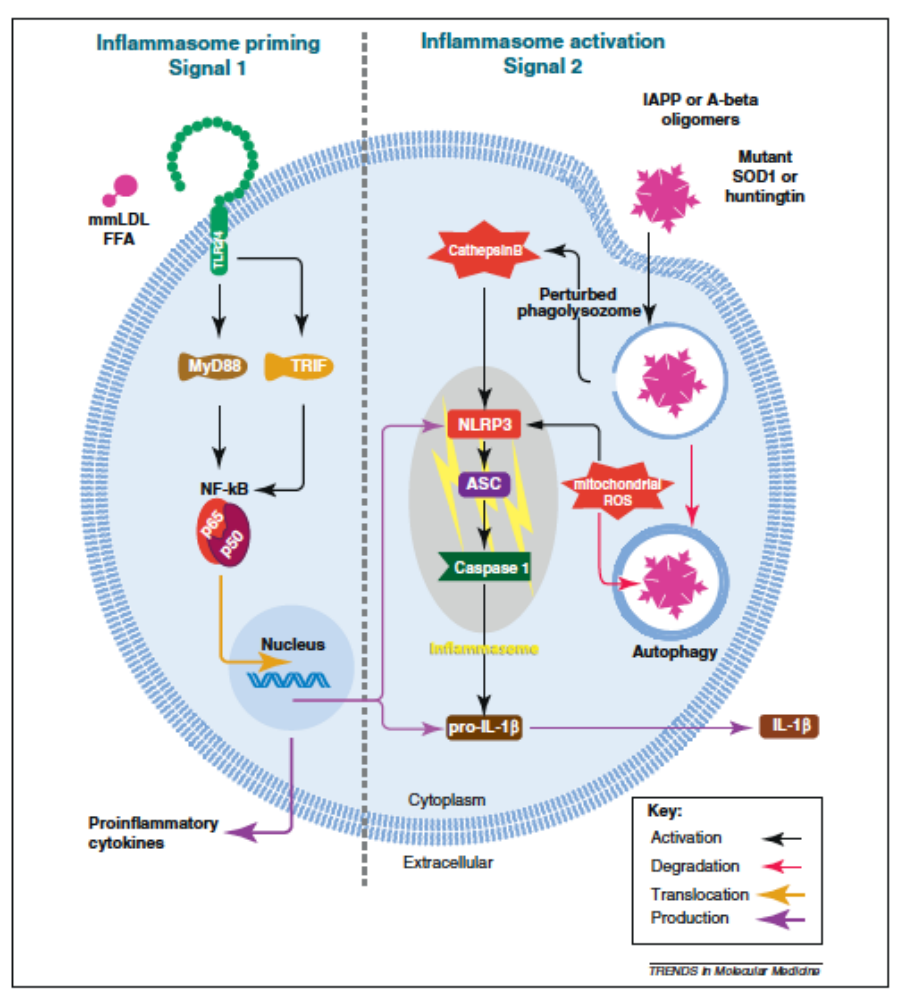

Figura 2- Ligação e subsequente ativação da via do inflamassoma por amiloide e agregado de proteínas mal formadas.

Nota fonte: Disease-associated amyloid and misfolded protein aggregates activate the inflammasome Seth L. Masters \& Luke A.J. O’Neill. Trends in Molecular Medicine. Volume 17, Issue 5, May 2011, Pages 276-282. 
Parte II

1.5 A microbiota na caquexia associada ao câncer

O trato gastrointestinal (TGI) pode ser considerado um ecossistema extremamente complexo, sendo composto por grande diversidade de espécie que apresentam diferentes funções no hospedeiro humano. No entanto, a microbiota não está presente somente no TGI, ela pode ser encontrada também nas cavidades oral e nasal, além de cabelo, olhos, vagina, pulmão, pele, pavilhão auricular, etc. (PENDERS et al., 2006). A microbiota do TGI é a mais amplamente estudada, devido à importância no papel de proteção, ao constituir-se como importante barreira contra micro-organismo patogênicos, ao participar do metabolismo de carboidratos, ao produzir nutrientes e, ainda, ao estar diretamente envolvida na modulação do sistema imune (BÖRNIGEN et al., 2013; MARCOBAL et al., 2013). A microbiota é composta por cepas de bactérias, podendo ser consideradas saudáveis (simbióticas) ou patogênicas (disbióticas) (PENDERS et al., 2006).

O microbioma é o meio ambiente ocupado pela microbiota no qual encontramos produtos e metabólitos produzidos pela mesma, como também produtos e metabólitos produzidos pelo hospedeiro (WHITESIDE et al., 2015). O microbioma é extremamente sensível a influências externas, sendo facilmente modulado. Estudo mostra que o tratamento com antibióticos afeta mais de $87 \%$ dos metabólitos produzidos e desestabiliza importantes vias na fisiologia do hospedeiro (CANI et al., 2008).

Tradicionalmente, é largamente aceito que o desenvolvimento da microbiota intestinal tem início no parto; por isso, aqueles indivíduos que nasceram de parto normal apresentam microbiota diferente dos que nasceram por cesariana (BRUMBAUGH et al., 2016). As primeiras bactérias que colonizam o intestino do recém-nascido são aquelas provenientes do canal vaginal e do períneo da mãe; a maioria dessas bactérias é anaeróbia, diferentemente do encontrado nos partos realizados por cesáreas, nos quais a microbiota é caracterizada por microrganismos aerófilos, provenientes do ambiente e dos profissionais da área de saúde (BRUMBAUGH et al., 2016; MUELLER et al., 2016).

$\mathrm{Na}$ microbiota do recém-nascido sob aleitamento materno, há grande predomínio de bifidobactérias e lactobacilos ( $>90 \%$ ), havendo pequena quantidade de espécies bacterianas potencialmente patogênicas (ANDREAS; KAMPMANN; MEHRING LE-DOARE, 2015). O leite humano é um dos principais fatores para a iniciação e o desenvolvimento da microbiota intestinal, por representar uma fonte contínua de substrato aos microrganismos por várias semanas após o nascimento. Além desse benefício, o leite humano contém prebióticos que 
auxiliam no crescimento de grupos, selecionados de bactérias consideradas saudáveis (ANDREAS; KAMPMANN; MEHRING LE-DOARE, 2015; LIU et al., 2016).

Apesar de a microbiota ser considerada madura quando a criança atinge os seus 8-10 anos, ela ainda pode ser alterada por fatores externos, como alimentação, doenças, meio ambiente, etc. (ACTIS, 2014; TLASKALOVÁ-HOGENOVÁ et al., 2004;). A microbiota de animais transgênicos (ob/ob) com capacidade de desenvolver obesidade apresenta-se diferente daquela de animais controles (RABOT et al., 2010). Estudos, realizados com camundongos wild type submetidos à dieta rica em lipídeos, mostraram composição da microbiota diferente de quando se iniciou a dieta (RABOT et al., 2010). Para enfatizar o quanto a microbiota é essencial para o desencadeamento da obesidade, foi realizado um estudo em que animais livres da microbiota submetidos à mesma dieta rica em lipídeos não apresentaram sobrepeso após 16 semanas de tratamento indutor da doença, enquanto o controle ganhava peso a cada semana (DING et al., 2010).

A relação entre microbiota e doença não acontece somente na obesidade, mas também, por exemplo, no desenvolvimento do diabetes (TLASKALOVÁ-HOGENOVÁ et al., 2004). Camundongos livres de microbiota apresentam melhor sensibilidade à insulina, tanto quando tratados com dieta normal, quanto quando tratados com dieta rica em lipídeos (RABOT et al., 2010). A microbiota mostra-se também essencial no tratamento de câncer, pois um estudo recente mostrou que animais com câncer tratados com antibióticos não respondem ao tratamento quimioterápico (cisplatina), enquanto a redução da massa tumoral nos animais controle não é encontrada nos animais tratados com antibiótico (IIDA et al., 2013).

Existem poucos estudos sobre a composição da microbiota em modelos de caquexia associada ao câncer; embora alguns estudos relatem que durante a progressão da caquexia acontecem alterações nas junções epiteliais da parede do intestino, permitindo a translocação bacteriana para o sangue e os órgãos específicos, como linfonodos (JIANG et al., 2014). Pouco se sabe sobre a participação dessas bactérias na contribuição ou na amenização da progressão do quadro de caquexia. Em pacientes com caquexia associada ao câncer gastrointestinal, relatou-se redução das proteínas ocludinas e claudinas presentes nas junções epiteliais e tal redução teve como consequência a maior permeabilização (JIANG et al., 2014). Nesse mesmo estudo, foi verificado que os pacientes sem e com caquexia sofrem translocação bacteriana no soro e nos linfonodos mesentéricos; no entanto, nos pacientes caquéticos, essa translocação aconteceu em maior número e diversidade de bactérias.

A microbiota está, assim, estreitamente relacionada com a modulação das células do sistema imune, podendo ativar ou inibir um grupo específico de linfócitos $\mathrm{T}$ regulatórios ou 
até mesmo modular a ativação das células dendríticas (BENGMARK, 2013). Estudos realizados em pacientes caquéticos mostraram que, durante a translocação bacteriana, há aumento das citocinas pró-inflamatórias sérica, como IL-6, TNFa e IFNg, comparado aos indivíduos não caquéticos (VARIAN et al., 2016).

O grande desafio no estudo da microbiota em pacientes caquéticos é restabelecer a simbiose como forma terapêutica no combate da caquexia, uma vez alterada durante a progressão do quadro. Como discutido, a translocação de bactérias em pacientes caquéticos está associada com o aumento de citocinas pró-inflamatórias séricas e, consequentemente, agrava o quadro.

A hipótese desse estudo foi mostrar o papel de distintos compartimentos durante a

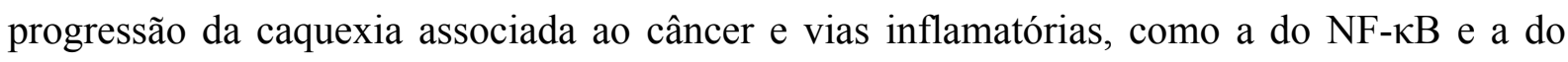
inflamassoma, sendo, esta última, ainda não estudada em modelos de caquexia. 


\section{JUSTIFICATIVA}

Atualmente, doenças cardiovasculares e câncer são as principais causas de morte no mundo. No câncer, a caquexia acomete $80 \%$ dos pacientes em estado terminal, sendo causa direta de morte entre $20-40 \%$ dos mesmo e diminuindo a resposta ao tratamento quimio- e radioterápico.

A caquexia é caraterizada pela progressiva perda de tecido muscular e adiposo, acompanhada pelo distúrbio do perfil bioquímico e a produção de citocinas pró-inflamatórias, tanto em pacientes com câncer quanto em modelos animais. Durante a progressão da caquexia há efetiva contribuição de compartimentos e orgãos, como $\mathrm{TAB}$, fígado e entre outros na inflamação sistêmica e crônica. Frente a esses dados, surgiram-nos algumas dúvidas: 1) Existe heterogeneidade na capacidade inflamatória nos diferentes depósitos de TAB na progressão da caquexia? 2) Qual é a contribuição dos adipócitos per se para a inflamação do TAB? 3) Qual é contribuição do fígado nesse cenário? 4) Há contribuição do fígado? 5) qual é o papel da microbiota. Para responder essas questões, estudamos a progressão da caquexia no modelo animal utilizando o carcinossarcoma Walker 256 e o de Lewis Lung Carcinoma. 


\section{OBJETIVOS}

\subsection{Geral}

Investigar qual é a contribuição dos adipócitos isolados do TAB de diferentes regiões anatômicas e do fígado para progressão do quadro de caquexia associada ao câncer e a relevância da microbiota intestinal na progressão da síndrome.

\subsection{Específicos}

- Caracterização do quadro de caquexia;

- Analisar a expressão gênica e proteica das citocinas pró e anti-inflamatórias em células adiposas, tecido adiposo e fígado;

- Verificar qualitativamente a infiltração de células imunes no fígado;

- Avaliar proteínas e genes da via do NF-kB e a do inflamassoma nos adipócitos isolados e no fígado;

- Correlacionar o conteúdo proteico de IL-1 $\beta$ do soro com o conteúdo das células adiposas e do fígado;

- Determinar a importância da microbiota no quadro de caquexia, com enfoque nas alterações no tecido adiposo. 


\section{MATERIAIS E MÉTODOS}

\subsection{Determinações gerais}

\subsubsection{Animais}

O estudo foi realizado com 50 ratos machos (Rattus norvegicus albinus) da linhagem Wistar (230-250 g) não isogênicos, com 8 semanas de vida, obtidos no biotério central do Instituto de Ciências Biomédicas I (ICB I) da Universidade de São Paulo (USP), mantidos no biotério de experimentação do Departamento de Biologia Celular e do Desenvolvimento. Durante o experimento, os animais foram mantidos em gaiolas plásticas, em ambiente com temperatura entre 23 a $25{ }^{\circ} \mathrm{C}$ e iluminação com ciclos de claro/escuro de 12/12 horas. O estudo encontra-se aprovado pelo Comitê de Ética no Uso de Animais (062/04CEEA).

\subsubsection{Desenho experimental}

Os animais foram divididos em dois grupos experimentais: (1) controle e (2) tumor. O grupo tumor foi subdividido, sendo o primeiro subgrupo denominado 7 dias (T7), constituído por animais sacrificados 7 dias após a inoculação; e o segundo, 14 dias (T14), sacrificados 14 dias após a inoculação. Um grupo controle sem tumor foi também atribuído a cada grupo experimental, para controle do ganho/perda de peso corporal e tecidual.

\subsubsection{Inoculação do tumor de Walker 256}

O tumor de Walker 256 foi inoculado subcutaneamente no flanco direito, em suspensão de $0.5 \mathrm{~mL}$ de solução salina $0,9 \%$ contendo $2 \times 10^{7}$ de células tumorais (MACHADO et al., 2004; SEELAENDER et al., 1996). As células do tumor Walker de 256 foram retiradas de ratos mantidos para obtenção das células tumorais in vivo (MACHADO et al., 2004; SEELAENDER et al., 1996).

\subsubsection{Obtenção de soro e tecidos}

Todos os animais utilizados nos experimentos foram sacrificados por decapitação sem anestesia. O sangue dos animais foi coletado em tubos cônicos de $15 \mathrm{ml}$. O soro foi separado após a centrifugação das amostras em $2500 \mathrm{rpm}$ por 15 minutos, à $4{ }^{\circ} \mathrm{C}$. Após o término da centrifugação, o soro foi armazenado à $-80^{\circ} \mathrm{C}$ para posterior análise.

Os tecidos foram extraídos imediatamente após o sacrifício e armazenados adequadamente de acordo com o protocolo planejado. Para os protocolos de qPCR RT e 
ELISA os tecidos foram colocados rapidamente em nitrogênio líquido e estocados à $-80{ }^{\circ} \mathrm{C}$. Tecidos para análise histológica foram colocados diretamente em meio de criopreservação OCT (Sakura Finetek Japan Co., Ltd., Tokyo, Japan), congelados em nitrogênio líquido e estocados à $-20^{\circ} \mathrm{C}$. No entanto, para isolamento das células adiposas os tecidos foram lavados previamente em salina e disposto em tampão específico ao protocolo, item 4.4.

4.2 Análises bioquímicas

\subsubsection{Determinações plasmáticas}

A determinação da concentração de triglicerídeos e HDL-colesterol foi realizada com o auxílio de kits comerciais colorimétricos Labtest ${ }^{\circledR}$, enquanto que para a determinação dos ácidos graxos livres (NEFA) adotou-se o kit Wako Chemicals (USA) e para glicerol, o Sigma-Aldricht (Switzerland).

\subsection{Análise histológica}

\subsubsection{Obtenção e processamento do tecido}

As amostras de fígado foram colocadas em cassetes de plástico, montados com meio de criopreservação OCT (Sakura Finetek Japan Co., Ltd., Tokyo, Japan), congelados em nitrogênio líquido a $-170{ }^{\circ} \mathrm{C}$. Cortes de $7 \mu \mathrm{m}$ de espessura foram fixados em metanol/acetona (1:1) e permeabilizados com $0,02 \%$ tween 20 in PBS (PBS-T). Uma lâmina de cada animal foi corada com Hematoxilina e Eosina (H\&E) para uma avaliação histológica prévia do fígado. A outra lâmina das mesmas amostras foi fixada, permeabilizada, bloqueada com $5 \%$ de soro de cabra em PBS-T; e após 1h, os cortes foram incubados com anticorpos CD68 1:200 (Abcam, ab 31630, rabbit) overnight a $4{ }^{\circ} \mathrm{C}$, para detectar macrófagos. Para observação adotou-se o anticorpo secundário conjugado com Biotina 1/500 (goat anti-rabbit IgG H\&L ab97049), Kit ABC para uma maior intensidade de quimiluminescência (Vector Laboratories) e por fim, o DAB3,3-diaminobenzidine (Sigma, St. Louis, MO). Os cortes foram contracorados com Hematoxilina.

Os cortes foram digitalizados com aumento de $40 \mathrm{x}$. As imagens foram obtidas utilizando um microscópio óptico Leica, modelo DMLP, com câmera CCD LG, modelo GC415N-MD.

\subsection{Isolamento de células adiposas}

Os diferentes tecidos adiposos foram extraídos e lavados em salina estéril 0,9\%. As amostras $(0,8 \mathrm{~g})$ foram colocadas imediatamente em meio de digestão DMEM (Sigma- 
D5671), albumina 5\% e colagenase do tipo I $2 \mathrm{mg} / \mathrm{mL}$ (Life-Technologies 17100-017), por 60 min a $37{ }^{\circ} \mathrm{C}$. O resultado da digestão foi filtrado utilizando um filtro de nylon $(250 \mu \mathrm{m}) \mathrm{e}$ centrifugado por $1 \mathrm{~min}$, a $500 \mathrm{rpm}$, à temperatura ambiente. A camada de adipócitos maduros dos diferentes depósitos, Mesentérico (MEa). Retroperitoneal (RPa) e Epididimal (Ea), presente no sobrenadante, foram retirados e lavados em salina estéril $0.9 \%$ e estocados à -80 ${ }^{\circ} \mathrm{C}$ para análises de qPCR RT, Western blot e ELISA.

4.5 Análise da expressão gênica por qPCR RT

\subsubsection{Extração do RNA total}

O RNA total foi isolado de tecido do TAB $(300 \mathrm{mg})$, do fígado $(50 \mathrm{mg})$ e das células adiposas, utilizando o reagente TRIzol ${ }^{\circledR}$, como no protocolo fornecido pelo fabricante (Invitrogen $^{\mathrm{TM}}$ ). A integridade do RNA foi verificada por eletroforese, usando 2,2 $\mathrm{M}$ formaldeído e gel de agarose a 1,5\%, corado com brometo de etídio. A concentração do RNA foi determinada medindo-se a absorção ótica da amostra no comprimento de onda de 260/280 $\mathrm{nm}$.

\subsubsection{Reação de transcrição reversa (RT)}

As amostras de RNA foram transcritas para cDNA em termociclador (Techne, Cambridge, UK). Para síntese do cDNA foi utilizado $1 \mu \mathrm{g}$ de RNA total de cada amostra e o kit High-Capacity cDNA Reverse Transcription (Invitrogen no. 4375575) com o volume final de $20 \mu 1$. A transcrição reversa foi efetuada em um ciclo único, cujas etapas foram: i) 10 minutos a $25{ }^{\circ} \mathrm{C}$; ii) 120 minutos a $37^{\circ} \mathrm{C}$; iii) 5 segundos a $85{ }^{\circ} \mathrm{C}$; e iv) termina a $4{ }^{\circ} \mathrm{C}$. A amostra de cDNA obtida foi estocada a $-20^{\circ} \mathrm{C}$, até que fosse realizado o experimento.

\subsubsection{Seleção dos primers}

Os primers foram sintetizados pela IDT (Integrated DNA Technologies). Para determinar a sequência do primer utilizou-se o Genbank (http://www.ncbi.nlm.nih.gov/nucleotide/). A seguir, utilizando o software spidey (disponível on-line em www.ncbi.nlm.nih.gov/spidey/) e o alinhamento, eliminou-se os íntrons do gene alvo. Com isto o software apresenta apenas os éxons do gene alvo, e com o software primer 3 (disponível on-line no site www.genome.wi.mit.edu), selecionamos os candidatos a primer de acordo com os seguintes critérios: i) comprimento entre 18 e $24 \mathrm{bp}$; ii) $\mathrm{T}_{\mathrm{m}}$ entre 58 e $62{ }^{\circ} \mathrm{C}$; iii) comprimento do produto amplificado entre 80 a 120 bp; e iv) as sequências Forward e Reverse nunca devem sair do mesmo éxon. Para determinar a especificidades do primer, as sequências foram comparadas com o Genbank usando o programa Blast (disponível em 
www.ncbi.nim.gov). Candidatos a primer que mostraram alta identidade somente com o gene alvo foram os escolhidos.

Tabela 1- Lista de Primers

\begin{tabular}{|c|c|}
\hline Genes (Espécie) & Sequências $5^{\prime} \rightarrow 3^{\prime}$ \\
\hline $\begin{array}{l}\text { Il-6 (Rattus norvegicus) } \\
\text { (NM 012589.2) }\end{array}$ & $\begin{array}{l}\text { Fw: GAA GCT GAA GAC CCT CTG GA } \\
\text { Rev: TAA GCC TCG GAC TTG TGA AGT GGT }\end{array}$ \\
\hline $\begin{array}{l}\text { Il-10 (Rattus norvegicus) } \\
\text { (NM 012854.2) }\end{array}$ & $\begin{array}{l}\text { Fw: AAG GCA TTC TTC ACC TGC TC } \\
\text { Rev: CCA AGC TGA GAA CCA AGA CC }\end{array}$ \\
\hline $\begin{array}{l}\text { Tnf- } \alpha \text { (Rattus norvegicus) } \\
\text { (NM 012675.3) }\end{array}$ & $\begin{array}{l}\text { Fw: ATC ACT CCA AAG TGC AGC AG } \\
\text { Rev: CTC TCT CCC CTG GAA AGG AC }\end{array}$ \\
\hline $\begin{array}{l}\text { p50 (Rattus norvegicus) } \\
\text { (NM 001276711.1) }\end{array}$ & $\begin{array}{l}\text { Fw: AGG TCC AGA AAG ATG ACA TCC A } \\
\text { Rev: CAA TGG CAA ACT GTC TGT GAA }\end{array}$ \\
\hline $\begin{array}{l}\text { p65 (Rattus norvegicus) } \\
\text { (NM 199267.2) }\end{array}$ & $\begin{array}{l}\text { Fw: ATG CAT CCA CAG CTT CCA G } \\
\text { Rev: TGC TCC TCT ATG GGA ACT TGA }\end{array}$ \\
\hline $\begin{array}{l}\text { Tlr4 (Rattus norvegicus) } \\
\text { (NM 019178.1) }\end{array}$ & $\begin{array}{l}\text { Fw: TCT AAA TGC CAA CTG GAA CAG A } \\
\text { Rev: ATG GGA TGG ATC CAG AAA CA }\end{array}$ \\
\hline $\begin{array}{l}\text { Myd88 (Rattus norvegicus) } \\
\text { (NM 198130.1) }\end{array}$ & $\begin{array}{l}\text { Fw: GCG AGC TCA TTG AGA AAA GG } \\
\text { Rev: ACA CCT GGA GAC AGG CTG A }\end{array}$ \\
\hline $\begin{array}{l}\text { Traf6 (Rattus norvegicus) } \\
\text { (NM 001107754.2) }\end{array}$ & $\begin{array}{l}\text { Fw: AAG TCC ATA AGG GAT GCA GGT } \\
\text { Rev: TCG CTT TGC AAA ATT GTC AG }\end{array}$ \\
\hline $\begin{array}{l}\text { Ikk- } \alpha \text { (Rattus norvegicus) } \\
\text { (NM 001107588.1) }\end{array}$ & $\begin{array}{l}\text { Fw: TCA AGA TGT TGG TGG GAA GAT A } \\
\text { Rev: CTC TGG GGC CAA ATA CTG TAA }\end{array}$ \\
\hline $\begin{array}{l}\text { Nlrp1 (Rattus norvegicus) } \\
\text { (NM 001145755.2) }\end{array}$ & $\begin{array}{l}\text { Fw: GCT TCA GCC CCC AAA GAT } \\
\text { Rev: TTG TCC AAG AGA GGG TCC AC }\end{array}$ \\
\hline $\begin{array}{l}\text { Nlrp3 (Rattus norvegicus) } \\
\text { (NM 001191642.1) }\end{array}$ & $\begin{array}{l}\text { Fw: GCT GAA CTT GAG CAA CAA CG } \\
\text { Rev: CAC CCA ACT GTA GGC TCT GC }\end{array}$ \\
\hline $\begin{array}{l}\text { Tlr2 (Rattus norvegicus) } \\
\text { (NM 198769.2) }\end{array}$ & $\begin{array}{l}\text { Fw: TTT GAT CAC TGC ACC CTC AA } \\
\text { Rev: ATG TGC AGG CTC CGT ATT GT }\end{array}$ \\
\hline $\begin{array}{l}\text { Hifla (Rattus norvegicus) } \\
\text { (NM } 024359.1 \text { ) }\end{array}$ & $\begin{array}{l}\text { Fw: CAA CTG CCA CCA CTG ATG A } \\
\text { Rev: GGG TAG AAG GTG GAG ATG C }\end{array}$ \\
\hline $\begin{array}{l}\text { Caspase1 (Rattus norvegicus) } \\
\text { (NM 012762.2) }\end{array}$ & $\begin{array}{l}\text { Fw: ACA TCT TTC TCC GAG GGT TG } \\
\text { Rev: CAC CTC TTT CAC CAT CTC CAG }\end{array}$ \\
\hline $\begin{array}{l}\text { Rpl19 (Rattus norvegicus) } \\
\text { (NM 031103.1) }\end{array}$ & $\begin{array}{l}\text { Fw: GAG GGA CGC TTC ATT TCT TG } \\
\text { Rev: CAT GGA GCA CAT CCA CAA AC }\end{array}$ \\
\hline $\begin{array}{l}\text { Rpl27 (Rattus norvegicus) } \\
\text { (NM 022514.1) }\end{array}$ & $\begin{array}{l}\text { Fw: CCT CAT GCC CAC AAG GTA CT } \\
\text { Rev: CTG TCT TGT ATC GCT CCT CAA A }\end{array}$ \\
\hline
\end{tabular}




\subsubsection{Reação em cadeia da polimerase em tempo real (RT-PCR)}

A expressão dos genes (Tabela 1) foi quantificada por qPCR RT, método descrito por (KUBISTA; et al., 2006), utilizando o aparelho QuantStudio ${ }^{\mathrm{TM}}$ 12K Flex (Applied Biosystems) e SYBER Green 2x como marcador de fluorescência (Invitrogen, USA). Para reação foi utilizado $2 \mu 1$ de cDNA da amostra para um volume final de $10 \mu 1$. A concentração de cDNA foi de $10 \mathrm{ng}$ por amostra e foi utilizado um intervalo de 200-800 $\mathrm{nM}$ de acordo com o primer, utilizando $5 \mu 1$ do mix SYBER Green 2 x (4309155, Applied Biosystems), que contem dNTP Tampão de reação, Taq DNA polimerase SYBER green 2 x. A reação ocorreu do seguinte modo: primeiramente, um ciclo de $50{ }^{\circ} \mathrm{C}$ por 2 minutos e $95^{\circ} \mathrm{C}$ por 10 minutos; seguido de 40 ciclos de amplificação: i- a desnaturação a $95{ }^{\circ} \mathrm{C}$ por 15 segundos, iianelamento a $63{ }^{\circ} \mathrm{C}$ por 60 segundos e iii- extensão a $72{ }^{\circ} \mathrm{C}$, por 2 minutos.

Os dados obtidos foram expressos como um limiar de ciclagem $\left(\mathrm{C}_{\mathrm{t}}\right)$ que representa uma linha de base de detecção de fluorescência, correspondente à fase exponencial. Baseando-se no $\mathrm{C}_{\mathrm{t}}$ obtido, estimamos a quantidade inicial de cDNA aplicado nas diferentes amostras. Assim o valor do $\mathrm{C}_{\mathrm{t}}$ está correlacionado com os níveis de mRNA utilizado na reação (Heid, 1996). A expressão gênica foi determinada através da fórmula: $2^{-\Delta \Delta \mathrm{Ct}}$, descrita por K. Livak no Manual do usuário do Biosystem Sequence Detector Bulletin 2, onde $\Delta \Delta \mathrm{C}_{\mathrm{t}}=$ $\left[\mathrm{C}_{\mathrm{t}}\right.$ alvo (amostra Tumor) $-\mathrm{C}_{\mathrm{t}}$ controle interno (mesma amostra) $]-\left[\mathrm{C}_{\mathrm{t}}\right.$ alvo (amostra controle) - controle interno (mesma amostra)]. Os resultados foram expressos com base na relação do mRNA de cada gene de interesse, relativizado com o conteúdo de mRNA do controle interno.

4.6 Análise da expressão protéica - (Western blot)

\subsection{1 extração proteica}

As células adiposas e o fígado foram homogeneizados em tampão RIPA (Radio Immuno Precipitation Assay Buffer) $50 \mathrm{mM}$ Tris, $\mathrm{pH}$ 7.4, 150mM de NaCL, $5 \mathrm{mM}$ de EDTA, $0,1 \%$ de SDS, $0,5 \%$ de Deoxiglicolato, $1 \%$ de Triton X-100 com o coquetel de inibidor de proteases e fosfatase (Roche ${ }^{\circledR}$, Brasil). Após a homogeneização a solução foi centrifugada em $14000 \mathrm{rpm}$ por 30 minutos a $4{ }^{\circ} \mathrm{C}$, a fração rica em proteína foi removida para fígado a sobrenadante enquanto para adipócitos e TAB a intermediaria todas foram coletadas e estocadas a $-20{ }^{\circ} \mathrm{C}$ para posteriores análises. 


\subsubsection{Eletroforese SDS-PAGE}

A dosagem de proteína foi realizada conforme o método descrito no BCA kit para quantificação de proteína (Pierce, IL, USA) utilizando-se albumina como referência. As proteínas forram desnaturadas através do calor $\left(95^{\circ} \mathrm{C}\right.$ por 10 minutos $)$, em tampão de amostra (Laemmil 4 x) 4\% SDS, 20\% Glicerol, Tris-HCL 0,125 M pH 6,8, DTT 0,2 M e 0,02\% Azul de bromofenol. Após esse procedimento, o volume equivalente a 30-70 $\mu \mathrm{g}$ de proteínas das amostras e $5 \mu \mathrm{L}$ do padrão de peso molecular (BioRad) foram aplicados ao gel de poliacrilamida (5\% para retenção e $10 \%$ Tricina SDS-PAGE para separação das proteínas) e as proteínas foram separadas por eletroforese por cerca de 1 horas e 20 minutos, a $110 \mathrm{~V}$.

\subsubsection{Transferência}

As proteínas das amostras separadas no gel de eletroforese foram transferidas para a membrana de PVDF (Hybondo X-tra ${ }^{\circledR}$, Amersham) utilizando o método semi seco à $25 \mathrm{~V}$ por 40 min (Trans-Blot Turbo Blotting System, Bio-Rad, USA) com a solução de transferência, $20 \mathrm{mM}$ Tris, $150 \mathrm{mM}$ Glicina e 10\% Metanol. Ao final da eletro-transferência, cada membrana foi lavada em PBS-T, rapidamente corada com vermelho de ponceau e descorada com água destilada e PBS-T.

\subsubsection{Bloqueio e incubação}

As membranas foram incubadas por 1 hora com 5\% de leite em pó desnatado em PBS-T para bloqueio dos sítios antigênicos inespecíficos. Decorrido este período, as membranas foram lavadas com PBS-T e incubadas (overnight), sob agitação (agitador orbital, Red Rotor, Hoefer) em solução de anticorpos para anti-IL-1ß (Santa Cruz, SC-1251, Goat), p65 (Cell Signalling, C22B4, Rabbit), Myd88 (Santa cruz, SC-11356, Goat), TNFr1 (Santa Cruz, SC-1070, Mouse), p50 (Santa Cruz, SC-8414, Rabbit), Gapdh (Sigma, G9545, Rabbit) pJNK (Cell Signalling, 9552, Rabbit) em $4{ }^{\circ} \mathrm{C}$. Após este período, as membranas foram lavadas com PBS-T e incubadas com o anticorpo secundário (goat anti-rabbit IgG ou chiken anti-goat $\operatorname{IgG}$ ) conjugado com peroxidase por 2 horas e após a incubação do secundário, foi realizada mais um lavagem com PBS-T e incubada por 3 minutos com ECL (Amersham, UK).

\subsubsection{Exposição e desenvolvimento do filme}

O desenvolvimento foi realizado em uma sala escura, sob luz vermelha e utilizando o kit de revelação e fixação (Kodak). O filme foi colocado acima da membrana por tempo determinado de acordo com o anticorpo, seguindo-se transferência para o revelador por um 
minuto, depois passagem em água rapidamente e fixador, por 30 segundos. As bandas foram registradas após a obtenção de imagem em scanner (EPSON STYLUS CX3200). A intensidade das bandas foi quantificadas pelo software Image $J^{\circledR}$.

4.7 Dosagem de citocinas por Enzyme-linked immune absorbent assay (ELISA)

Para dosagem das citocinas foi utilizado o método (ELISA) de captura (ReD System, Inc., Minneapolis, USA). As amostras utilizadas foram as mesmas utilizadas para Western blot, provenientes dos diferentes grupos experimentais. Placas de 96 poços foram sensibilizadas com $100 \mu \mathrm{l}$ de anticorpo monoclonal de acordo com a proteína especifica, IL-6 (DY506), TNF- $\alpha$ (DY510), IL-10 (DY522) e IL-1ß (DY501), e incubadas overnight à $4{ }^{\circ} \mathrm{C}$. Após este período, os poços foram lavados por três vezes com o tampão para lavagem $(0,05 \%$ Tween 20 em PBS pH 7,4). Posteriormente, as placas foram bloqueadas, para evitar ligações inespecíficas com $300 \mu 1$ de solução de bloqueio (1\% BSA em PBS, pH 7,4, 0,2 $\mu$ m filtrado) e incubadas por uma hora em temperatura ambiente.

Após o período, foi adicionado $100 \mu \mathrm{l}$ da amostra por poço e dos padrões diluídos previamente em reagente de diluição. Para IL-6 o intervalo da concentração variou de 125$8000 \mathrm{pg} / \mathrm{ml}$, enquanto para o TNF- $\alpha$, a IL-10 e a IL-1 $\beta$ o intervalo foi de $62,5-4000 \mathrm{pg} / \mathrm{ml}$. Em dois poços foram colocados apenas o reagente de diluição para caracterização do branco. A placa foi incubada por 2 horas em temperatura ambiente. Em seguida, foram adicionados $100 \mu 1$ do anticorpo de detecção (Anticorpo anti-rato biotinilado), diluído previamente em reagente de diluição na concentração estabelecida, cobertos com fita adesiva e incubado por 2 horas em temperatura ambiente. Posteriormente, foram adicionados $100 \mu 1$ de Streptovidina$H R P$ (1:250) por poço e incubados por 30 minutos em temperatura ambiente, evitando o contato direto com a luz. Por fim, foi adicionado a solução de substrato (mistura dos reagentes de cores $\mathrm{A}-\mathrm{H}_{2} \mathrm{O}_{2}$ B - (Tetrametibenzidina), na diluição 1:1, por poços e incubado por 30 minutos em temperatura ambiente, onde se evitou o contato direto com a luz. A reação foi interrompida com $50 \mu \mathrm{l}$ da solução Stop $\left(\mathrm{H}_{2} \mathrm{SO}_{4} 30 \%\right)$ por poço sob agitação lenta. A leitura foi realizada em leitor de ELISA (PowerWave ${ }^{\mathrm{TM}}$, Bio-tek), utilizando-se filtro de $450 \mathrm{~nm}$.

4.8 Parte II - referente ao estudo da microbiota

\subsubsection{Animais}

O estudo foi realizado com aproximadamente 50 camundongos machos da linhagem C57B1/6, com 7-10 semanas de vida, obtidos no biotério do prédio 37 localizado no Campus NIH-Bethesda. Durante o experimento, os animais foram mantidos em gaiolas plásticas em 
ambiente com temperatura entre 23 a $25^{\circ} \mathrm{C}$ e iluminação com ciclos de claro/escuro de $12 / 12$ horas. Os camundongos Germ Free foram obtidos do biotério somente para camundongos Germ Free NCI-Frederick e mantidos durante todo o experimento e, no $17^{\circ}$ dia após a inoculação das células tumorais, os animais foram enviados para o laboratório em Bethesda para eutanásia (LEI-003).

\subsubsection{Desenho experimental e implantação das células tumorais}

Os camundongos foram divididos em 4 grupos, (1) grupo Convencional Controle (Conv), (2) Convencional Tumor (Conv TB), (3) Germ Free (GF) e (4) Germ Free Tumor (GF). As células tumorais utilizadas para indução da caquexia associada ao câncer foram Lewis Lung Carcinoma (LLC), elas foram cultivadas e mantidas mantidas em garrafas de cultura à $37^{\circ} \mathrm{C}$ em uma atmosfera humidificada, a $5 \%$ de $\mathrm{CO} 2 \mathrm{em}$ meio especificado pela empresa ATTC. As células foram injetadas subcutâneamente no flanco direito dos camundongos $4 \times 10^{6}$ células viáveis diluídas em solução salina à $0,9 \%$. Os animais controle receberam o mesmo volume de salina à $0,9 \%$. A viabilidade celular foi avaliada por exclusão de Trypan Blue.

\subsubsection{Variação do peso corporal e obtenção dos tecidos}

Os animais foram pesados antes e 17 dias após inoculação das células tumorais. Todos os animais utilizados nos experimentos foram sacrificados por deslocamento cervical após serem anestesiados com O2. Os tecidos foram extraídos imediatamente após o sacrifício e armazenados adequadamente de acordo com o protocolo planejado. Para os protocolos de qPCR RT e Western Blot os tecidos foram colocados rapidamente em gelo seco aproximadamente $-78{ }^{\circ} \mathrm{C}$ e estocados à $-80{ }^{\circ} \mathrm{C}$. Tecidos para análise histológica foram colocados em Formalina por 24h, transferido para álcool $70 \%$ e armazenados em $4{ }^{\circ} \mathrm{C}$ até o procedimento. Os tecidos extraídos foram gastrocnêmio, tecidos adiposos adiposos (retroperitoneal e epididimal) e fígado.

\subsection{Análise histológica}

\subsubsection{Obtenção e processamento do tecido}

Os fragmentos dos diferentes depósitos TAB armazenados em formalina, por 24h, a $4^{\circ} \mathrm{C}$, para a fixação. Os tecidos fixados foram então desidratados com concentrações crescentes de álcool: 70, 95 e 100\%. Após a desidratação foram clareadas com banhos de xilol e finalmente, incrustadas (ou incluídas) em parafina Paraplast X-tra da SEM e emblocados em Tissue Cassetes da Fisher Scientific. As amostras foram cortadas no micrótomo rotatório R 
Jung-Heidelberg. Cortes de $5 \mu \mathrm{m}$ de espessura foram colocados sobre lâminas previamente cobertas com polilisina.

\subsubsection{Desparafinização/Hidratação}

Os cortes foram desparafinizados com 2 banhos sucessivos de 30 minutos de xilol. A seguir foram hidratados em e banhos de 5 minutos com concentrações decrescentes de álcool: 100, 95 e $70 \%$, respectivamente, e, por fim, lavados em água destilada.

\subsubsection{Hematoxilina e Eosina (HeE)}

A coloração com HeE (Hematoxilina e Eosina) foi realizada após a desparafinização e hidratação das lâminas na seguinte sequência: i) 2 minutos com hematoxilina; e ii) 1 minuto com eosina. Após o processo de coloração, a lâmina foi fechada com permonte.

\subsubsection{Imunohistoquímica}

Para a imunohistoquímica, as laminas foram bloqueadas com 5\% de soro de cabra em PBS-T; após 1h, os cortes foram incubados com anticorpos UCP-1 1:200 (Cell Signaling, , rabbit) overnight a $4{ }^{\circ} \mathrm{C}$. Para observação adotou-se o anticorpo secundário conjugado com Biotina 1/500 (goat anti-rabbit IgG H\&L ab97049), Kit ABC para uma maior intensidade de quimiluminescência (Vector Laboratories) e por fim, o DAB3,3-diaminobenzidine (Sigma, St. Louis, MO). Os cortes foram contra-corados com Hematoxilina.

\subsubsection{Análise das imagens}

Os cortes tanto em H\&E quanto imunohistoquímica foram digitalizados com aumento de $20 \mathrm{x}$. As imagens foram obtidas utilizando um microscópio óptico Leica, modelo DMLP, com câmera CCD LG, modelo GC-415N-MD.

4.10 qPCR RT e Western blot

Os procedimentos utilizados para as técnicas qPCR RT e Western blot foram as mesmas descritas nos subcapítulos 4.5 e 4.6 da tese. As sequências de Primers usadas para espécie camundongo foram: UCP1 Forward AGGCTTCCAGTACCATTAGG e Reverse CTGAGTGAGGCAAAGCTGATTT; PPAR $\alpha$ Forward AGAGCCCCATCTGTCCTCTC e Reverse ACTGGTAGTCTGCAAAACCAAA; PGC-1 $\alpha$ Forward CCCTGCCATTGTTAAGACC e Reverse TGCTGCTGTTCCTGTTTTC; PRDM16 Forward CAGCACGGTGAAGCCATTC e Reverse GCGTGCATCCGCTTGTG; Sirt-1 Forward GCTGACGACTTCGACGACG e Reverse TCGGTCAACAGGAGGTTGTCT. E os anticorpos usados foram: Anti-HSL (Cell Signalling, 4107, Rabbit); Anti-Phospho-HSL 
Ser660 (Cell Signalling 4126, Rabbit); Antibody Anti-ATGL (Cell Signalling 2138, Rabbit); Anti-Phospho-HSL Ser565 (Cell Signalling 4137, Rabbit); Anti-Phospho-Adipose Triglyceride Lipase Ser406 (ab, 135093, Rabbit); Ati-Actin (Cell Signalling, 4970, Rabbit); anti secundário (Cell Signalling, goat anti-rabbit IgG)

\subsection{Análise estatística}

Os dados obtidos no Brasil, estão expressos como média e erro padrão da média. As diferenças relativas nos grupos de estudos (T0, T7 e T14) foram analisadas com software GraphPad5 (GraphPad, San Diego, CA, USA) e o nível de significância foi determinado pelo One-Way ANOVA seguido pelo pós-teste de Tukey para comparação entre os grupos. Para os resultados relacionados massa corporal e tecidual no grupo câncer (T7 e T14) e controle (C7 e C14) utilizamos two-way ANOVA, seguido pelo pós-teste de Tukey. O nível de significância estabelecido foi de $\mathrm{p}<0,05$.

Os resultados do estudo da microbiota, estão expressos como média e erro padrão da média. As diferenças relativas nos grupos de estudos (Conv, Conv TB, Germ Free e Germ Free TB) foram analisadas com software GraphPad5 (GraphPad, San Diego, CA, USA). O nível de significância foi determinado pelo two-way ANOVA, seguido pelo pós-teste de Tukey. O nível de significância estabelecido foi de $\mathrm{p}<0,05$. 


\section{RESULTADOS}

\subsection{Parâmetros de validação da caquexia}

Após 14 dias da inoculação das células tumorais, os animais apresentaram redução no peso corporal $(10,6 \% ; \mathrm{p}<0,05)$ e na massa do TAB $(42,5 \%$ em TAME e 40,2\% em TARP; $\mathrm{p}<0,05$ ) (Tabela 2), comparado aos animais do grupo controle de mesma idade. A caquexia terminal foi acompanhada pelo aumento da concentração de AGL, HDL e TG no plasma (Tabela 3).

Tabela 2 - Peso corporal e dos tecidos dos grupos Controle (C) e Caquéticos (TB)

\begin{tabular}{|c|c|c|c|c|c|c|c|c|}
\hline & \multicolumn{5}{|l|}{ Inicial } & \multicolumn{3}{|c|}{ 2-Way Anova p-values } \\
\hline & T0 & C7 & TB7 & C14 & TB14 & Tempo & Tumor & $\begin{array}{c}\text { Tempo/Tu } \\
\text { mor }\end{array}$ \\
\hline MC-T (g) & $220,8 \pm 18,4$ & $264,4 \pm 21,4$ & $247,8 \pm 17,8$ & $285,4 \pm 19,7^{* *}$ & $255,1 \pm 21,4^{*}$ & $\mathrm{~ns}$ & $* \mathrm{p}<0,05$ & $* * p<0,01$ \\
\hline MT (g) & & & $4,4 \pm 2,53$ & & $12,05 \pm 6,43$ & & & \\
\hline Fígado (g) & $6,32 \pm 0,72$ & & $8,60 \pm 0,71$ & $11,03 \pm 1,13$ & $11,17 \pm 1,56^{*}$ & $* p<0,05$ & $\mathrm{~ns}$ & $\mathrm{~ns}$ \\
\hline TAME (g) & $1,03 \pm 0,33$ & $1,82 \pm 0,47$ & $1,37 \pm 0,32$ & $2,54 \pm 0,43 * *^{\#}$ & $1,46 \pm 0,22^{\& \&}$ & ${ }^{\#} \mathrm{p}<0,05$ & $\& \& p<0,01$ & $* * \mathrm{p}<0,01$ \\
\hline TEA $(g)$ & $1,52 \pm 0,38$ & $2,15 \pm 0,34$ & $2,04 \pm 0,41$ & $3,46 \pm 0,40$ & $2,83 \pm 0,45$ & ns & ns & ns \\
\hline TARP (g) & $0,87 \pm 0,38$ & $2,12 \pm 0,35$ & $1,39 \pm 0,40$ & $3,45 \pm 0,48 * *$ & $2,06 \pm 0,46^{* \#}$ & ${ }^{\#} \mathrm{p}<0,05$ & $* \mathrm{p}<0,05$ & $* * p<0,01$ \\
\hline
\end{tabular}

NOTA: C: controle; TB: câncer-caquexia; MC-T: massa corporal - massa tumoral; MT: massa tumoral; TAME: tecido adiposo mesentérico; TEA: tecido adiposo epididimal; TARP: tecido adiposo retroperitoneal. Dados expressos em média \pm erro padrão; $\mathrm{n}=5 /$ grupo.

Tabela 3 - Perfil lipídico durante a progressão da caquexia

\begin{tabular}{lccccccccc}
\hline & \multicolumn{3}{c}{ T0 } & & T7 & \multicolumn{3}{c}{ T14 } \\
\hline Glicerol (mg/mL) & 0,14 & \pm & 0,09 & 0,09 & \pm & 0,02 & 0,11 & \pm & 0,04 \\
AGL (mE/mL) & 0,75 & \pm & 0,03 & 0,80 & \pm & 0,03 & 1,25 & \pm & $0,22^{*}$ \\
HDL (mg/dL) & 43,73 & \pm & 2,24 & 46,80 & \pm & 4,54 & 52,12 & \pm & $1,15^{\#}$ \\
TG (mg/dL) & 82,95 & \pm & 5,38 & 114,81 & \pm & 29,00 & 151,30 & \pm & $50,18^{*}$ \\
\hline
\end{tabular}

NOTA: T0, T7 e T14: tempo em dias após a inoculação das células tumorais; AGL: ácido graxo livre; HDL: lipoproteína de alta densidade; TG: triacilglicerol. Dados expressos em média \pm erro padrão; $n=5 / g r u p o . ~ * p<0,05$ diferença entre os tempos; ${ }^{\#} \mathrm{p}<0,05$ em relação ao T0.

5.2 Inflamação durante a caquexia associada ao câncer

Tecido adiposo mesentérico: foi observado aumento na expressão gênica do Tnf- $\alpha$ (Figura 3-B) no T7, mantido até o T14 $(\mathrm{p}<0,05)$, quando comparado ao T0. O conteúdo proteico de Il-1 $\beta$ (Figura 3-G) se apresentou elevado no T14 ( $<<0,05)$ em relação ao T0.

Tecido adiposo retroperitoneal: aumento da expressão dos genes de Il-6 e Tnf- $\alpha$ (Figuras 3-A e B) foi detectado somente no estágio final da caquexia $(T 14 ; p<0,05)$. Para o conteúdo proteico de Il-1 $\beta$ (Figura $3-G$ ), verificamos aumento semelhante ao TAME $(p<0,05$; 
T14); no entanto, embora a expressão gênica da citocina anti-inflamatória Il-10 (Figura 3-C) tenha sido elevada no T14 $(\mathrm{p}<0,05)$, seu conteúdo proteico (Figura 3-F) não apresentou diferença significativa.

Tecido adiposo epididimal: neste tecido, a expressão das citocinas pró-inflamatórias Il-6 e Tnf- $\alpha$ (Figuras 3-A e B) estava aumentada somente no T14 ( $<<0,05)$. Ao mesmo tempo, houve aumento na expressão proteica de Tnf- $\alpha$ e Il-1 $\beta$ (Figuras 3-E e G) $(\mathrm{p}<0,05)$ quando comparado ao T0. Contudo, semelhantemente ao observado no TARP, a expressão gênica da citocina Il-10 (Figura 3-C) mostrou-se elevada no T7 e manteve-se assim até o T14, comparando-se tempos $(\mathrm{p}<0,05)$.
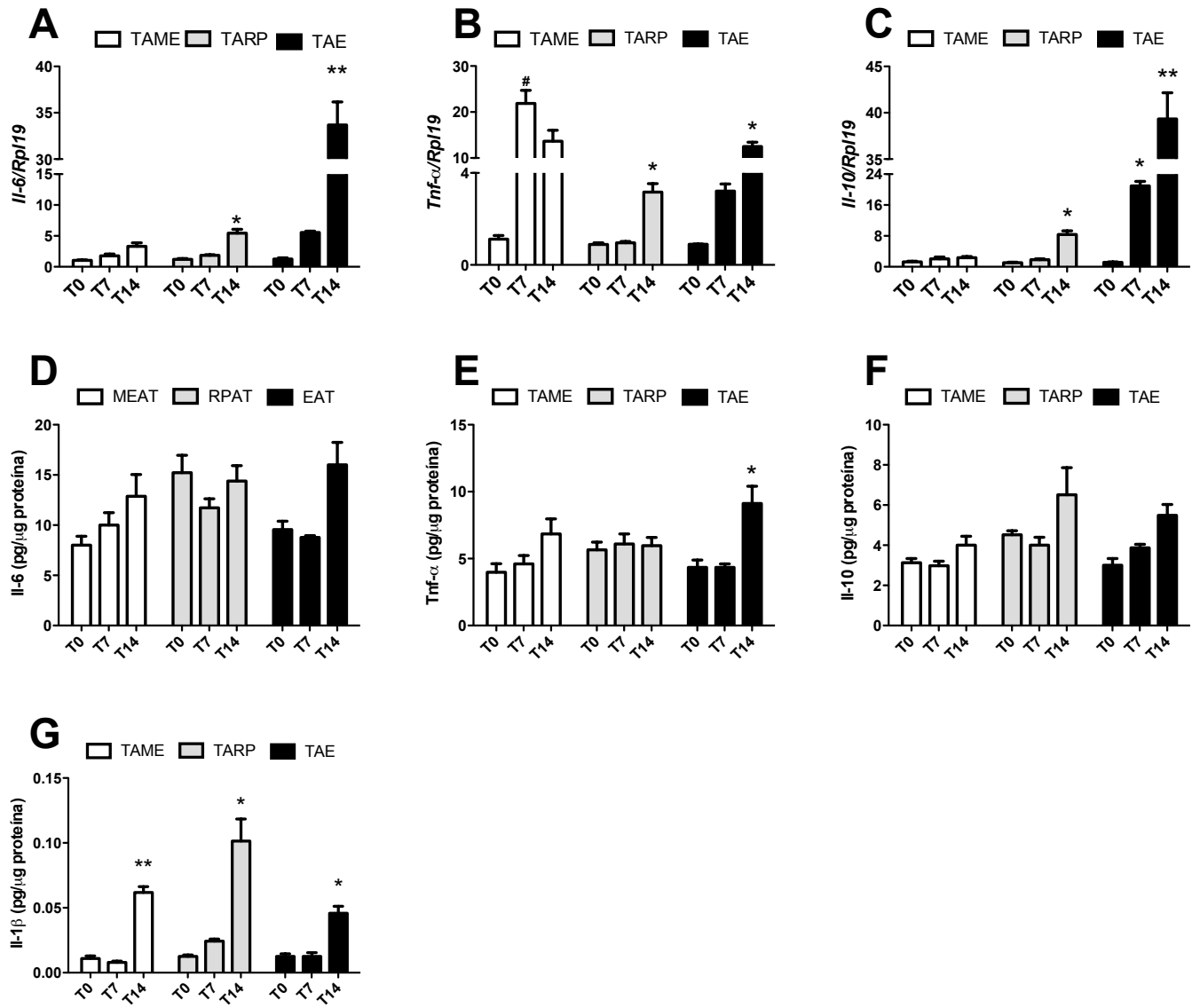

Figura 3 - Expressão gênica e proteica de citocinas inflamatórias no tecido adiposo branco durante a progressão da caquexia. A - expressão gênica de Il-6; B - expressão gênica de Tnf- $\alpha$; C - expressão gênica de Il-10; D expressão proteica de Il-6, E - expressão proteica de Tnf- $\alpha, \mathrm{F}$ - expressão proteica de Il-10; G - expressão proteica de Il-1ß. TAME: tecido adiposo mesentérico; TARP: tecido adiposo retroperitoneal; TAE: tecido adiposo epididimal; T0, T7 e T14: tempo em dias após a inoculação das células tumorais. Dados expressos em média \pm erro padrão; $n=5 /$ grupo. ${ }^{*} \mathrm{p}<0,05$ diferença entre os tempos; $* * \mathrm{p}<0,01$ diferença entre os tempos; ${ }^{\#} \mathrm{p}<0,05$ em relação ao T0. 
5.3 Estudo dos adipócitos durante o desenvolvimento da caquexia associada ao câncer

O tecido adiposo é composto por diferentes tipos celulares, todos com grande potencial inflamatório. Assim, procuramos entender qual seria a relevância das células adiposas per se contribuindo na inflamação local e sistêmica ocasionada pela caquexia.

Adipócitos mesentéricos (MEa): nas células isoladas do tecido adiposo mesentérico (MEa), somente a expressão gênica da citocina Tnf- $\alpha$ (Figura 4-B) apresentou-se elevada no T14 ( $<$ <0,05) em relação aos demais tempos. Em adição, verificarmos aumento na expressão proteica de Il-6, Tnf- $\alpha$, Il-10 e Il-1 $\beta$ (Figuras 4-D, E, F e G) no estágio terminal da caquexia (T14; $\mathrm{p}<0,05)$. O conteúdo proteico encontrado em MEa de IL-1 $\beta$ teve comportamento similar ao encontrado no TAME. Assim, especulamos que o aumento das outras citocinas, como Il-6, Tnf- $\alpha$ e Il-10, nos MEa foi insuficiente para afetar valores significativos em T14 comparado a T0 no tecido total (TAME).

Adipócitos retroperitoneais $(\mathrm{RPa})$ : células adiposas isoladas do tecido adiposo retroperitoneal $(\mathrm{RPa})$ apresentaram a expressão gênica de Tnf- $\alpha$ (Figura 4-B) aumentada em T14, em comparação com o T0 $(\mathrm{p}<0,05)$. Tal incremento foi paralelo ao encontrado no tecido (TARP) no mesmo tempo (T14). Observamos valores elevados na expressão gênica de Il-10 (Figura 4-C) em T14, comparado aos tempos T0 e T7 (p<0,05) nessas células. O aumento de Il-10 pode estar associado ao aumento da expressão do gene de TNF- $\alpha$ nessas células. Como já mencionado, o conteúdo proteico de Il-1 $\beta$ (Figura 3-G) mostrou-se elevado no TARP, mas não em RPa e, portanto, postulamos uma possível contribuição da FVE, composta pelos demais tipos celulares que não o adipócito maturo do tecido. Apesar de encontrarmos concentração elevada das proteínas de Il-6 e TNF- $\alpha$ (Figura 4-D e E) em adipócitos obtidos no T14, comparado com o T0, o aumento nos adipócitos não foi suficiente para ser refletido em aumento tecidual (TARP).

Adipócitos epididimais (Ea): no Ea, apenas a expressão gênica de Tnf- $\alpha$ (Figura 4-B) elevou-se no T14 em relação a T0 $(\mathrm{p}<0,05)$. Contudo, o conteúdo proteico de todas as citocinas pró-inflamatórias (Figuras 4-D, E e G) apresentou-se elevado na fase terminal da caquexia (T14) $(\mathrm{p}<0,05)$. Provavelmente, o aumento do conteúdo proteico de Tnf- $\alpha$ e Il-1 $\beta$ no TAE seja decorrência da produção pelo Ea. Os adipócitos (Ea) mostraram aumento da expressão proteica de Il-10 (Figura 4-F) na fase terminal da caquexia $(p<0,05)$, talvez numa tentativa de compensar a inflamação crescente. 

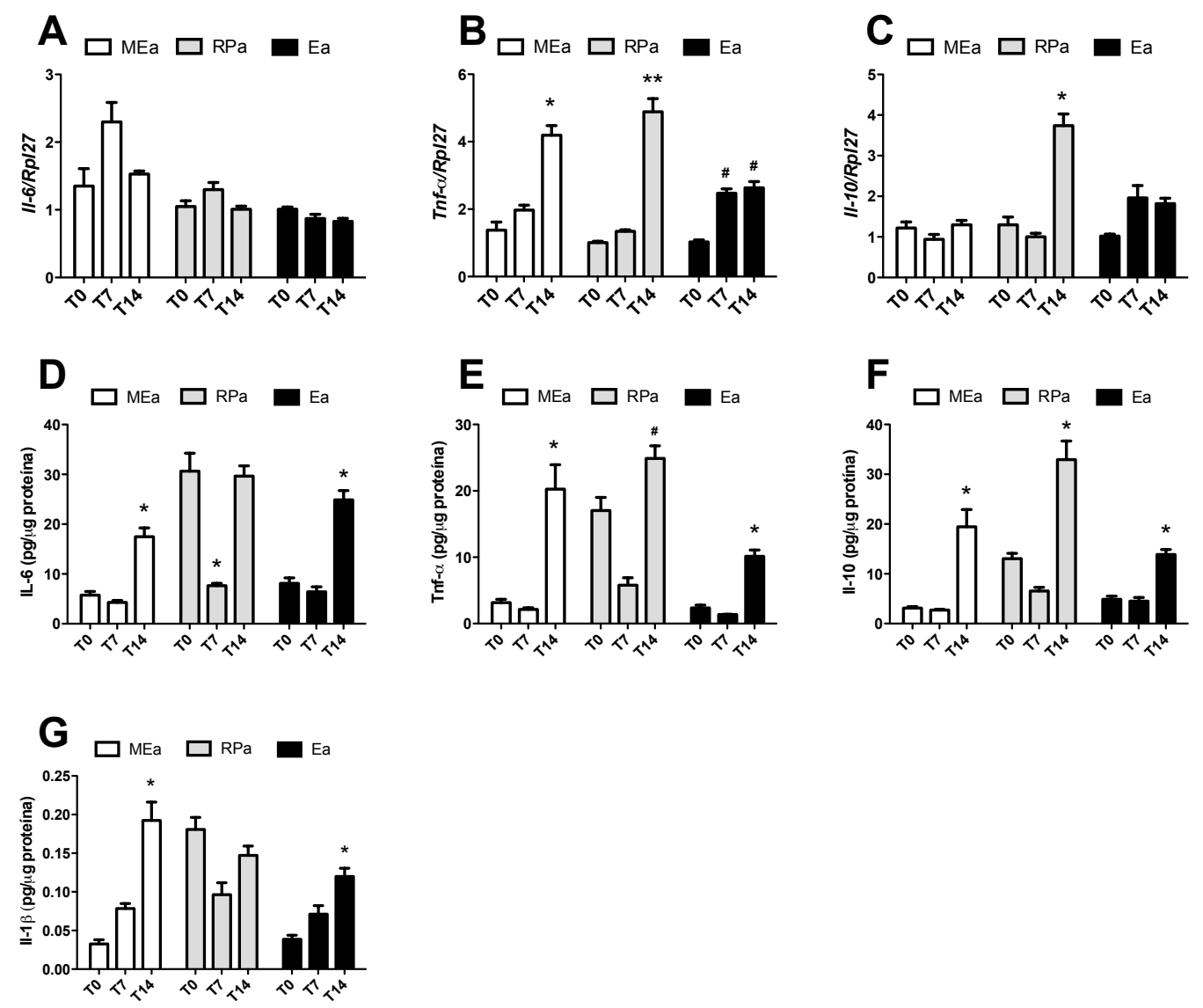

Figura 4- Expressão gênica e proteica de citocinas inflamatórias em células adiposas isoladas durante a progressão da caquexia. A - expressão gênica de Il-6; B - expressão gênica de Tnf- $\alpha$; C - expressão gênica de Il10; D - expressão proteica de Il-6; E- expressão proteica de Tnf- $\alpha$; F - expressão proteica de Il-10; G- expressão proteica de Il-1ß. MEa: adipócito mesentérico; RPa: adipócito retroperitonial; Ea: adipócito epididimal; T0, T7 e T14: tempo em dias após a inoculação das células tumorais. Dados expressos em média \pm erro padrão; $\mathrm{n}=5$ /grupo. ${ }^{*} \mathrm{p}<0,05$ diferença entre os tempos; ${ }^{\&} \mathrm{p}<0,05$ em relação ao T7.

Em seguida, avaliamos vias relacionadas com a indução de citocinas inflamatórias nos adipócitos de diferentes depósitos.

MEa: a expressão dos genes fator nuclear kappa $B$ (NF-кB), subunidades p50 e p65, Ikk- $\alpha$, Tlr2, Myd88 e Traf6 (Figuras 5-A, B, C, E, F e G), apresentou-se aumentada no T14 comparado ao T0 $(\mathrm{p}<0,05)$. Desse modo, observamos que todos os genes da via de Tlr/NF- $\mathrm{KB}$ foram regulados positivamente durante a caquexia associada ao câncer. Em concordância ao encontrado na expressão gênica, a expressão das proteínas NF-кBp65 e MyD88 (Figuras 6-B e C) aumentou na fase terminal da caquexia, comparado ao T0 ( $p<0,05)$.

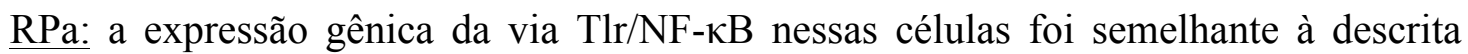
para MEa. Os genes de NF-кBp50 e p65, Ikk- $\alpha$, Tlr2, MyD88 e Traf6 (Figuras 5-A, B, C, D, F e G) aumentaram em T14 comparado com T0 $(p<0,05)$. No entanto, em contraste com os

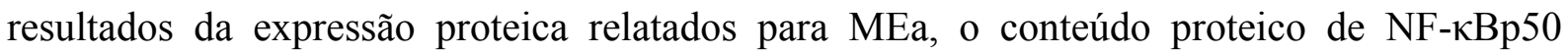


aumentou no T14 e, na contramão, o de NF-кBp65 (Figuras 6-A e B) diminuiu no T14 sempre quando comparado ao T0 $(\mathrm{p}<0,05)$.

Ea: essa população celular mostrou novamente comportamento paralelo ao de MEa. A expressão gênica de NF-кBp50, p65, Ikk- $\alpha$, Tlr2, MyD88 e Traf6 (Figuras 5-A, B, C, D, F e G) aumentou na fase terminal da caquexia, comparando-se com T0 $(\mathrm{p}<0,05)$. O conteúdo das proteínas NF-אBp65 e Myd88 (Figuras 6-B e C) apresentou-se elevado no T14 em relação ao $\mathrm{T} 0(\mathrm{p}<0,05)$.
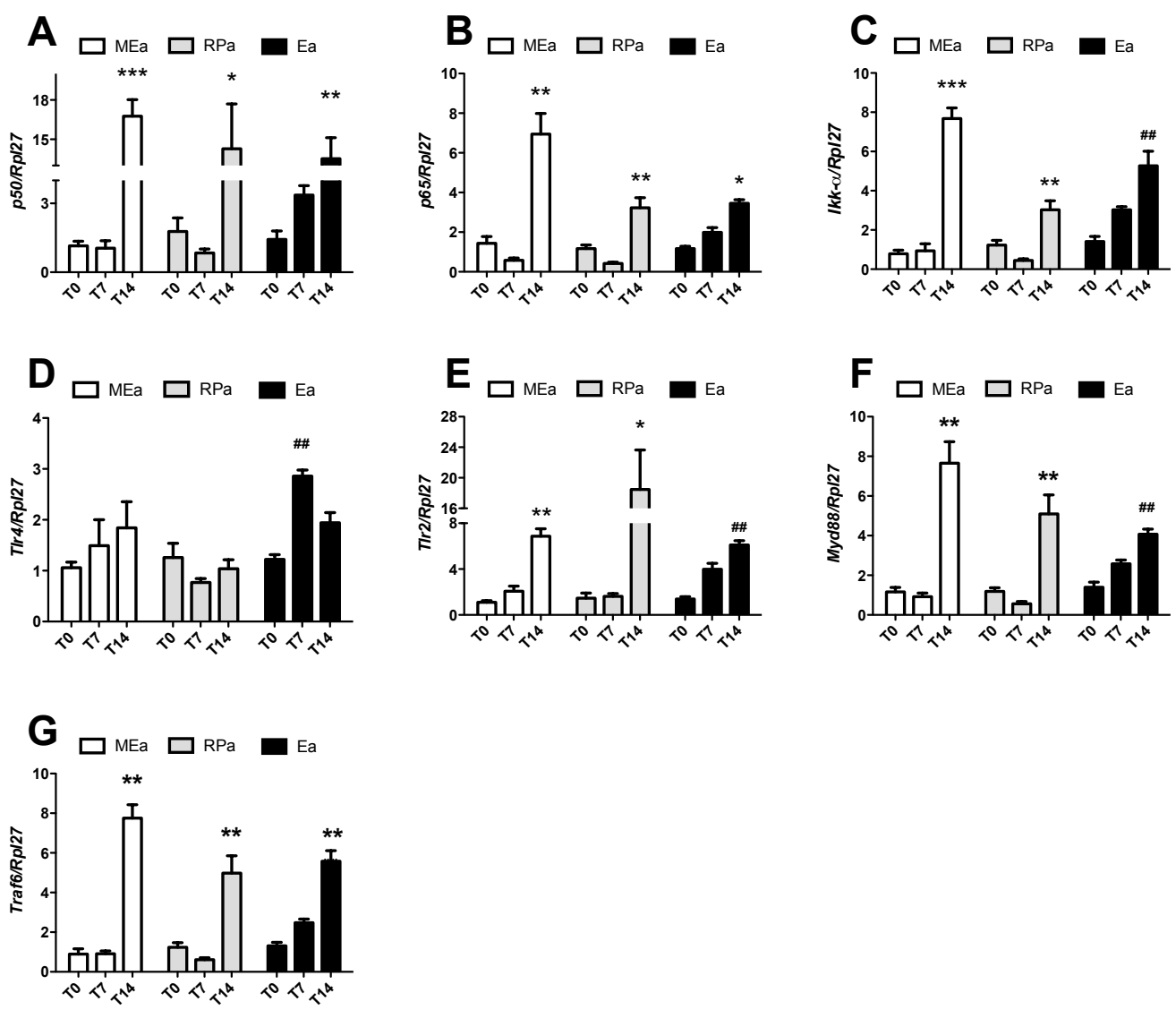

Figura 5- Expressão gênica dos fatores de transcrição envolvidos na via inflamatória em células adiposas

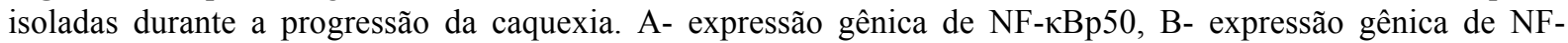
$\kappa B p 65$, C- expressão gênica de Ikk- $\alpha$, D- expressão gênica de Tlr4, E- expressão gênica de Tlr2, F- expressão gênica de Myd88 e G- expressão gênica de Traf6. MEa: adipócito mesentérico; RPa: adipócito retroperitonial; Ea: adipócito epididimal; T0, T7 e T14: tempo em dias após a inoculação das células tumorais. Dados expressos em média \pm erro padrão; $\mathrm{n}=5 /$ grupo. ${ }^{* *} \mathrm{p}<0,01$ diferença entre todos os grupos, para o mesmo tecido; ${ }^{*} \mathrm{p}<0,05 v s$ T0; ${ }^{\#} \mathrm{p}<0,01$ vs T0. 

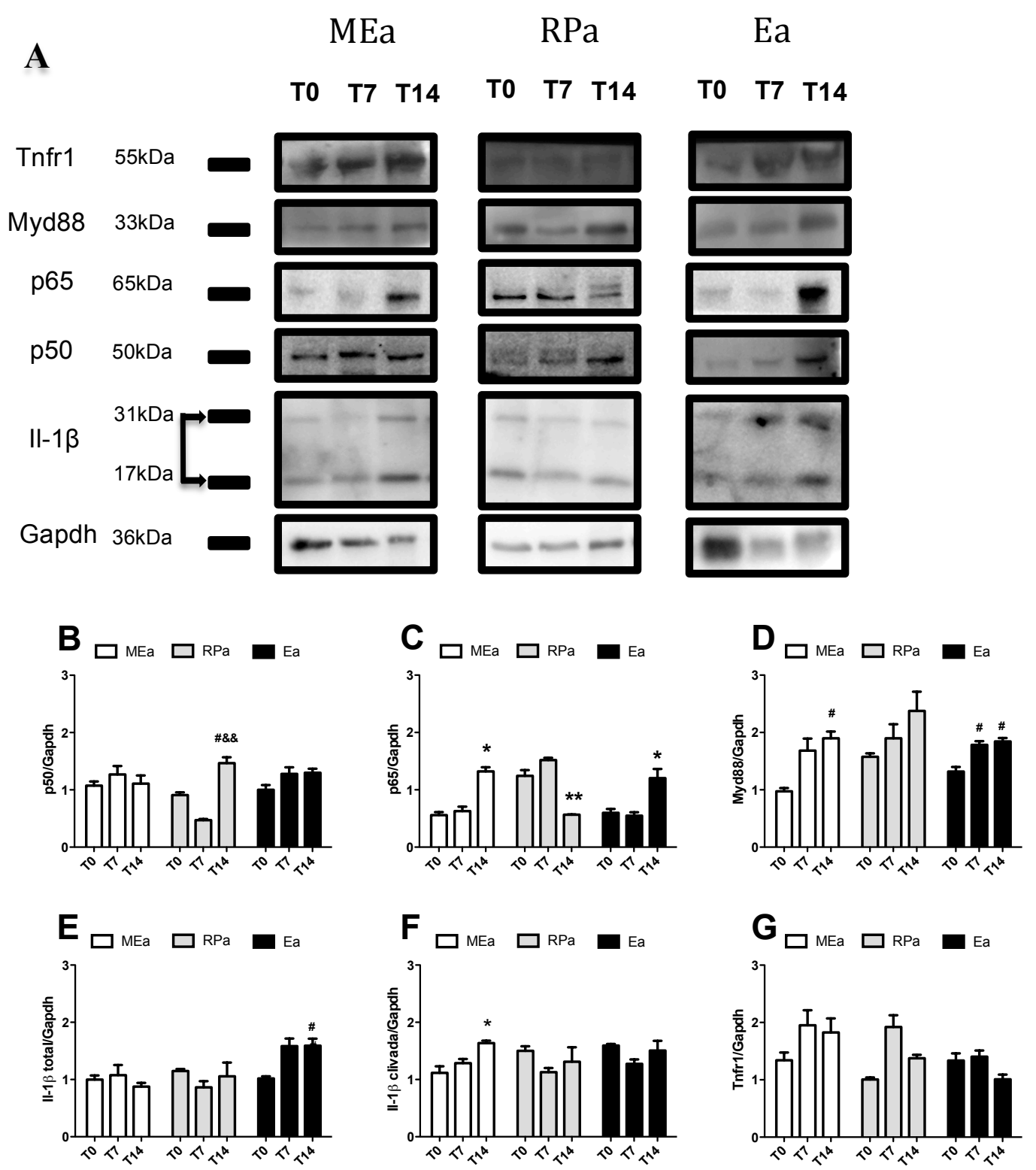

Figura 6- Expressão proteica em células adiposas isoladas durante a progressão da caquexia. A- As imagens dos blots selecionadas são representativas para NF- $\mathrm{kBp} 50$ e p65, Myd88, Il-1ß (total e a forma clivada), Tnfr1 e Gapdh (proteína normalizadora), B-F a expressão proteica foi realizada pelo software Image $j$. MEa: adipócito mesentérico; RPa: adipócito retroperitonial; Ea: adipócito epididimal; T0, T7 e T14: tempo em dias após a inoculação das células tumorais. Dados expressos em média \pm erro padrão; $n=3 /$ grupo. ${ }^{*} p<0.05 v$ s todos os todos o grupos, para o mesmo tecido; ${ }^{\#} \mathrm{p}<0,01$ vs $\mathrm{T} 0 ;{ }^{\& \&} \mathrm{p}<0,05$ vs $\mathrm{T} 7$.

Ao observarmos o aumento da proteína IL-1 $\beta$ clivada, fomos verificar o comportamento da via do inflamassoma, uma vez conhecido na literatura seu papel na clivagem da prémadura IL-1 $\beta$ à madura.

MEa: a expressão dos genes relacionados com a atividade da via de inflamassoma foi alterada durante a progressão da caquexia. A expressão gênica de Nlrp-1, -3 e Caspase-1 (Figuras 7-A, B e C) mostrou-se elevada no T14 (p<0,01) em relação ao T0. Em adição aos 
resultados encontrados da via do inflamassoma, verificamos aumento da proteína Il-1 $\beta$ clivada (Figura 6-F) no T14 em relação ao T0 $(\mathrm{p}<0,05)$.

RPa: no RPa, apenas a expressão do gene de Nlrp3 (Figura 7-B) foi aumentada em T14 comparado com o T0 $(\mathrm{p}<0,05)$.

Ea: a expressão dos genes de Nlrp-1 e -3 (Figura 7-A e B) aumentou em T14 em comparação com o T0 $(\mathrm{p}<0,01)$. No entanto, não observamos mudanças no conteúdo da proteína Il-1 $\beta$ clivada e na expressão gênica de Caspase-1.
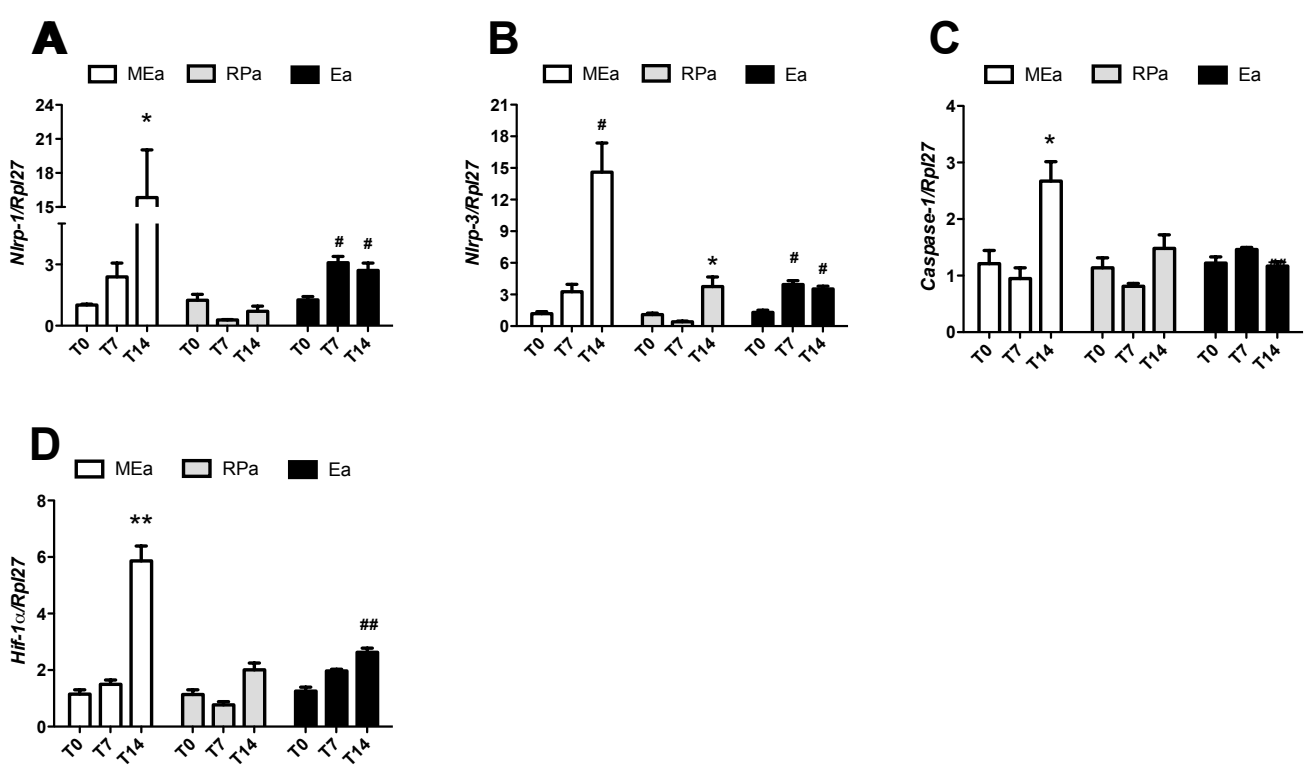

Figura 7- Expressão gênica da via do inflamassoma em células adiposas isoladas durante a progressão da caquexia. A- Expressão gênica de Nalp1, B- Expressão gênica de Nalp3, C- Expressão gênica de Caspase 1 e DExpressão gênica de Hif-1 $\alpha$. MEa: adipócito mesentérico; RPa: adipócito retroperitonial; Ea: adipócito epididimal; T0, T7 e T14: tempo em dias após a inoculação das células tumorais. Dados expressos em média \pm erro padrão; $\mathrm{n}=4$ /grupo. ${ }^{*} \mathrm{p}<0,05$ vs todos os grupos para o mesmo tecido; ${ }^{*} \mathrm{p}<0,05$ vs $\mathrm{T} 0 ;{ }^{\# \#} \mathrm{p}<0,01$ vs $\mathrm{T} 0$.

5.4 Estudo do fígado durante o desenvolvimento da caquexia associada ao câncer

Avaliamos o comportamento do fígado na produção de citocinas pró-inflamatórias. Para a citocina Il-1 $\beta$ (Figura 4-E), observamos que a expressão gênica estava elevada no T7 e manteve-se até o T14, quando comparada entre os tempos $(\mathrm{p}<0,01)$. O conteúdo proteico da Il-1 $\beta$ (Figura 4-A), no T14, seguiu o relatado para a expressão gênica $(\mathrm{p}<0,01)$. Porém, o conteúdo proteico das demais citocinas avaliadas, como Tnf- $\alpha$, Il-6 e Il-10 (Figuras 4-B, C e D), não apresentou diferença significativa. Em seguida, procuramos avaliar o perfil de macrófagos infiltrados no fígado durante a progressão da síndrome. Observamos que o número de macrófagos residentes aumentou já em T7 e este aumento foi ainda mais pronunciado, quando observamos a fase terminal da caquexia, correspondente a T14 (Figura 5-A-F). 

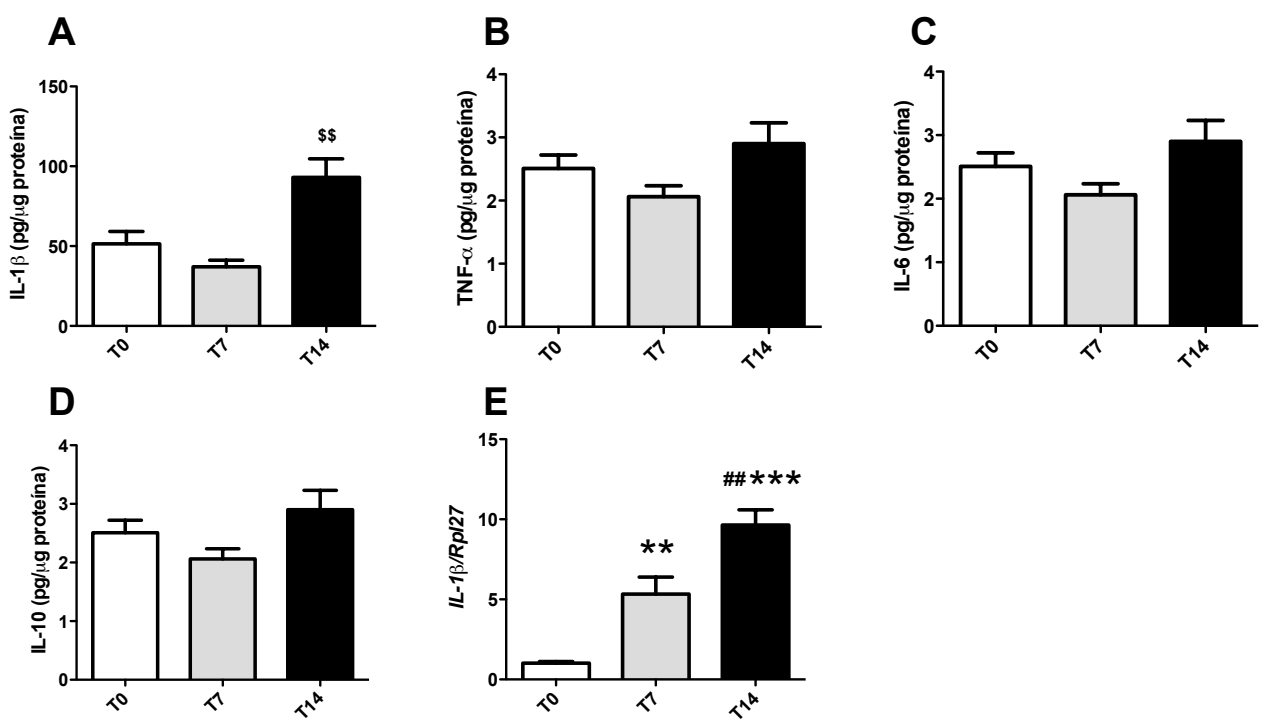

Figura 8- Expressão de citocinas inflamatórias no fígado durante a progressão da caquexia. A - expressão proteica de Il-1 $\beta$; B - expressão proteica de Tnf- $\alpha$; C - expressão proteica de Il-6; D - expressão proteica de Il-10; E - expressão gênica de Il-1 $\beta$. T0, T7 e T14: tempo em dias após a inoculação das células tumorais. Dados expressos em média \pm erro padrão; $n=5$ /grupo. ${ }^{\$} \mathrm{p}<0,001$ diferença entre os tempos.

$H \& E$
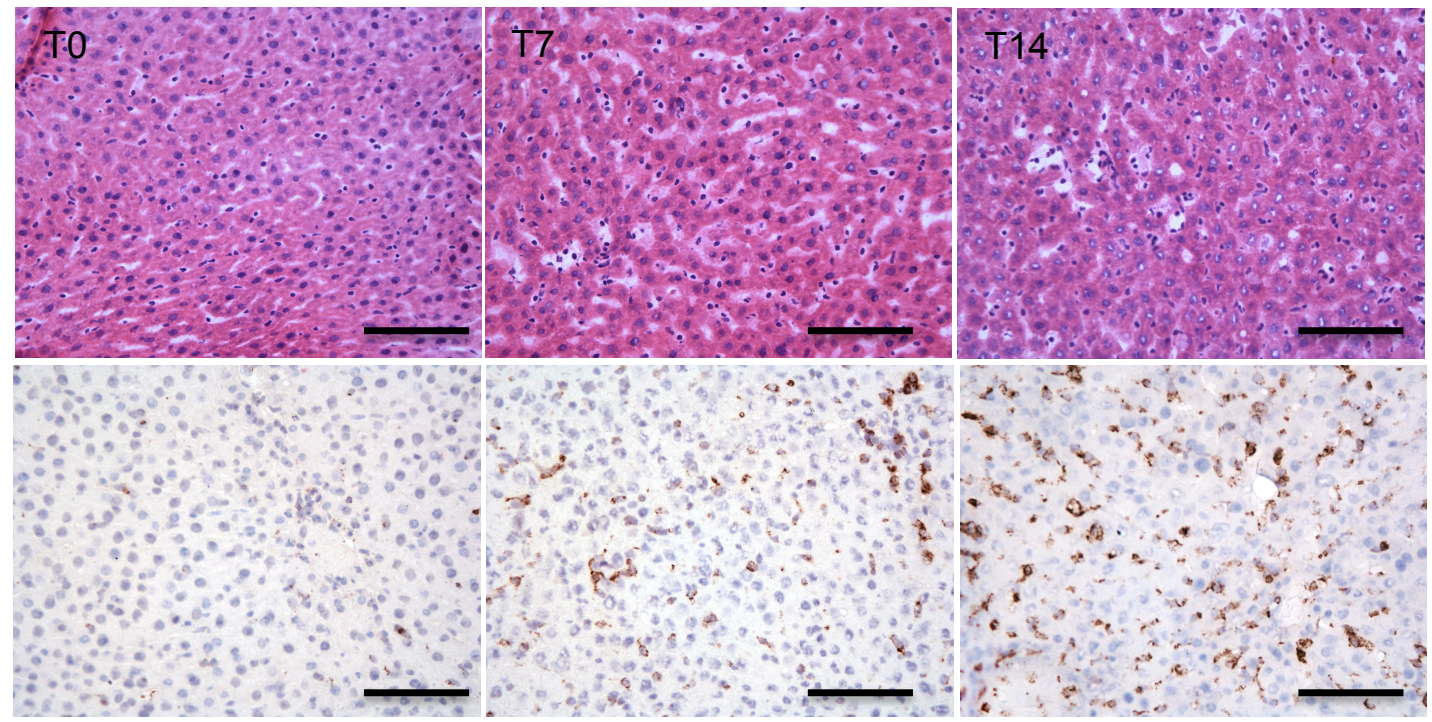

Figura 9 - Coloração de Hematoxilina e Eosina $(\mathrm{H} \& \mathrm{E})$ e imunohistoquímica para CD68. T0= controle, T7= 7 dias após inoculação das células tumorais e T14=14 dias após inoculação das células tumorais. A escala é de $100 \mu \mathrm{m}$.

Ao verificarmos o aumento qualitativo de macrófagos infiltrados e o aumento no conteúdo proteico de IL-1 $\beta$, fomos avaliar genes e proteínas importantes para produção da IL$1 \beta$ na progressão da caquexia no fígado.

A expressão dos genes de Tlr4, Tlr2, Ccl-2 e F4/80 (Figuras 10-A, E, F e G) aumentou no T14 em relação ao T0 (p<0,01), enquanto a expressão gênica de CD68 (Figura 8-H) apresentou-se aumentada no dia 7 e manteve-se até o dia $14(p<0,01)$. Em adição, 
encontramos aumento no conteúdo proteico de pNF-кBp65 e pJNK (Figuras 11-B e C) no T14 comparado com T0 $(\mathrm{p}<0,05)$, apesar de observarmos que a expressão gênica de NFкBp65, MyD88 e Traf-6 não estar alterada durante o desenvolvimento da caquexia.

A
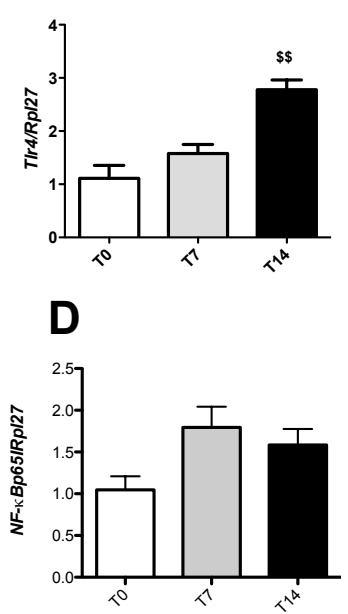

G

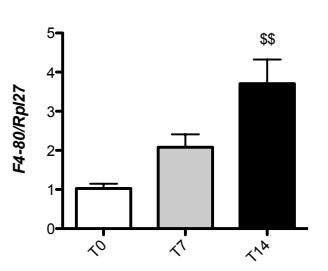

B

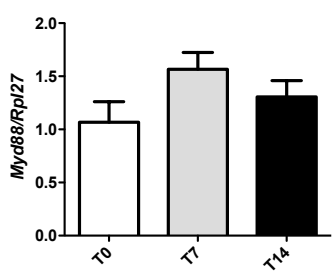

E

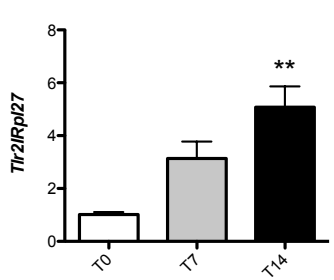

H

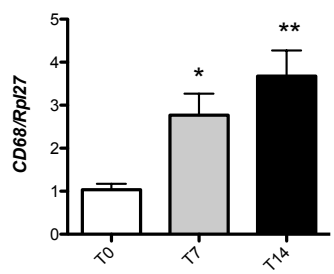

C

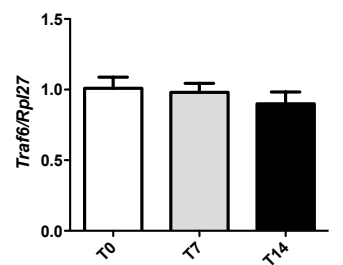

$\mathbf{F}$

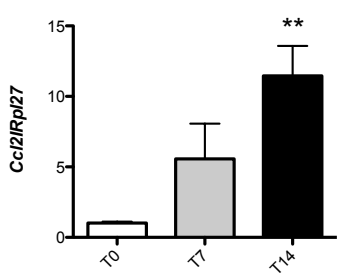

Figura 10- Expressão gênica dos fatores de transcrição envolvidos na via inflamatória no fígado durante a progressão da caquexia. A- expressão gênica de Tlr4. B- expressão gênica de Myd88. C- expressão gênica de Traf6. D- expressão gênica de NF-אBp65. E- expressão gênica de Tlr2. F- expressão gênica de Ccl2. Gexpressão gênica de CD68. H- expressão gênica de F4/80. T0, T7 e T14: tempo em dias após a inoculação das células tumorais. Dados expressos em média \pm erro padrão; $n=5 /$ grupo. ${ }^{*} \mathrm{p}<0,05$ vs $\mathrm{T} 0$; ${ }^{* *} \mathrm{p}<0,001$ vs T0; $* * * \mathrm{p}<0,0001$ vs T0; \#\#p<0,001 vs T7; $\$ \mathrm{p}<0,001$ vs todos os tempos. 
B

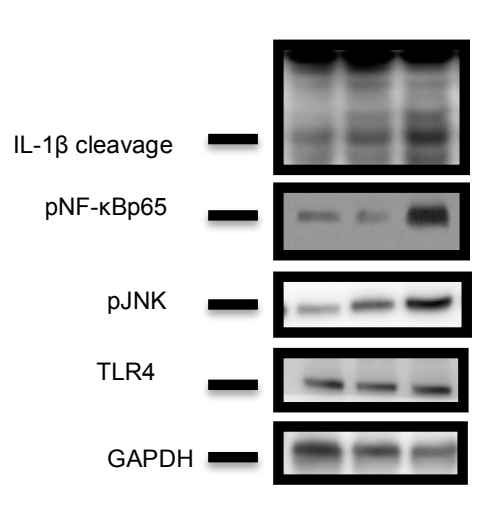

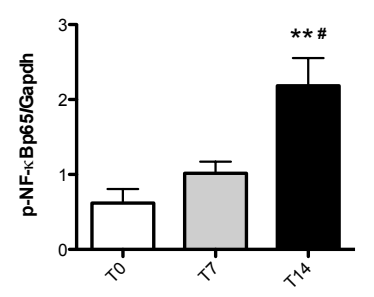

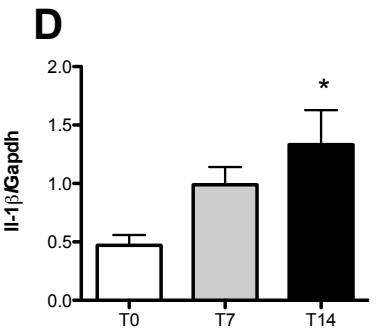

C

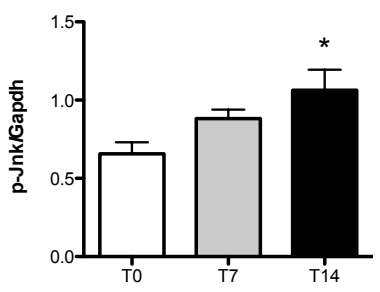

E

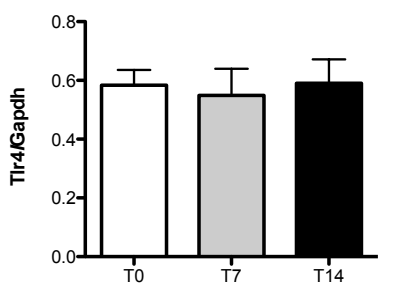

Figura 11- Expressão proteica no fígado durante a progressão da caquexia. A- As imagens dos blots

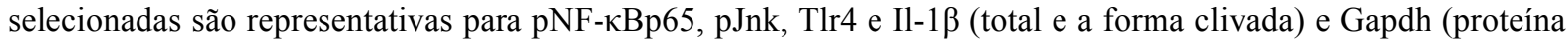
normalizadora), B-F expressão proteica foi realizada pelo software Image j. T0, T7 e T14: tempo em dias após a inoculação das células tumorais. Dados expressos em média \pm erro padrão; $\mathrm{n}=3 /$ grupo. $\quad{ }^{*} \mathrm{p}<0,05$ vs $\mathrm{T} 0 ; * * \mathrm{p}<0,001$ vs $\mathrm{T} 0 ; \# \mathrm{p}<0,05$ vs $\mathrm{T} 7$.

Semelhantemente ao encontrado no adipócito isolado de $\mathrm{MEa}$, encontramos, no fígado, aumento da proteína IL-1 $\beta$ clivada. Assim, fomos analisar a expressão gênica de genes importante da via do inflamassoma.

A expressão gênica de Nlrp-1, -3 e Caspase-1 (Figura 12-A, B e F) aumentou no T14 comparado aos tempos $(\mathrm{p}<0,01)$, enquanto a expressão do gene Nod 2 (Figura 12-E) elevouse apenas no T7 $(\mathrm{p}<0,01)$, retornando ao nível basal no T14. Em seguida, avaliamos o conteúdo proteico de Il-1 $\beta$ clivada (Figura 10-D), que apresentou-se elevada na fase terminal da caquexia $(p<0,05)$, concomitantemente com a expressão dos genes envolvido na via do inflamassoma. 

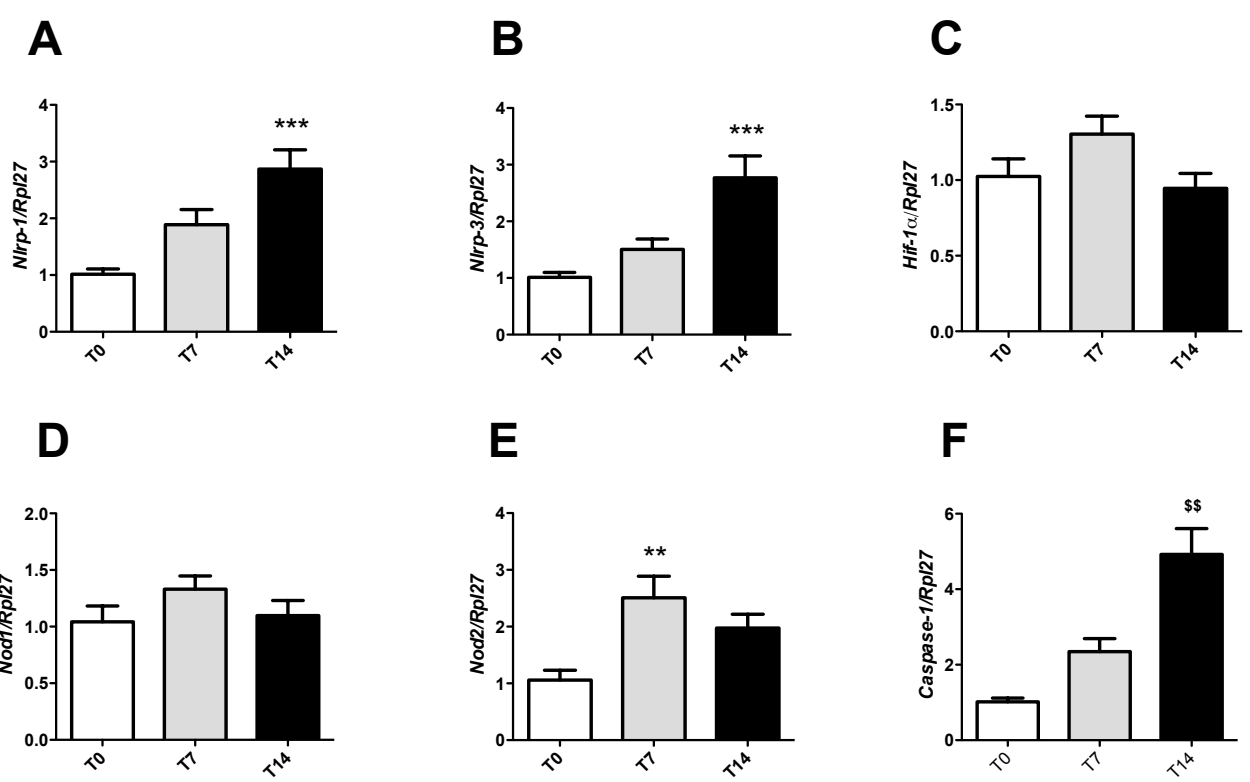

Figura 12- Expressão gênica da via do inflamassoma no fígado durante a progressão da caquexia. T0, T7 e T14: tempo em dias após a inoculação das células tumorais. Dados expressos em média \pm erro padrão; $\mathrm{n}=5 / \mathrm{grupo}$. AExpressão gênica de Nlrp1. B- Expressão gênica de Nlrp3. C- Expressão gênica de Hif-1 $\alpha$. D- Expressão gênica de Nod1. E- Expressão gênica de Nod2. F- Expressão gênica de Caspase 1. *p<0,05 vs T0; **p<0,001 vs T0; $* * * \mathrm{p}<0,0001$ vs $\mathrm{T} 0 ; \$ \$ \mathrm{p}<0,001$ vs comparado todos os tempos.

5.5 Contribuição do tecido adiposo e fígado para o desenvolvimento da inflamação sistêmica

Para avaliar se o adipócito e as células imunológicas residentes no fígado estavam contribuindo para a inflamação sistêmica, decidimos avaliar o perfil da proteína IL-1 $\beta$ no soro dos animais. Encontramos aumento da proteína Il-1 $\beta$ sérica (Figura 13-A) no T14 (p<0,01). Após detectarmos o quadro de inflamação sistêmica nos animais, buscamos observar qual seria a correlação do aumento sérico dessa proteína com aqueles verificados no MEa e no fígado. Encontramos, tanto para o MEa quanto para o fígado (Figuras 13-B e C), correlação positiva e significativa $(\mathrm{p}<0,001$ e 0,03$)$. Sendo assim, os resultados sugerem que ambos, MEa e células imunes residentes no fígado, podem estar contribuindo como mantenedores da inflamação sistêmica. 

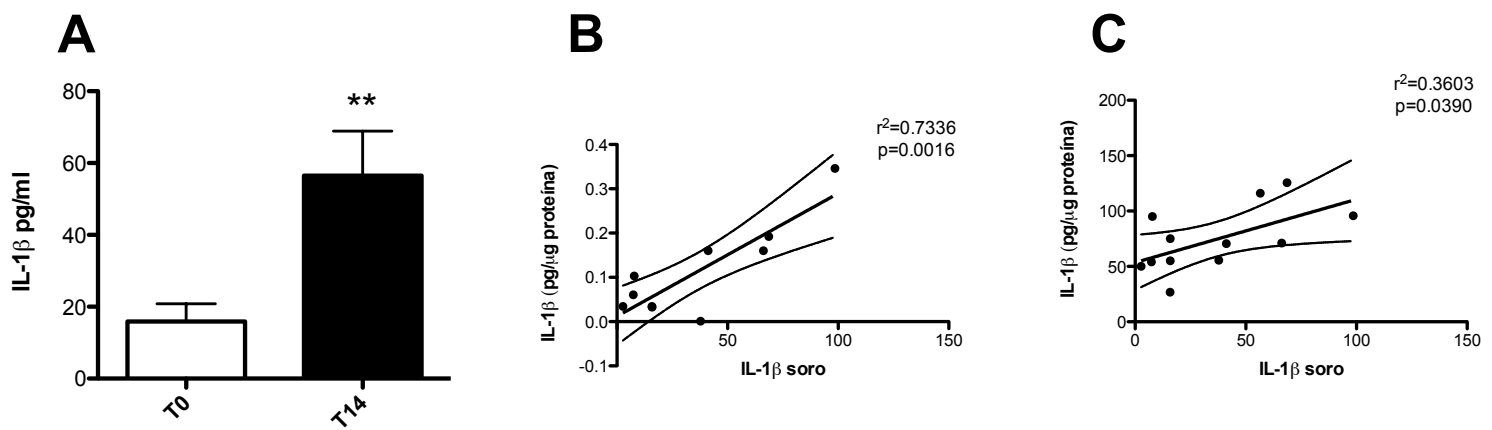

Figura 13- IL-1 $\beta$ sérica durante na fase terminal da caquexia. Os resultados estão expresso como média ( $\mathrm{n}=5-7)$ \pm E.P.M. O soro foi coletado no tempo T0 e T14 após a inoculação das células tumorais. **p<0,01 vs T0.

5.6 Resultados do estudo da microbiota

Utilizamos o modelo de camundongo Germ Free para avaliar o quanto a microbiota pode estar relacionada com o desenvolvimento da caquexia induzida pelo carcinoma de Lewis Lung Carcinoma (LLC).

Neste protocolo, os camundongos foram acompanhados por 17 dias após a inoculação das células tumorais e eutanasiados. Quando avaliamos o peso corporal dos grupos estudados (Figuras 14- A e B), verificamos que, no $17^{\circ}$. Dia, os animais Germ Free com tumor apresentaram redução de 4,9\%, enquanto que, nos convencionais com tumor, essa redução foi de 0,6\% ( $<<0,05)$. Em adição, verificamos que os depósitos adiposos EP e RP (Figuras 14- C e D) reduziram no Germ Free tumor comparado aos controles tanto convencional quanto Germ Free $(\mathrm{p}<0,05)$. No entanto, observarmos redução do peso muscular do gastrocnêmio (Figura 14-F) em ambos os grupos com tumor, convencional e Germ Free, comparados aos controles $(p<0,05)$. 
A

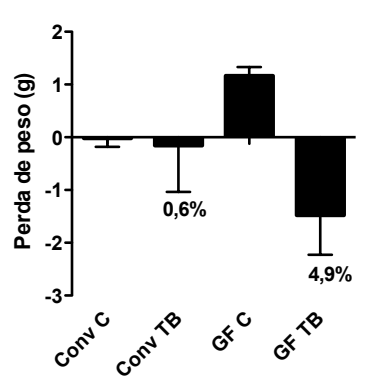

D

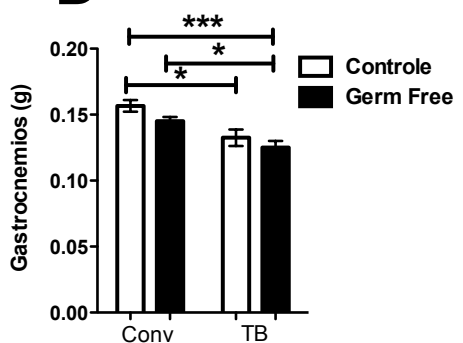

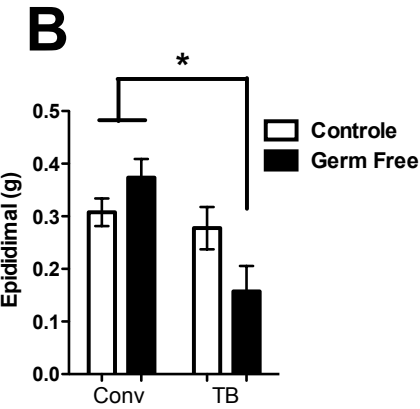

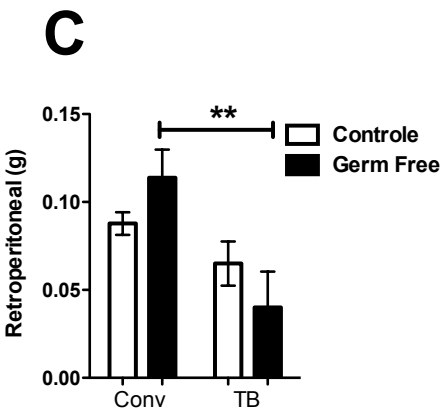

Figura 14- Perda de peso e peso dos tecidos dos grupos Convencionais e Germ Free, com e sem caquexia. Dados expressos em média \pm erro padrão; $\mathrm{n}=4$-8grupo. A- Perda de peso corporal, B- Peso do epididimal, CPeso do retroperitoneal, D- Peso do gastrocnêmio e E- Peso do tumor. Conv= Convencional, GF= Germ Free e $\mathrm{TB}=$ tumor. $* \mathrm{p}<0,05 ; * * \mathrm{p}<0,001 ; * * * \mathrm{p}<0,0001$.

Em seguida, fomos verificar qual mecanismo poderia estar relacionado com a antecipação da caquexia no modelo Germ Free, em termos de seu efeito sobre o TAB. A literatura sustenta que o TAB pode sofrer browning no desenvolvimento da caquexia (KIR et al., 2016). Avaliamos genes específicos relacionados a esse perfil de alteração, como UCP-1, PPAR-a, PRDM16, PGC-1a e Sirt-1 (Figuras 15- A, B, C, D e E). Contudo, nenhum dos genes estudados apresentou alteração de expressão no grupo Germ Free tumor quando comparados aos demais. 

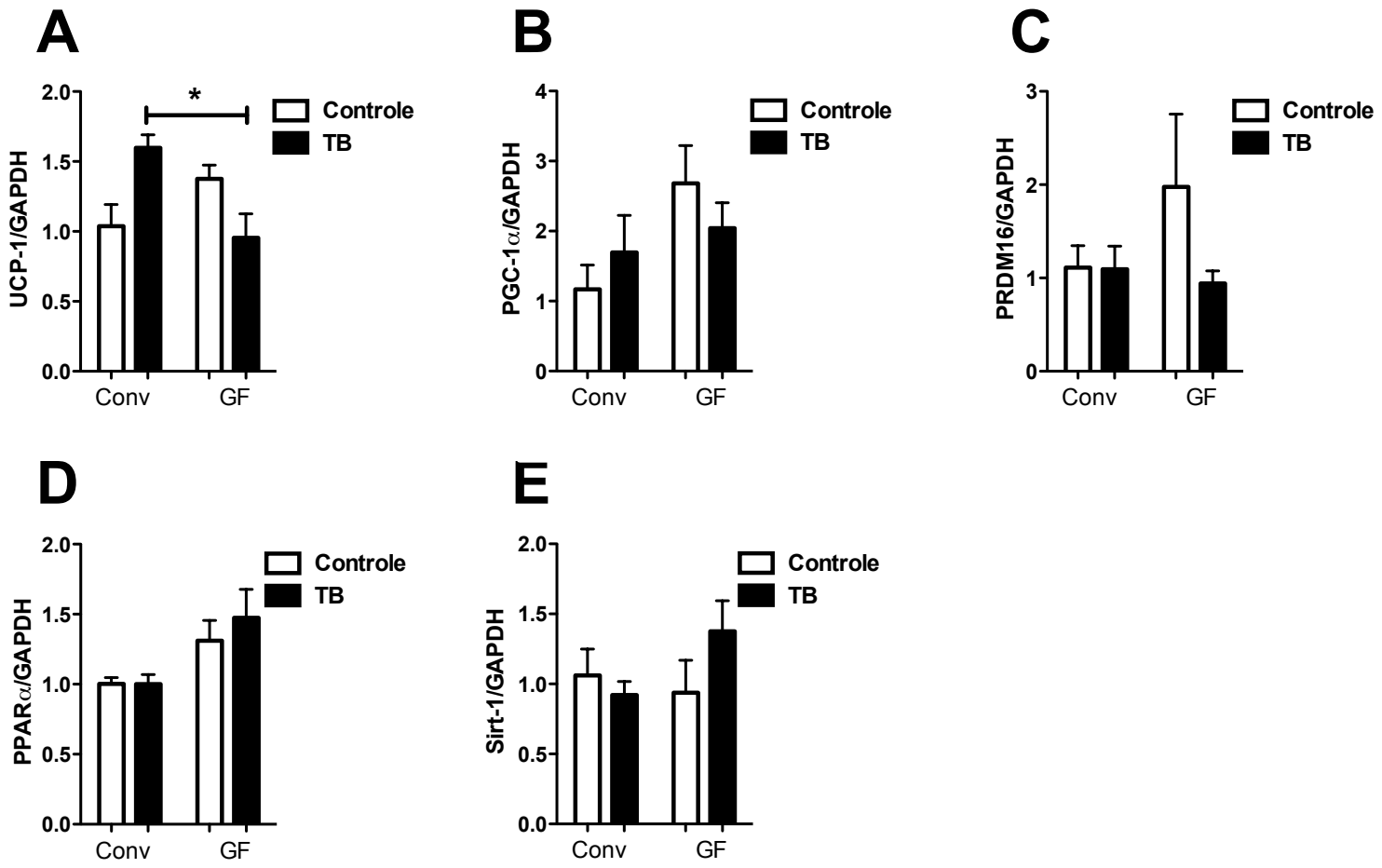

Figura 15- Expressão gênica no $\mathrm{TAB}$, epididimal, durante a progressão da caquexia. A- Expressão gênica UCP-1, B- Expressão gênica de PGC-1 $\alpha$, C- Expressão gênica de PRMD16, D- Expressão gênica de PPRA $\alpha$ e E- Expressão gênica de Sirt-1. Dados expressos em média \pm erro padrão; $n=4-8 /$ grupo. Conv= Convencional, $\mathrm{GF}=$ Germ Free e $\mathrm{TB}=$ tumor. ${ }^{*} \mathrm{p}<0,05$.

Para confirmar que o processo de browning não está ativo, obtivemos imagens histológicas do TAB epididimal, bem como marcação para UCP-1 (Figura 16). Novamente, observamos que o grupo Germ Free tumor não apresenta a via do browning aumentada, pois a expressão da proteína UCP-1 não foi distinta entre os grupos analisados, sugerindo que outras vias podem ser responsáveis pela redução do $\mathrm{TAB}$.

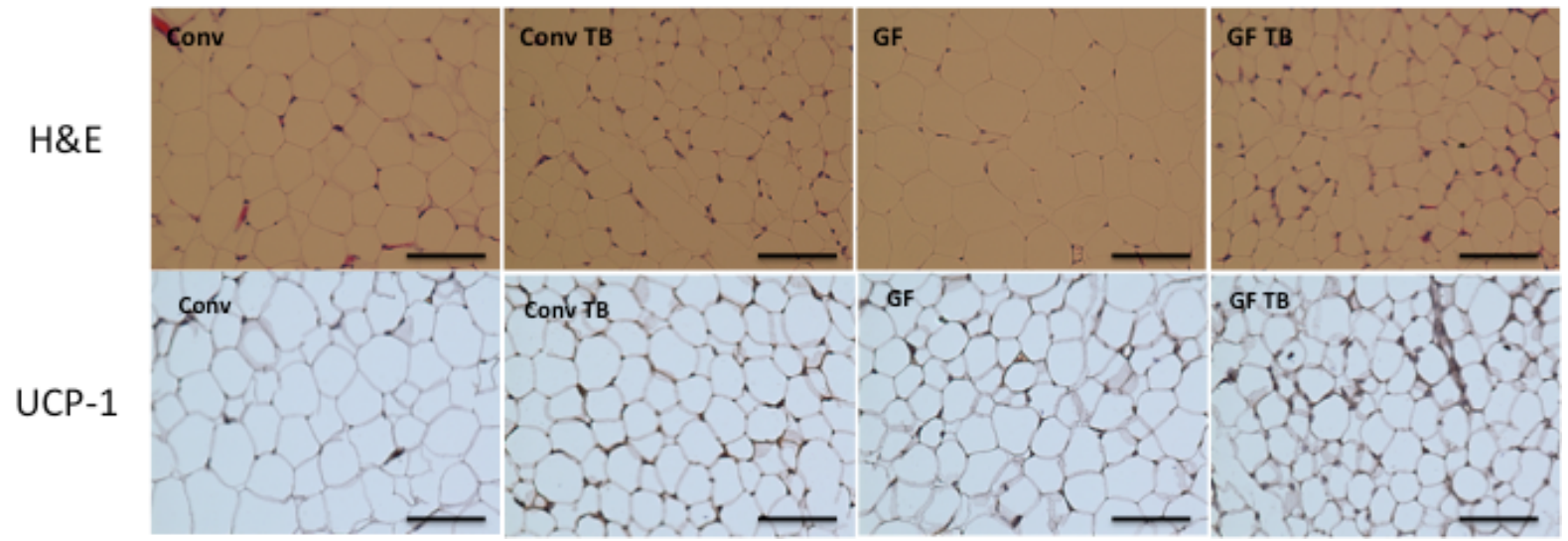

Figura 16- Coloração de Hematoxilina e Eosina (H\&E) e imunohistoquímica para UCP-1. Conv= Convencional, $\mathrm{GF}=\mathrm{Germ}$ Free e $\mathrm{TB}=$ tumor. A escala é de $100 \mu \mathrm{m}$. 
De acordo com a literatura, a via da lipólise é bem caracterizada na caquexia associada ao câncer; sendo assim, avaliamos proteínas importantes da via lipolítica. A proteína ATGL fosforilada (Figura 17- B) aumentou apenas no grupo Germ Free tumor $(\mathrm{p}<0,01)$, comparando todos os grupos, enquanto a HSL fosforilada no sítio serina 660 (Figura 17- C) aumentou nos grupos convencional e Germ Free tumores $(\mathrm{p}<0,05)$. Quando avaliamos a HSL fosforilada no sítio serina 565 (Figura 17- D), responsável pela inibição da lipólise, apenas o grupo Germ Free controle apresentou aumento comparado ao grupo Germ Free tumor $(\mathrm{p}<0,05)$.
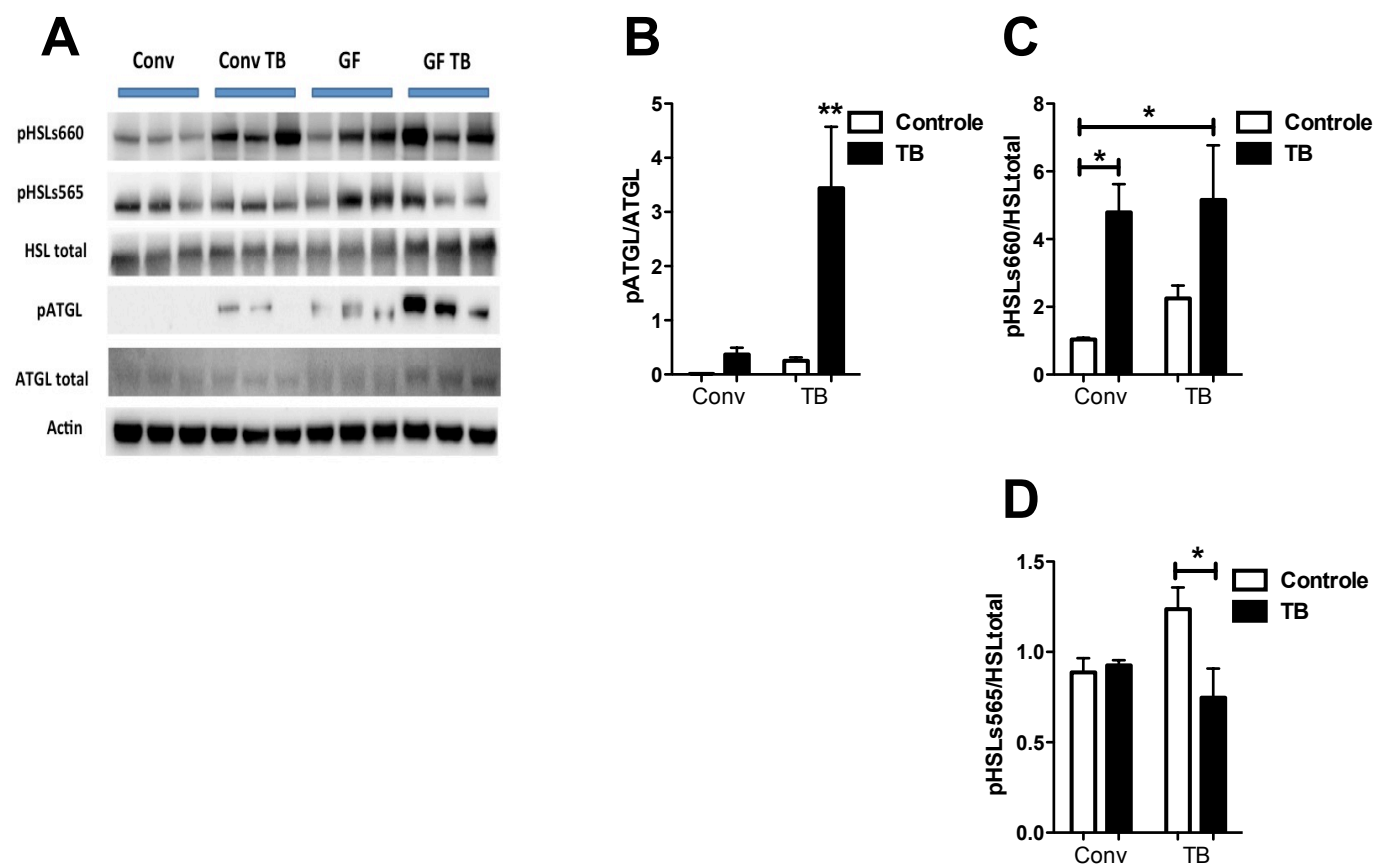

Figura 17- Expressão proteica da via da lipólise no TAB, epididimal, durante a progressão da caquexia. A- As imagens dos blots selecionadas são representativas para pATGL, pHSLs660, pHSLs565 e Actin (proteína normalizadora), B-D expressão proteica foi realizada pelo software Image $j$. T. Dados expressos em média \pm erro padrão; $\mathrm{n}=3$ /grupo Conv $=$ Convencional, $\mathrm{GF}=$ Germ Free e $\mathrm{TB}=$ tumor. ${ }^{*} \mathrm{p}<0,05 ;{ }^{*} \mathrm{p}<0,001$ vs todos os grupos. 


\section{DISCUSSÃO}

A caquexia é caraterizada pela progressiva perda de tecido muscular e adiposo, acompanhada pelo distúrbio do perfil bioquímico e pela produção de citocinas próinflamatórias, tanto em pacientes com câncer quanto em modelos animais (DONATTO et al., 2013; EVANS et al., 2008; TISDALE, 1997). Durante a progressão da caquexia, há efetiva contribuição de compartimentos e órgãos, como TAB, nas inflamações sistêmica e crônica (DALAMAGA, 2013; DONATTO et al., 2013 LIRA et al., 2009; LIRA et al., 2011; LIRA; CARNEVALI, et al., 2012; LIRA; YAMASHITA, et al., 2012;). Frente a esses achados, surgiram-nos algumas dúvidas: 1) Existe heterogeneidade na capacidade inflamatória nos diferentes depósitos de TAB na progressão da caquexia? 2) Qual é a contribuição dos adipócitos per se para a inflamação do TAB? 3) Qual é contribuição do fígado nesse cenário? 4) Há contribuição do fígado? Para responder essas questões, estudamos a progressão da caquexia no modelo animal de carcinossarcoma Walker 256.

Todos os diferentes depósitos de TAB mostraram expressão de citocinas inflamatórias aumentada com a progressão da caquexia. No entanto, somente o conteúdo proteico de IL-1 $\beta$ foi consistentemente aumentado em todos os depósitos estudados. O conteúdo proteico de Tnf- $\alpha$ mostrou-se aumentado somente em TAE no estágio final da caquexia. Nossos resultados corroboram os importantes estudos realizados para descrever a biologia de cada depósito anatômico, uma vez que é bem caracterizado que os TAB de diferentes regiões anatômicas têm heterogeneidade na organização microanatômica, no metabolismo e nos aspectos fisiológicos e moleculares (DIGIROLAMO et al., 1998; POND, 1999).

Um estudo demonstrou heterogeneidade da resposta $\mathrm{TAB}$ durante a progressão da caquexia (BATISTA et al., 2013). O TAB subcutâneo reage mais rapidamente à síndrome já no início da caquexia, com o aumento na secreção de citocinas inflamatórias, quando comparado ao depósito mesentérico, em pacientes com caquexia associada ao câncer (BATISTA et al., 2013). Em nossos resultados, avaliamos diferentes depósitos adiposos viscerais e mostramos que o TAE apresentou leve inflamação inicial, quando comparado aos demais depósitos. Parece claro que os tecidos adiposos de diferentes depósitos apresentam dinâmica distinta em resposta à síndrome. No entanto, não havia, até momento, estudos para diagnosticar a contribuição dos adipócitos per se na inflamação tecidual. Estudos realizados em animais ou em humanos obesos mostram a grande participação das células do sistema 
imune, infiltradas no TAB, como gatilho da inflamação tecidual (FOSTER; PAGLIASSOTTI, 2012; HAUSMAN et al., 2003; LEE et al., 2014; LEE; PETKOVA; GRANNEMAN, 2013; MACHADO; COSTA ROSA; SEELAENDER, 2004).

Após verificar que os TAB apresentaram inflamação local, como já demonstrado na literatura, fomos avaliar o comportamento das células adiposas isoladas de cada tecido.

Os adipócitos isolados de TARP apresentaram perfil anti-inflamatório, visto que o conteúdo proteico de IL-10 apresentou-se elevado, enquanto, na contramão, o conteúdo proteico de IL-1 $\beta$ apresentou-se igual ao do controle na fase terminal da caquexia. Assim, o $\mathrm{RPa}$ parece tentar contrabalançar a inflamação local ocasionada pela alta concentração da proteína IL-1 $\beta$ - essa sendo proveniente da FVE, considerando sua concentração elevada no tecido (TARP). Em contraste, os adipócitos isolados a partir dos tecidos mesentérico e epididimal mostraram nítido perfil pró-inflamatório. Em Ea, observamos secreção de citocinas na fase inicial, enquanto que a inflamação em MEa aconteceu na fase terminal da caquexia. Os adipócitos de ambos os depósitos contribuem de forma consistente para inflamação local, na fase terminal da caquexia, podendo ser relevantes também para o início da inflamação sistêmica.

Tais diferenças confirmam a heterogeneidade entre os adipócitos obtidos a partir de diferentes depósitos viscerais; enquanto $\mathrm{MEa}$ e Ea exibiram padrão pró-inflamatório progressivo, $\mathrm{RPa}$ aumentou a expressão da proteína de IL-10. Um estudo recente mostrou que os diferentes depósitos de TAB derivam de origens embrionárias distintas (CHAU et al., 2014). Podemos, assim, sugerir que a resposta heterogênea exibida pelas células isoladas a partir dos depósitos pode estar relacionada com a diversidade intrínseca destas células.

Depois de examinar a produção de citocinas inflamatórias nas células adiposas isoladas dos diferentes depósitos, investigamos, nos mesmos, se as vias intracelulares poderiam estar associadas com a modulação da inflamação. Em primeiro lugar, analisamos a via clássica envolvida em processos inflamatórios crônicos: NF-kB (KIM et al., 2013; TAMAI et al., 2010). A literatura fornece evidências detalhadas de que a via do NF- $\kappa B$, no tecido adiposo e no fígado, é modulada na presença da obesidade (NOV et al., 2013; YIN, LEE et al., 2014; YIN, PENG et al., 2014), sendo que o mesmo trajeto de sinal é sugerido para modelos animais e pacientes com caquexia associada ao câncer (BATISTA et al., 2013; DONATTO et al., 2013).

Nossos resultados confirmam que o aumento da concentração das citocinas próinflamatórias, em MEa e Ea, foi acompanhado por maior expressão proteica do fator de transcrição NF-אBp65 e do conteúdo proteico de MyD88. Na obesidade, o aumento da 
atividade de NF-אBp65 foi atribuído à infiltração de células imunitárias, ao invés dos adipócitos (LEE et al., 2014; LEE; LEE, 2014; RAHMAN et al., 2012). Este é o primeiro relato do envolvimento de adipócitos com a via do NF- $\kappa \mathrm{B}$ durante a inflamação do TAB na caquexia associada ao câncer.

Nós apuramos aumento do conteúdo proteico de IL-1 $\beta$ em todos os TAB e em duas diferentes populações de adipócitos ( $\mathrm{MEa}$ e Ea). Porém, o aumento da forma bioativa da proteína (IL-1 $\beta$ clivada) foi encontrado apenas em MEa. A proteína IL-1 $\beta$ é um dos principais alvos da via do inflamassoma (SCHRODER; TSCHOPP, 2010). Além de mostrarem que a via do NF-кBp65 é modulada em MEa e Ea, durante a caquexia, nossos resultados confirmam que a caquexia também é capaz de modular a via do inflamassoma, frente ao aumento da IL$1 \beta$ clivada e da expressão de genes importantes, como NLPR-1, -3 e Caspase-1, desse complexo proteico. Durante a obesidade, o aumento na atividade da via do inflamassoma está relacionado com a progressão desfavorável da doença.

Muita atenção tem sido dada às proteínas Nlrp-3 e Caspase-1, por desempenharem papel importante para o funcionamento da via (BENETTI et al., 2013; REYNOLDS et al., 2012). Estudos com modelo knockout para Nlrp-3 e para Caspase-1 mostram que os animais apresentam resistência a desenvolver obesidade após serem submetidos à dieta rica em gordura. Estes mesmos animais também apresentaram maior sensibilidade à insulina, em comparação com os wild-type (STIENSTRA et al., 2011; VANDANMAGSAR et al., 2011). Acreditamos que somos os primeiros a mostrar uma modulação da via inflamassoma nos adipócitos e, ainda, no fígado durante a caquexia associada ao câncer.

O estudo do fígado, por sua vez, apresentou resultados semelhantes ao observados nos TAB: aumento no conteúdo proteico de IL-1 $\beta$. Como conhecido, o fígado desempenha importante papel no controle das vias metabólicas (KAZANTZIS; SEELAENDER, 2005). Em algumas doenças, incluindo a caquexia, tem sido observado desequilíbrio das taxas metabólicas; por consequência, tem se atribuído a este órgão importante papel no desencadeamento do caos metabólico, característico da síndrome (ROSA; KAZANTZIS; SEELAENDER, 1998; SEELAENDER; KAZANTZIS; COSTA ROSA, 1999).

Diferentes tipos celulares compõem o fígado; por exemplo, as células imunitárias, representadas no órgão por grande diversidades de macrófagos, conhecidas como as células de Kuppfer (TAKEZAWA; WATANABE; AKAIKE, 1995). Estudos em obesos mostraram que o número das células de Kuppfer aumentou nesses pacientes (BERTOLA et al., 2010). Observamos que, no fígado dos animais caquéticos, houve aumento qualitativo dos macrófagos residentes nos tempos analisados ao longo da progressão da caquexia. Por isso, 
especulamos esse aumento de macrófagos infiltrados como um dos fatores responsáveis pelo aumento da IL-1 $\beta$.

Assim como nos adipócitos, estudamos, no fígado, fatores de transcrição importantes

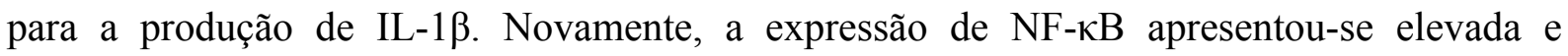
concomitante à do fator de transcrição JNK. Isso sugere que a caquexia é capaz de não só modular a inflamassoma nos adipócitos (MEa), mas também no fígado, induzindo a produção de IL-1 $\beta$. Da mesma forma, encontramos o conteúdo da proteína IL-1 $\beta$ clivada aumentada e, consequentemente, os genes da via do inflamassoma.

Finalmente, investigamos o quanto os adipócitos e o fígado estariam comprometidos com a inflamação sistêmica, tendo, para isso, verificado o conteúdo sérico da proteína IL-1ß. Corroborando a literatura, nossos animais apresentaram inflamação sistêmica no estágio terminal da caquexia (DE MATOS-NETO et al., 2015). Ao correlacionarmos o conteúdo sérico da proteína IL-1 $\beta$ com sua produção pelo $\mathrm{MEa}$ e pelo fígado, identificamos significâncias positivas para ambos e demonstramos que os hospedeiros (adipócitos e fígado) contribuem como mantenedores da inflamação sistêmica durante o quadro de caquexia associada ao câncer.

$\mathrm{Na}$ segunda fase do estudo, examinamos o quanto a microbiota intestinal poderia estar modulada na progressão da caquexia. Para isso, estudamos o modelo de caquexia associada ao câncer, utilizando as LLC por 17 dias após a inoculação das células tumorais no modelo de camundongos Germ Free.

De acordo com a literatura, a composição da microbiota está relacionada com mudanças na função barreira das células epiteliais, as quais incluem permeabilidade e função das células imunológicas. Tem sido discutido que o microbioma está envolvido com o metabolismo energético e, consequentemente, com o estado nutricional (GENTON; CANI; SCHRENZEL, 2015).

O estudo da microbiota na caquexia é ainda novo na literatura, todavia, alguns autores relatam a influência da microbiota na progressão da doença (VARIAN et al., 2016). Foi verificado que pacientes caquéticos com câncer de colo podem ou não apresentar translocação bacteriana. Aqueles que apresentaram translocação bacteriana mostraram redução do número de linfócitos e células Natural Killer na circulação. Ademais, proteínas responsáveis pela junção oclusiva foram reduzidas nesses pacientes (JIANG; LIN et al., 2014).

Um estudo semelhante ao anterior, publicado pelo mesmo grupo, mas com pacientes com câncer gastrointestinal, mostrou que, nos pacientes com caquexia e translocação bacteriana no sangue periférico e no sangue da veia cólica, houve aumento das citocinas IL-6, 
TNFa e IFNg sérica, quando comparado com pacientes caquéticos sem translocação bacteriana e pacientes com câncer, mas não caquéticos, porém com translocação bacteriana (JIANG; GUO et al., 2014).

Em nosso estudo, verificamos que o modelo de camundongo Germ Free, quando caquéticos, apresenta maior perda de peso corporal e de tecidos, como tecido adiposo branco e músculo estriado esquelético, quando comparado aos camundongos convencionais. Nicolas Suárez-Zamorano et al. (SUÁREZ-ZAMORANO et al., 2015) mostraram que camundongos tratados com antibióticos ou Germ Free apresentam redução do TAB, quando comparado a controles ou convencional, respectivamente. No entanto, nossos resultados em Germ Free controles não apresentaram redução do volume de $\mathrm{TAB}$, quando comparados aos convencionais controles.

Um grupo de pesquisadores usou sódio sulfato dextrano (DSS) para causar danos ao intestino e observou redução da massa muscular e do TAB. Todavia, quando os animais foram tratados com antibióticos, não houve redução do peso corporal após o tratamento de DSS. Esses autores utilizaram espécies específicas de bactérias para identificar a espécie envolvida. Quando os animais foram transfectados com Burkholderia thailandensis ou com Salmonella typhimurium e tratados com DSS, os animais continuavam a perder peso como o controle tratado com DSS. Contudo, quando eles utilizaram uma outra espécie, Escherichia spp, em adição às cepas bacterianas anteriores, os autores relataram resultados semelhantes aos encontrados com o tratamento com antibiótico (SCHIEBER et al., 2015).

Camundongos tratados com antibiótico apresentam aumento de RNA mensageiros e proteínas normalmente expressos em tecido adiposo marrom, caracterizando mudança morfológica de TAB para tecido adiposo marrom, chamado de browning (SUÁREZZAMORANO et al., 2015), demostrando que o mecanismo para redução do TAB é via browning. A literatura fornece indícios de aumento de tecido browning no TAB de camundongos com caquexia associada ao câncer (KIR et al., 2016). Com essas informações, julgamos pertinente analisar se o tecido adiposo dos animais Germ Free caquéticos apresentava expressão aumentada desses genes. Nosso modelo de caquexia, contudo, não permitiu essa alteração, uma vez que o TAB epididimal não teve alteração de expressão gênica de genes importantes para caracterização do aparecimento de adipócitos browning.

A via da lipólise é uma das principais estudadas na caquexia e animais knockout para ATGL e HSL não mostram a redução do TAB quando inoculados com células tumorais. No entanto, pesquisadores observaram que os camundongos, quando knockout para ATGL, apresentavam melhor resposta contra a perda de TAB comparados ao knockout para HSL 
(DAS et al., 2011). Os animais Germ Free com caquexia associada ao câncer apresentaram aumento na expressão proteica da ATGL fosforilada, quando comparados aos animais convencionais, sugerindo que a redução do TAB acentuado em Germ Free seja causada pela hiperativação da via lipolítica, em detrimento do processo de browning.

Nossos resultados apontam para o papel relevante da modulação pela microbiota intestinal nos efeitos da caquexia sobre o tecido adiposo. 


\section{CONCLUSÃO}

A partir dos modelos de indução de caquexia utilizados nessa tese, podemos concluir que:

Ambos os modelos de indução da caquexia associada ao câncer (Walker 256 e LLC) foram eficaz. O modelo de Walker 256 mostrou redução no ganho da massa corpórea e da massa gorda quando comparado a controle de mesma idade, enquanto o modelo LLC ocasionou uma redução de aproximadamente $5 \%$ da massa corporal comparado ao início do protocolo.

Os adipócitos isolados dos diferentes depósitos apresentam heterogeneidade durante a progressão da caquexia. $\mathrm{RPa}$ apresentou-se com características anti-inflamatórias enquanto que MEa e Ea apresentaram-se com características pró-inflamatórias mostrando o conteúdo elevado de IL-1 $\beta$.

O fígado, também, apresentou-se com características pró-inflamatórias e consequentemente foi observado um aumento qualitativo de células da linhagem mielóide infiltradas.

Mostramos que genes e proteínas da via do NF- $\kappa B$ apresentou-se elevada em adipócitos isolados e no fígado de animais caquéticos. Genes da via do inflamassoma apresentou-se elevados e contudo, verificamos o conteúdo IL-1 $\beta$ clivada aumentada tanto local quando sérica.

Assim, sugerimos que o hospedeiro deixa de ser apenas vitima durante o quadro de caquexia e passa a ser contribuinte para a inflamação sistêmica crônica.

A integridade da microbiota intestinal apresenta-se extremamente importante no freamento do quadro de caquexia, pois alteração neste ambiente pode antecipar processos caracterizado na síndrome, como a lipólise, visto nesse estudo, agravada em animais Germ Free.

Este estudo traz importantes contribuições no estudo da caquexia, ao mostrar mecanismo ainda não estudado, como inflamassoma e também o estudo das células adiposas e fígado como mantenedores do quadro, em adição mostramos a importância da microbiota intestinal para manter o estado normal do TAB durante a progressão da doença. Sugerindo o tratamento com probióticos como forma de atenuar o quadro de caquexia. 


\section{REFERÊNCIAS*}

ACTIS, G. C. The gut microbiome. Inflamm Allergy Drug Targets, v. 13, n. 4, p. 217-223, 2014. ISSN 2212-4055. Disponível em: < http://www.ncbi.nlm.nih.gov/pubmed/24953716 >

ANDREAS, N. J.; KAMPMANN, B.; MEHRING LE-DOARE, K. Human breast milk: A review on its composition and bioactivity. Early Hum Dev, v. 91, n. 11, p. 629-635, Nov 2015. ISSN 1872-6232. Disponível em: < http://www.ncbi.nlm.nih.gov/pubmed/26375355 >.

ARGILÉS, J. M.; ALVAREZ, B.; LÓPEZ-SORIANO, F. J. The metabolic basis of cancer cachexia. Med Res Rev, v. 17, n. 5, p. 477-498, Sep 1997. ISSN 0198-6325. Disponível em: $<$ http://www.ncbi.nlm.nih.gov/pubmed/9276862 >.

ARGILÉS, J. M. et al. Mediators involved in the cancer anorexia-cachexia syndrome: past, present, and future. Nutrition, v. 21, n. 9, p. 977-985, Sep 2005. ISSN 0899-9007. Disponível em: < http://www.ncbi.nlm.nih.gov/pubmed/16043325 >.

. Catabolic mediators as targets for cancer cachexia. Drug Discov Today, v. 8, n. 18, p. 838-844, Sep 2003. ISSN 1359-6446. Disponível em: < http://www.ncbi.nlm.nih.gov/pubmed/12963320 >.

. Cancer cachexia: the molecular mechanisms. Int J Biochem Cell Biol, v. 35, n. 4, p. 405-409, Apr 2003. ISSN 1357-2725. Disponível em: < http://www.ncbi.nlm.nih.gov/pubmed/12565701 >.

. Optimal management of cancer anorexia-cachexia syndrome. Cancer Manag Res, v.

2, p. 27-38, 2010. ISSN 1179-1322. Disponível em: < http://www.ncbi.nlm.nih.gov/pubmed/21188094 >.

BAEUERLE, P. A.; BALTIMORE, D. NF-kappa B: ten years after. Cell, v. 87, n. 1, p. 13-20, Oct 1996. ISSN 0092-8674. Disponível em: < http://www.ncbi.nlm.nih.gov/pubmed/8858144 $>$.

BATISTA, M. L., JR. et al. Heterogeneous time-dependent response of adipose tissue during the development of cancer cachexia. J Endocrinol, v. 215, n. 3, p. 363-373, Dec 2012. ISSN 0022-0795.

. Adipose tissue-derived factors as potential biomarkers in cachectic cancer patients.

Cytokine, v. 61, n. 2, p. 532-539, Feb 2013. ISSN 1043-4666.

BATISTA, M. L. et al. Adipose tissue inflammation and cancer cachexia: possible role of nuclear transcription factors. Cytokine, v. 57, n. 1, p. 9-16, Jan 2012. ISSN 1096-0023. Disponível em: < http://www.ncbi.nlm.nih.gov/pubmed/22099872 >.

*De acordo com:

ASSOCIAÇÃO BRASILEIRA DE NORMAS TÉCNICAS. NBR 6023: informação e documentação: referências: elaboração. Rio de Janeiro, 2002. 
BENETTI, E. et al. The NLRP3 Inflammasome as a novel player of the intercellular crosstalk in metabolic disorders. Mediators Inflamm, v. 2013, p. 678627, 2013. ISSN 1466-1861. Disponível em: < http://www.ncbi.nlm.nih.gov/pubmed/23843683 >.

BENGMARK, S. Gut microbiota, immune development and function. Pharmacol Res, v. 69, n. 1, p. 87-113, Mar 2013. ISSN 1096-1186. Disponível em: < http://www.ncbi.nlm.nih.gov/pubmed/22989504 >.

BERG, A. H.; COMBS, T. P.; SCHERER, P. E. ACRP30/adiponectin: an adipokine regulating glucose and lipid metabolism. Trends Endocrinol Metab, v. 13, n. 2, p. 84-89, Mar 2002. ISSN 1043-2760. Disponível em: < http://www.ncbi.nlm.nih.gov/pubmed/11854024 >.

BERNARD, N. J.; O'NEILL, L. A. Mal, more than a bridge to MyD88. IUBMB Life, v. 65, n. 9, p. 777-786, Sep 2013. ISSN 1521-6551. Disponível em: < http://www.ncbi.nlm.nih.gov/pubmed/23983209 >.

BERTOLA A.; BONNAFOUS S.; ANTY R.; PATOURAUX S.; SAINT-PAUL MC.; IANNELLI A.; GUGENHEIM J.; BARR J.; MATO J. M.; LE MARCHAND-BRUSTEL Y.; TRAN A.; GUAL P. Hepatic expression patterns of inflammatory and immune response genes associated with obesity and NASH in morbidly obese patients. PLoS One 5: e13577, 2010 .

BING, C. et al. Zinc-alpha2-glycoprotein, a lipid mobilizing factor, is expressed in adipocytes and is up-regulated in mice with cancer cachexia. Proc Natl Acad Sci U S A, v. 101, n. 8, p. 2500-2505, Feb 2004. ISSN 0027-8424. Disponível em: < http://www.ncbi.nlm.nih.gov/pubmed/14983038 >.

Increased gene expression of brown fat uncoupling protein (UCP)1 and skeletal muscle UCP2 and UCP3 in MAC16-induced cancer cachexia. Cancer Res, v. 60, n. 9, p. 2405-2410, May 2000. ISSN 0008-5472. Disponível em: < http://www.ncbi.nlm.nih.gov/pubmed/10811117>.

BING, C.; TRAYHURN, P. Regulation of adipose tissue metabolism in cancer cachexia. Curr Opin Clin Nutr Metab Care, v. 11, n. 3, p. 201-207, May 2008. ISSN 1363-1950. Disponível em: < http://www.ncbi.nlm.nih.gov/pubmed/18403913 >.

BRUMBAUGH, D. E. et al. Mode of Delivery Determines Neonatal Pharyngeal Bacterial Composition and Early Intestinal Colonization. J Pediatr Gastroenterol Nutr, Mar 2016. ISSN 1536-4801. Disponível em: < http://www.ncbi.nlm.nih.gov/pubmed/27035381 >.

BRUUN, J. M. et al. Monocyte chemoattractant protein-1 release is higher in visceral than subcutaneous human adipose tissue (AT): implication of macrophages resident in the AT. $\mathbf{J}$ Clin Endocrinol Metab, v. 90, n. 4, p. 2282-2289, Apr 2005. ISSN 0021-972X. Disponível em: < http://www.ncbi.nlm.nih.gov/pubmed/15671098 $>$.

BÖRNIGEN, D. et al. Functional profiling of the gut microbiome in disease-associated inflammation. Genome Med, v. 5, n. 7, p. 65, 2013. ISSN 1756-994X. Disponível em: < http://www.ncbi.nlm.nih.gov/pubmed/23906180 >. 


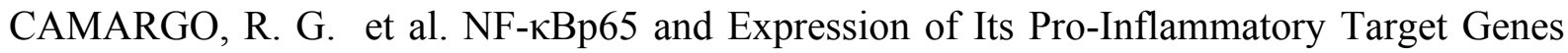
Are Upregulated in the Subcutaneous Adipose Tissue of Cachectic Cancer Patients. Nutrients, v. 7, n. 6, p. 4465-4479, Jun 2015. ISSN 2072-6643. Disponível em: < http://www.ncbi.nlm.nih.gov/pubmed/26053616 >.

CANI, P. D. et al. Changes in gut microbiota control metabolic endotoxemia-induced inflammation in high-fat diet-induced obesity and diabetes in mice. Diabetes, v. 57, n. 6, p. 1470-1481, Jun 2008. ISSN 1939-327X. Disponível em: < http://www.ncbi.nlm.nih.gov/pubmed/18305141 >.

CHAU, Y. Y. et al. Visceral and subcutaneous fat have different origins and evidence supports a mesothelial source. Nat Cell Biol, v. 16, n. 4, p. 367-375, Apr 2014. ISSN 14764679. Disponível em: < http://www.ncbi.nlm.nih.gov/pubmed/24609269>.

DALAMAGA, M. Interplay of adipokines and myokines in cancer pathophysiology: Emerging therapeutic implications. World J Exp Med, v. 3, n. 3, p. 26-33, Aug 2013. ISSN 2220-315X. Disponível em: < http://www.ncbi.nlm.nih.gov/pubmed/24520543 >.

DAS, S. K. et al. Adipose triglyceride lipase contributes to cancer-associated cachexia. Science, v. 333, n. 6039, p. 233-238, Jul 2011. ISSN 1095-9203. Disponível em: < http://www.ncbi.nlm.nih.gov/pubmed/21680814 >.

DE MATOS-NETO, E. M. et al. Systemic Inflammation in Cachexia - Is Tumor Cytokine Expression Profile the Culprit? Front Immunol, v. 6, p. 629, 2015. ISSN 1664-3224. Disponível em: < http://www.ncbi.nlm.nih.gov/pubmed/26732354 >.

DIGIROLAMO, M.; FINE, J. B. Cellularity measurements. Methods Mol Biol, v. 155, p. 6575, 2001. ISSN 1064-3745. Disponível em: < http://www.ncbi.nlm.nih.gov/pubmed/11293084 >.

DIGIROLAMO, M. et al. Qualitative regional differences in adipose tissue growth and cellularity in male Wistar rats fed ad libitum. Am J Physiol, v. 274, n. 5 Pt 2, p. R1460-1467, May 1998. ISSN 0002-9513. Disponível em: < http://www.ncbi.nlm.nih.gov/pubmed/9612415 >.

DING, S. et al. High-fat diet: bacteria interactions promote intestinal inflammation which precedes and correlates with obesity and insulin resistance in mouse. PLoS One, v. 5, n. 8, p. e12191, 2010. ISSN 1932-6203. Disponível em: < http://www.ncbi.nlm.nih.gov/pubmed/20808947>.

DONATTO, F. F. et al. Resistance exercise modulates lipid plasma profile and cytokine content in the adipose tissue of tumour-bearing rats. Cytokine, v. 61, n. 2, p. 426-432, Feb 2013. ISSN 1043-4666.

DUMAS, J. F. et al. Efficiency of oxidative phosphorylation in liver mitochondria is decreased in a rat model of peritoneal carcinosis. J Hepatol, v. 54, n. 2, p. 320-327, Feb 2011. ISSN 1600-0641. Disponível em: < http://www.ncbi.nlm.nih.gov/pubmed/21094554 >.

EVANS, W. J. et al. Cachexia: a new definition. Clin Nutr, v. 27, n. 6, p. 793-799, Dec 2008. ISSN 1532-1983. Disponível em: < http://www.ncbi.nlm.nih.gov/pubmed/18718696 >. 
FEARON, K. et al. Definition and classification of cancer cachexia: an international consensus. Lancet Oncol, v. 12, n. 5, p. 489-495, May 2011. ISSN 1474-5488. Disponível em: $<$ http://www.ncbi.nlm.nih.gov/pubmed/21296615 $>$.

FEARON, K. C.; MOSES, A. G. Cancer cachexia. Int J Cardiol, v. 85, n. 1, p. 73-81, Sep 2002. ISSN 0167-5273. Disponível em: < http://www.ncbi.nlm.nih.gov/pubmed/12163211 >.

FOSTER, M. T.; PAGLIASSOTTI, M. J. Metabolic alterations following visceral fat removal and expansion: Beyond anatomic location. Adipocyte, v. 1, n. 4, p. 192-199, Oct 2012. ISSN 2162-3945. Disponível em: < http://www.ncbi.nlm.nih.gov/pubmed/23700533 >.

GENTON, L.; CANI, P. D.; SCHRENZEL, J. Alterations of gut barrier and gut microbiota in food restriction, food deprivation and protein-energy wasting. Clin Nutr, v. 34, n. 3, p. 341349, Jun 2015. ISSN 1532-1983. Disponível em: < http://www.ncbi.nlm.nih.gov/pubmed/25459400 >.

GUILHERME, A. et al. Adipocyte dysfunctions linking obesity to insulin resistance and type 2 diabetes. Nat Rev Mol Cell Biol, v. 9, n. 5, p. 367-377, May 2008. ISSN 1471-0080. Disponível em: < http://www.ncbi.nlm.nih.gov/pubmed/18401346 $>$.

GUO, H.; CALLAWAY, J. B.; TING, J. P. Inflammasomes: mechanism of action, role in disease, and therapeutics. Nat Med, v. 21, n. 7, p. 677-687, Jul 2015. ISSN 1546-170X. Disponível em: < http://www.ncbi.nlm.nih.gov/pubmed/26121197 >.

HAUSMAN, D. B. et al. The biology of white adipocyte proliferation. Obes Rev, v. 2, n. 4, p. 239-254, Nov 2001. ISSN 1467-7881. Disponível em: < http://www.ncbi.nlm.nih.gov/pubmed/12119995 >.

Regional fat pad growth and cellularity in obese zucker rats: modulation by caloric restriction. Obes Res, v. 11, n. 5, p. 674-682, May 2003. ISSN 1071-7323. Disponível em: < http://www.ncbi.nlm.nih.gov/pubmed/12740458 >.

IIDA, N. et al. Commensal bacteria control cancer response to therapy by modulating the tumor microenvironment. Science, v. 342, n. 6161, p. 967-970, Nov 2013. ISSN 1095-9203. Disponível em: < http://www.ncbi.nlm.nih.gov/pubmed/24264989 >.

INUI, A. Cancer anorexia-cachexia syndrome: current issues in research and management. CA Cancer J Clin, v. 52, n. 2, p. 72-91, 2002 Mar-Apr 2002. ISSN 0007-9235. Disponível em: < http://www.ncbi.nlm.nih.gov/pubmed/11929007 >.

JIANG, Y. et al. The altered tight junctions: an important gateway of bacterial translocation in cachexia patients with advanced gastric cancer. J Interferon Cytokine Res, v. 34, n. 7, p. 518-525, Jul 2014. ISSN 1557-7465. Disponível em: < http://www.ncbi.nlm.nih.gov/pubmed/24720758 >.

Bacterial translocation contributes to cachexia and its possible pathway in patients with colon cancer. J Clin Gastroenterol, v. 48, n. 2, p. 131-137, Feb 2014. ISSN 1539-2031. Disponível em: < http://www.ncbi.nlm.nih.gov/pubmed/24162171 >. 
JO, E. K. et al. Molecular mechanisms regulating NLRP3 inflammasome activation. Cell Mol Immunol, v. 13, n. 2, p. 148-159, Mar 2016. ISSN 2042-0226. Disponível em: < http://www.ncbi.nlm.nih.gov/pubmed/26549800 >.

KAZANTZIS, M.; SEELAENDER, M. C. Cancer cachexia modifies the zonal distribution of lipid metabolism-related proteins in rat liver. Cell Tissue Res, v. 321, n. 3, p. 419-427, Sep 2005. ISSN 0302-766X (Print) 0302-766x.

$\mathrm{KIM}, \mathrm{S}$. et al. Endoplasmic reticulum stress is sufficient for the induction of IL-1 $\beta$ production via activation of the NF- $\kappa \mathrm{B}$ and inflammasome pathways. Innate Immun, Nov 2013. ISSN 1753-4267. Disponível em: < http://www.ncbi.nlm.nih.gov/pubmed/24217221 >.

KRIEG, A. M. CpG motifs in bacterial DNA and their immune effects. Annu Rev Immunol, v. 20, p. 709-713, 2002. ISSN 0732-0582. Disponível em: < http://www.ncbi.nlm.nih.gov/pubmed/11861616 >.

LAPPAS, M. Activation of inflammasomes in adipose tissue of women with gestational diabetes. Mol Cell Endocrinol, v. 382, n. 1, p. 74-83, Jan 2014. ISSN 1872-8057. Disponível em: < http://www.ncbi.nlm.nih.gov/pubmed/24055273 >.

LATZ, E. The inflammasomes: mechanisms of activation and function. Curr Opin Immunol, v. 22, n. 1, p. 28-33, Feb 2010. ISSN 1879-0372. Disponível em: < http://www.ncbi.nlm.nih.gov/pubmed/20060699 >.

LEE, B. C.; LEE, J. Cellular and molecular players in adipose tissue inflammation in the development of obesity-induced insulin resistance. Biochim Biophys Acta, v. 1842, n. 3, p. 446-462, Mar 2014. ISSN 0006-3002. Disponível em: < http://www.ncbi.nlm.nih.gov/pubmed/23707515 >.

LEE, Y. H.; PETKOVA, A. P.; GRANNEMAN, J. G. Identification of an adipogenic niche for adipose tissue remodeling and restoration. Cell Metab, v. 18, n. 3, p. 355-367, Sep 2013. ISSN 1932-7420. Disponível em: < http://www.ncbi.nlm.nih.gov/pubmed/24011071 >.

LEE, Y. H. et al. Exploring the activated adipogenic niche: interactions of macrophages and adipocyte progenitors. Cell Cycle, v. 13, n. 2, p. 184-190, Jan 2014. ISSN 1551-4005. Disponível em: < http://www.ncbi.nlm.nih.gov/pubmed/24394850 >.

LIRA, F. S. et al. Exercise intensity modulation of hepatic lipid metabolism. J Nutr Metab, v. 2012, p. 809576, 2012. ISSN 2090-0724.

. Regulation of inflammation in the adipose tissue in cancer cachexia: effect of exercise. Cell Biochem Funct, v. 27, n. 2, p. 71-75, Mar 2009. ISSN 1099-0844. Disponível em: < http://www.ncbi.nlm.nih.gov/pubmed/19226603 >.

Exercise training decreases adipose tissue inflammation in cachectic rats. Horm Metab Res, v. 44, n. 2, p. 91-98, Feb 2012. ISSN 1439-4286. Disponível em: < http://www.ncbi.nlm.nih.gov/pubmed/22266827>.

Hypothalamic inflammation is reversed by endurance training in anorectic-cachectic rats. Nutr Metab (Lond), v. 8, n. 1, p. 60, 2011. ISSN 1743-7075. 
LIU, Z. et al. Human Breast Milk and Infant Formulas Differentially Modify the Intestinal Microbiota in Human Infants and Host Physiology in Rats. J Nutr, v. 146, n. 2, p. 191-199, Feb 2016. ISSN 1541-6100. Disponível em: < http://www.ncbi.nlm.nih.gov/pubmed/26674765 >.

MACHADO, A. P.; COSTA ROSA, L. F.; SEELAENDER, M. C. Adipose tissue in Walker 256 tumour-induced cachexia: possible association between decreased leptin concentration and mononuclear cell infiltration. Cell Tissue Res, v. 318, n. 3, p. 503-514, Dec 2004. ISSN 0302-766X (Print)

0302-766x.

MADRIGAL-MATUTE, J.; CUERVO, A. M. Regulation of Liver Metabolism by Autophagy. Gastroenterology, v. 150, n. 2, p. 328-339, Feb 2016. ISSN 1528-0012. Disponível em: < http:/www.ncbi.nlm.nih.gov/pubmed/26453774 >.

MAGNANI, M. et al. The ubiquitin-dependent proteolytic system and other potential targets for the modulation of nuclear factor-kB (NF-kB). Curr Drug Targets, v. 1, n. 4, p. 387-399, Dec 2000. ISSN 1389-4501. Disponível em: < http://www.ncbi.nlm.nih.gov/pubmed/11467077 >.

MARCOBAL, A. et al. A metabolomic view of how the human gut microbiota impacts the host metabolome using humanized and gnotobiotic mice. ISME J, v. 7, n. 10, p. 1933-1943, Oct 2013. ISSN 1751-7370. Disponível em: < http://www.ncbi.nlm.nih.gov/pubmed/23739052 >.

MARTIGNONI, M. E. et al. Liver macrophages contribute to pancreatic cancer-related cachexia. Oncol Rep, v. 21, n. 2, p. 363-369, Feb 2009. ISSN 1021-335X. Disponível em: < http://www.ncbi.nlm.nih.gov/pubmed/19148509 >.

MARTINON, F.; MAYOR, A.; TSCHOPP, J. The inflammasomes: guardians of the body. Annu Rev Immunol, v. 27, p. 229-265, 2009. ISSN 0732-0582. Disponível em: < http://www.ncbi.nlm.nih.gov/pubmed/19302040 >.

MITCHELL, S.; VARGAS, J.; HOFFMANN, A. Signaling via the NFkB system. Wiley Interdiscip Rev Syst Biol Med, Mar 2016. ISSN 1939-005X. Disponível em: < http://www.ncbi.nlm.nih.gov/pubmed/26990581 >.

MOHAMED, M. R.; MCFADDEN, G. NFkB inhibitors: strategies from poxviruses. Cell Cycle, v. 8, n. 19, p. 3125-3132, Oct 2009. ISSN 1551-4005. Disponível em: < http://www.ncbi.nlm.nih.gov/pubmed/19738427>.

MUELLER, N. T. et al. Birth mode-dependent association between pre-pregnancy maternal weight status and the neonatal intestinal microbiome. Sci Rep, v. 6, p. 23133, 20162016. ISSN 2045-2322. Disponível em: < http://www.ncbi.nlm.nih.gov/pubmed/27033998 >.

MUSCARITOLI, M. et al. Consensus definition of sarcopenia, cachexia and pre-cachexia: joint document elaborated by Special Interest Groups (SIG) "cachexia-anorexia in chronic wasting diseases" and "nutrition in geriatrics". Clin Nutr, v. 29, n. 2, p. 154-159, Apr 2010. ISSN 1532-1983. Disponível em: < http://www.ncbi.nlm.nih.gov/pubmed/20060626 >. 
NARSALE, A. A. et al. Liver Inflammation and Metabolic Signaling in ApcMin/+ Mice: The Role of Cachexia Progression. PLoS One, v. 10, n. 3, p. e0119888, 2015. ISSN 1932-6203. Disponível em: < http://www.ncbi.nlm.nih.gov/pubmed/25789991 >.

NEVES, R. X. et al. White adipose tissue cells and the progression of cachexia inflammatory pathways, Journal of Cachexia, Sarcopenia and Muscle Early View. Journal of Cachexia, Sarcopenia and Muscle: n/a p. 2015.

NOLAN, G. P. et al. The bcl-3 proto-oncogene encodes a nuclear I kappa B-like molecule that preferentially interacts with NF-kappa B p50 and p52 in a phosphorylation-dependent manner. Mol Cell Biol, v. 13, n. 6, p. 3557-3566, Jun 1993. ISSN 0270-7306. Disponível em: $<$ http://www.ncbi.nlm.nih.gov/pubmed/8497270 $>$.

NOV, O. et al. Interleukin-1beta regulates fat-liver crosstalk in obesity by auto-paracrine modulation of adipose tissue inflammation and expandability. PLoS One, v. 8, n. 1, p. e53626, 2013. ISSN 1932-6203.

PENDERS, J. et al. Factors influencing the composition of the intestinal microbiota in early infancy. Pediatrics, v. 118, n. 2, p. 511-521, Aug 2006. ISSN 1098-4275. Disponível em: < http://www.ncbi.nlm.nih.gov/pubmed/16882802 >.

POND, C. M. Physiological specialisation of adipose tissue. Prog Lipid Res, v. 38, n. 3, p. 225-248, May 1999. ISSN 0163-7827. Disponível em: < http://www.ncbi.nlm.nih.gov/pubmed/10664794 >.

RABOT, S. et al. Germ-free C57BL/6J mice are resistant to high-fat-diet-induced insulin resistance and have altered cholesterol metabolism. FASEB J, v. 24, n. 12, p. 4948-4959, Dec 2010. ISSN 1530-6860. Disponível em: < http://www.ncbi.nlm.nih.gov/pubmed/20724524 >.

RAHMAN, S. M. et al. CCAAT/enhancer-binding protein $\beta(\mathrm{C} / \mathrm{EBP} \beta)$ expression regulates dietary-induced inflammation in macrophages and adipose tissue in mice. $\mathbf{J}$ Biol Chem, v. 287, n. 41, p. 34349-34360, Oct 2012. ISSN 1083-351X. Disponível em: < http://www.ncbi.nlm.nih.gov/pubmed/22902781 >.

REYNOLDS, C. M. et al. Dietary saturated fatty acids prime the NLRP3 inflammasome via TLR4 in dendritic cells-implications for diet-induced insulin resistance. Mol Nutr Food Res, v. 56, n. 8, p. 1212-1222, Aug 2012. ISSN 1613-4133. Disponível em: < http://www.ncbi.nlm.nih.gov/pubmed/22700321 >.

RIUS, J. et al. NF-kappaB links innate immunity to the hypoxic response through transcriptional regulation of HIF-1alpha. Nature, v. 453, n. 7196, p. 807-811, Jun 2008. ISSN 1476-4687. Disponível em: < http://www.ncbi.nlm.nih.gov/pubmed/18432192 >.

ROSA, L. F.; KAZANTZIS, M.; SEELAENDER, M. C. The effect of Walker-256 tumour development upon Kupffer cell metabolism. Cell Biochem Funct, v. 16, n. 3, p. 195-202, Sep 1998. ISSN 0263-6484 (Print)

0263-6484. 
SCHERER, P. E. et al. A novel serum protein similar to $\mathrm{C} 1 \mathrm{q}$, produced exclusively in adipocytes. J Biol Chem, v. 270, n. 45, p. 26746-26749, Nov 1995. ISSN 0021-9258. Disponível em: < http://www.ncbi.nlm.nih.gov/pubmed/7592907 >.

SCHIEBER, A. M. et al. Disease tolerance mediated by microbiome E. coli involves inflammasome and IGF-1 signaling. Science, v. 350, n. 6260, p. 558-563, Oct 2015. ISSN 1095-9203. Disponível em: < http://www.ncbi.nlm.nih.gov/pubmed/26516283 >.

SCHRODER, K.; TSCHOPP, J. The inflammasomes. Cell, v. 140, n. 6, p. 821-832, Mar 2010. ISSN 1097-4172. Disponível em: < http://www.ncbi.nlm.nih.gov/pubmed/20303873 >.

SEELAENDER, M. C.; KAZANTZIS, M.; COSTA ROSA, L. F. The effect of adrenaline and Walker-256 tumour-induced cachexia upon Kupffer cell metabolism. Cell Biochem Funct, v. 17, n. 3, p. 151-156, Sep 1999. ISSN 0263-6484 (Print)

$0263-6484$.

SKURK, T. et al. Production and release of macrophage migration inhibitory factor from human adipocytes. Endocrinology, v. 146, n. 3, p. 1006-1011, Mar 2005. ISSN 0013-7227. Disponível em: < http://www.ncbi.nlm.nih.gov/pubmed/15576462 >.

STIENSTRA, R. et al. The inflammasome-mediated caspase- 1 activation controls adipocyte differentiation and insulin sensitivity. Cell Metab, v. 12, n. 6, p. 593-605, Dec 2010. ISSN 1932-7420. Disponível em: < http://www.ncbi.nlm.nih.gov/pubmed/21109192 >.

Inflammasome is a central player in the induction of obesity and insulin resistance. Proc Natl Acad Sci U S A, v. 108, n. 37, p. 15324-15329, Sep 2011. ISSN 1091-6490. Disponível em: < http://www.ncbi.nlm.nih.gov/pubmed/21876127 >.

SUZUKI, N.; SAITO, T. IRAK-4--a shared NF-kappaB activator in innate and acquired immunity. Trends Immunol, v. 27, n. 12, p. 566-572, Dec 2006. ISSN 1471-4906. Disponível em: < http://www.ncbi.nlm.nih.gov/pubmed/17046325 >.

SUÁREZ-ZAMORANO, N. et al. Microbiota depletion promotes browning of white adipose tissue and reduces obesity. Nat Med, v. 21, n. 12, p. 1497-1501, Dec 2015. ISSN 1546-170X. Disponível em: < http://www.ncbi.nlm.nih.gov/pubmed/26569380 >.

TAKEZAWA, R.; WATANABE, Y.; AKAIKE, T. Direct evidence of macrophage differentiation from bone marrow cells in the liver: a possible origin of Kupffer cells. $\mathbf{J}$ Biochem, v. 118, n. 6, p. 1175-1183, Dec 1995. ISSN 0021-924X. Disponível em: < http://www.ncbi.nlm.nih.gov/pubmed/8720132>.

TAMAI, M. et al. Selective deletion of adipocytes, but not preadipocytes, by TNF-alpha through C/EBP- and PPARgamma-mediated suppression of NF-kappaB. Lab Invest, v. 90, n. 9, p. 1385-1395, Sep 2010. ISSN 1530-0307. Disponível em: < http://www.ncbi.nlm.nih.gov/pubmed/20567236 >.

TISDALE, M. J. Cancer cachexia: metabolic alterations and clinical manifestations. Nutrition, v. 13, n. 1, p. 1-7, Jan 1997. ISSN 0899-9007. Disponível em: < http://www.ncbi.nlm.nih.gov/pubmed/9058439>. 
. Molecular pathways leading to cancer cachexia. Physiology (Bethesda), v. 20, p. 340-348, Oct 2005. ISSN 1548-9213. Disponível em: < http://www.ncbi.nlm.nih.gov/pubmed/16174873 >.

TISDALE, M. J. et al. Catabolic factors in cancer cachexia. In Vivo, v. 10, n. 2, p. 131-136, 1996 Mar-Apr 1996. ISSN 0258-851X. Disponível em: < http://www.ncbi.nlm.nih.gov/pubmed/8744791 >.

TLASKALOVÁ-HOGENOVÁ, H. et al. Commensal bacteria (normal microflora), mucosal immunity and chronic inflammatory and autoimmune diseases. Immunol Lett, v. 93, n. 2-3, p. 97-108, May 2004. ISSN 0165-2478. Disponível em: < http://www.ncbi.nlm.nih.gov/pubmed/15158604 >.

TODOROV, P. et al. Characterization of a cancer cachectic factor. Nature, v. 379, n. 6567, p. 739-742, Feb 1996. ISSN 0028-0836. Disponível em: < http://www.ncbi.nlm.nih.gov/pubmed/8602222 >.

VANDANMAGSAR, B. et al. The NLRP3 inflammasome instigates obesity-induced inflammation and insulin resistance. Nat Med, v. 17, n. 2, p. 179-188, Feb 2011. ISSN 1546170X. Disponível em: < http://www.ncbi.nlm.nih.gov/pubmed/21217695 >.

VARIAN, B. J. et al. Beneficial bacteria inhibit cachexia. Oncotarget, Feb 2016. ISSN 1949-2553. Disponível em: < http://www.ncbi.nlm.nih.gov/pubmed/26933816 >.

VERSTREPEN, L. et al. TLR-4, IL-1R and TNF-R signaling to NF-kappaB: variations on a common theme. Cell Mol Life Sci, v. 65, n. 19, p. 2964-2978, Oct 2008. ISSN 1420-682X. Disponível em: < http://www.ncbi.nlm.nih.gov/pubmed/18535784 >.

WANG, W.; CASSIDY, J. Constitutive nuclear factor-kappa B mRNA, protein overexpression and enhanced DNA-binding activity in thymidylate synthase inhibitorresistant tumour cells. Br J Cancer, v. 88, n. 4, p. 624-629, Feb 2003. ISSN 0007-0920. Disponível em: < http://www.ncbi.nlm.nih.gov/pubmed/12592379>.

WEISBERG, S. P. et al. Obesity is associated with macrophage accumulation in adipose tissue. J Clin Invest, v. 112, n. 12, p. 1796-1808, Dec 2003. ISSN 0021-9738. Disponível em: < http://www.ncbi.nlm.nih.gov/pubmed/14679176 >.

WEN, H.; TING, J. P.; O'NEILL, L. A. A role for the NLRP3 inflammasome in metabolic diseases--did Warburg miss inflammation? Nat Immunol, v. 13, n. 4, p. 352-357, Apr 2012. ISSN 1529-2916. Disponível em: < http://www.ncbi.nlm.nih.gov/pubmed/22430788 >.

WHITESIDE, S. A. et al. The microbiome of the urinary tract--a role beyond infection. Nat Rev Urol, v. 12, n. 2, p. 81-90, Feb 2015. ISSN 1759-4820. Disponível em: < http://www.ncbi.nlm.nih.gov/pubmed/25600098 >.

YIN, J. et al. Regulation of hepatocyte growth factor expression by NF- $\kappa$ B and PPAR $\gamma$ in adipose tissue. Am J Physiol Endocrinol Metab, v. 306, n. 8, p. E929-936, Apr 2014. ISSN 1522-1555. Disponível em: < http://www.ncbi.nlm.nih.gov/pubmed/24569592 >. 
Toll-like receptor $2 / 4$ links to free fatty acid-induced inflammation and $\beta$-cell dysfunction. J Leukoc Biol, v. 95, n. 1, p. 47-52, Jan 2014. ISSN 1938-3673. Disponível em: $<$ http://www.ncbi.nlm.nih.gov/pubmed/24018354 $>$.

ZEYDA, M.; STULNIG, T. M. Adipose tissue macrophages. Immunol Lett, v. 112, n. 2, p. 61-67, Oct 2007. ISSN 0165-2478. Disponível em: < http://www.ncbi.nlm.nih.gov/pubmed/17719095 >.

ZHANG, Y. et al. Positional cloning of the mouse obese gene and its human homologue. Nature, v. 372, n. 6505, p. 425-432, Dec 1994. ISSN 0028-0836. Disponível em: < http://www.ncbi.nlm.nih.gov/pubmed/7984236>. 
ANEXO A - Artigo publicado 


\title{
White adipose tissue cells and the progression of cachexia: inflammatory pathways
}

Rodrigo X. Neves ${ }^{1}$, Jose Cecar Roca-Neto ${ }^{2}$, Alex S. Yamashita', Emidio M. Matos-Neto ${ }^{1}$, Daniela M. R. Riccardí, Fabio S Uira", Mikuel L Batista Jr' \& Marilia Seelaender ${ }^{1, *}$

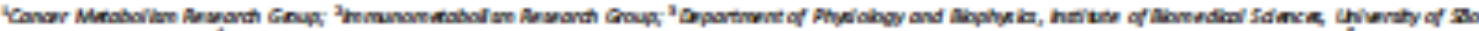

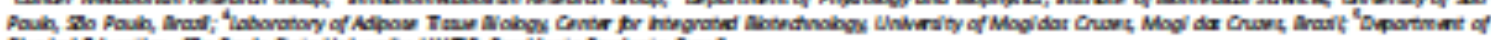

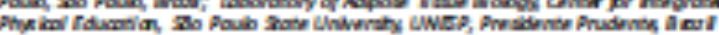

\begin{abstract}
Badkground Cxhexla is a systamic syndrome leading to body wasting, systamic inflammation, and to metabolic chaos. It is a progrexcive condition, and ittle is inown about its dpnamics. Datection of the early slgns of the disease may limd to the attenuation of the assodated symptoms. The white adipose tisoue is an orgen with endocrine functions, capable of syntheslaing and secreting a plethora of proteins, induding cytokines, chemokines, and adipokines. it is well established that different adjose tisoue depots demonstrate heterogeneous responses to physiological and pathological stimuli. The present study aimed at providing indight into adipocyte imolvement in inflammation along the progreselon of achexia

Methods Elghtweeks-oid mak rats were suboutaneoualy inocuhted with a Walker $\mathbf{D 6}$ crainocarcoma cell surpendion $\left(2 \times \boldsymbol{D}^{7}\right.$ cdls in $1.0 \mathrm{~mL}$; tumour bering $\left.\mathrm{T}\right)$ or Phosphate buttared salme (control, C). The retroperitoneal, epididymal, and mesentaric adpose pads were exdised on Days 0,7 , nd 14 post tumour cdl injection, and the adpocytes were bolated.

Resuls Mesentaric and epididpmal adipocytes showed upregulation of Il-1/p protain expreselon and activation of the inflammasome pathway, contribusting for whole tisoue inflammation. The stroma vasoular fratton of the ratropertioned adipose tkoue, on the other hand, seems to be the major contributor for the inflammation in this spedic pad.

Conclusion Adpocytas seem to play a rekvant role in the establehmant of whte adpose tsoue inflammation, through the activation of the NF-aB and inflammzoome pathways. In epididymal adpocytes, induction of the inflammzome may be detactad alrandy on Day 7 post tumour call inocuhtion.

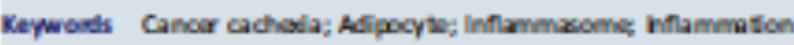

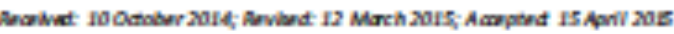

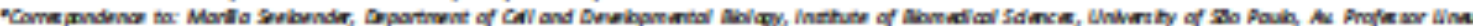

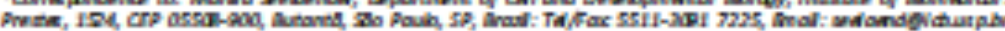

\section{Background}

Cancer cachexla $\mathrm{k}$ a spadrome with complex atiologi, 1,2 which affects up to $80 \%$ of pationts with advanced cancer. It is assodatnd with diminished expected effects of chemothenapy and radiotherapy tratment, compromised ife quality, and decreased survival, ${ }^{25}$. The main symptoms indude maked decrexe in body weight, with depletion of both white alpose tooue (WAT) and sheletal musde, profound matabolic deruption, moduction of appette,
Impoalbuminemla and spatemic inflammation. 2 it This syn. drome has been recently proposed to comptse at least three stages: the first is assodatud with metabolic changeand with weight bss $(<96)$, while in the second stage, a $5 \%$ decrexe of body $\mathrm{m} 2 \mathrm{~s}$ is consetently mported, diong with syetemic in. flammition and anorexh. In the last stage patients are no bn ger responalve to anticancer trentment, and the expectind suvival does not exeeed 3 monthe. in

There is current edidence pointing out WaT as an impor. tant contributor to cacherla ${ }^{11,2}$ WAT biology $k$ impaind

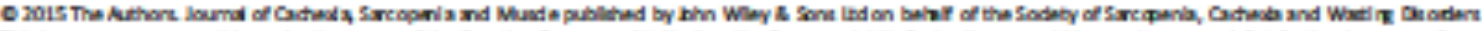

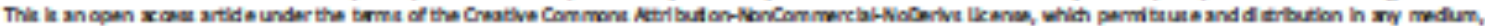

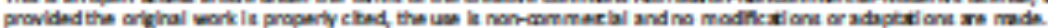


both in human cachexth and in animal models, and it is sug gested that WAT altaration precode musde watting. ${ }^{\text {t1, } 12}$ Therefore, WAT $\mathbf{k}$ not only a 'Victim' of the syndrome, $\mathbf{r}$ is abo a relavant player, actwely synthesising a plethon of proinflammatocy cyokines, ${ }^{14}$ which take part in contrbuting to sytemic inflamm stion

White adpose tsose is composed of different cellubr elammt, mong which resident and intitrzed immune cells. ${ }^{15}$ in addition, the proportion of the stromal vasoular traction, as wel $\mathbf{x}$ the biology of the adpocyte, are subject to dvesity according to anstomical varbtion, regarding lasculartzation and innernation of the pad ${ }^{16-19}$ Thk implies that the response of differmint depots is heterogreneous under

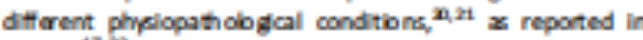
obesity. ${ }^{17,}$, Predious studies of our group (seehender et ab, 1996" have reported differences in veceral WAT depots in concern to the morphology and bioch mika char acteristice of adipocytes in the Walker 256 animal model of cancer cadhexh.

Given these condidentions, we presenty sought to exm ine whether the alpose cell partipates in the estabish. ment of whole adipose trosue inflammzion ind to address the impothesis that adpocytes obtained from different anzomical tht depots behave heterogeneourly during the progression of cachese. For that purpose, we studied three pads $x$ three tme points (prior to tumour cel injoction-TO; and 7 (T7) or 14 days (T14) post inoculation]. These time points, although not necessarily bexing correspondence with the these staps proposed for cachectic patents (Feron at al, 2011 1 ), wee chosen $\mathbf{x}$ to proudde halght on the dynamics of inflammation in WAT.

One of the man inflammatory pathways in mammalian cells is that of the nudear hetor of kappa light polypeptide gone enhrncer $n$ BCels (NFxB). NFxB is composed of subunits p50, p105, p52, p100, and p65 whikh induce gene

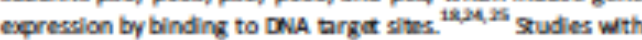
obese pationts showed an increased activity of the NFis patwway in the alpose thoue and, consequentik, of local inflammation. ${ }^{25}$ The inflammasome pathway has abo been simlariy desorbed as having an important role $n$ the inflam.

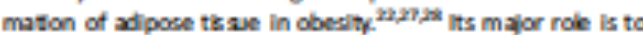
activate the pro-inflammatory cytoitnes Il. 1 ip and IL. 19 which are spothesined as immature protens and moulre the inflammzome pathway for desvage and rekase, yelding the mature, biblogically active cyokine forme. pathway compriss twocomprtments: the (nudeotde binding alkomertzation doman) (NOD) -ike racotor (NLR) tamily (NLRP1 NLRP2, NLRP3 NLRPS, NLRC4, and NLRPI2), and the pyrin and HineO0 (mematopoletc intarteronindudble nu. dex antigens) domah containing proteh (PrHin) tomly. To the best of our lnowilodge, there is no study in the litura ture mporting a posible contribution of this pathway to the enhroed inflammatory cytokine secretion by the adpose those in cachese.
Tharefore, a third aim of the present study was to imvest. gite the pathays assodatad with adpocyte inflammation and their activation diong the aggavation of the spndrome.

\section{Materials and methods}

\section{Animals}

Male adult Wistar rats $(160-250 \mathrm{gl}$, obtained from the inst. wite of Biomedical Solences, University of Slo Paulo, were maintahed in metibolic cages, und $\alpha$ a $12 \mathrm{~h}$ light/12 h dark opke filghts on at 7:00a m.l, and controlled tumperziturecon. dtions $\left(23 \pm 1^{*} \mathrm{C}\right)$, receiling water and food (kommerdal chow; Nudlab, Nuval, Brzi 1) ad Ibitum. The Bbmedica Sd. ances insttuhe/USP Etical Commithe for Animal Reserch aporoved al the adopted procedures (050/102 ECARl, which were carted out in acoordance with the ethical principles statind by the Bryilin Colloge of Animal Eeeftmentation. The eqeriments ware perfomed as a time coure studk. and the rats were illed by decapitzicion on Days 47 , and 14 following subcutrneous injection of a suspencibn of Waker 36 tumour $\left(2 \times 10^{7}\right)$ cells, ${ }^{*}$ or of the same wiume of Phos. phatebutfered saine ( $n-5$ group); atter $12 \mathrm{~h}$ that, dways in the intewal between 8.00 and $11.00 \mathrm{2m}$. The folowing groups werestudied: To (rats euthn bed on the day on which $T 7$ and 74 were injected with the tumour cdls), $T 7$ (rats euthanbed 7 days fatur tumour cell injection), and T14 (ats euthanbed 14 days atter tumour cel injection). Additonal groups of nontumour beaiting rimals (C) were induded, $x$ a control for body and tsoue waight on Days 7 (C. T) and 14 (C14).

\section{Blood samples and adipose tissue callection}

Approdemstdy $8 \mathrm{~mL}$ of blood were colectud. In briet, smples were centruged at $500 \mathrm{~g}$ at $4^{*} \mathrm{C}$ for $15 \mathrm{~min}$, and serum wr. somd at $-8{ }^{\circ} \mathrm{C}$. Epididpmal adpose tinue (EAT) retopenttaneal alpose thous, (RPAT), and mesontark alpose tiksue (MEAT) (fturer camtul ramoval of adpoert lymph noded were removed weighed, senp frosm in liquid nitrogon, and stomed $\boldsymbol{x}-80^{\circ} \mathrm{C}$

\section{Serum analysis}

All serum andyses were performed with commerchal kts: total cholesterol, tiglycerides ( $\left(T^{6}\right)$, and high-deneity lipoprotain (labtest", Basil); tree dycerol (Slgma-Aidinch, Switsorland): and nonestarified tatty xids (Wakio Chemicak, USA).

\section{Adipose cell isolation}

The different visceral adipose tsoue pads were exdised and washed in sterle saline (09\% $\mathrm{NxC}$ ). Thesamples $(0.8 \mathrm{~g})$ were 
placed immedately in digestion butfer (DMEM Signa DS671). S6 RSA and $2 \mathrm{mg} / \mathrm{mL}$ type I collagenase (utetachnologies $17100017 \mathrm{~h}$ and digested for $60 \mathrm{mh}, \pi 3 T^{\circ} \mathrm{C}$ The resulting suspension was then filtared through a stentle $250 \mu m$ nyion mesh and the mature adipocytes (mesonterk adpocptes (MEa), mtropeittoned adpocytes (RPa), and $\varphi$ i didpmal adipocytes (Ba)l, obtained from the supernatant. The celk were wached twice with stentle $0.96 \mathrm{NaC}$ and stored $\boldsymbol{x}-80^{+} \mathrm{C}$ for mRNA and proteh malyels.

\section{Red time PCR}

Tobal RNA wa lsolatnd from the tisoues and cdls, with Trisol* (invitrogen, CA, USA) following the manufacturer's recommendations. The first strand of CDNA wr. generated from $2 \mu$ g of total RNA, employing a comm ardal ift (High Capxity CDNA Reverse Transcifption $\mathrm{kit}$, Imitrogen). Polymarase chain rextion (PCR) amplification was performed in dupls. cates, with SYBR Green PCR Master MX (Applied Blosystems, CA, US.A) in the Quantstudo" $12 \mathrm{~K}$ Fiex Real Time PCR (Applied Biosystems, CA, USAL, employing the primars isted in Table 1 Gene expeselon was nomalined to the Rpol19 and $R p / 27$ reference genes. Data ware caloulated with the 2-AMCT method and are presented as the fold change in gene expreselon relative to the control sample.

\section{White adpose tissue adipokine levets}

Rat WAT (0.4-07 N) was homogentaed in RIPA buffer $10.625 \%$ Nonidet P.40, 0.525\% sodlum dooxpholate, 6.25 mu sod um phosphate, and 1 mu etwylene-daminetetraxetic add, $x$ pH 7.4l, containing a protece ih bitor codetal (Roche*, Braxil). Homogenstes were centritu grod at $12000 \mathrm{~g}$ for $30 \mathrm{~min} \times 4 \mathrm{C}$; the suparnatant wrx colected, and proteh concentration wa datermined with a commerchl kt (Bio-Rad, CA, USA).
Total adipose tisave protein exracts were employed for the quritituthe assexem ant by enaymo inked immunosorbent as. $\Rightarrow$ (Duoset B.5A, RE D Syatems, MN, USA) of 1.6 (Drsos)

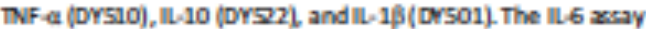
saneitvity was found to be $8.000 \mathrm{pg} / \mathrm{mL}$ in the range of 125

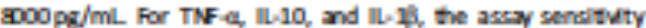
was found to be $4.000 \mathrm{pg} / \mathrm{mL}$ in the ange of $25-4000 \mathrm{pg} / \mathrm{mL}$ All samples were arayed as duplicates and the menn viue was mported. The resuts were equalind to total protain.

\section{Western blotting}

Froson adpose ticoue and adpocytes wore homogentad in Radiolmmunopredipitation xay (RIPA) buffer (0625\% Nonidet P.40, 0.525\% sodium decoeph h hte, $6.25 \mathrm{~mm}$ sodium phorphate, and 1 mu etylenedaminetatrancetic adid at pH 7.A with proteinee) and phosphatase in bitors (Roche*, Basil and contrfuged at $15000 \mathrm{~g}$ for $30 \mathrm{~min}$ at $4^{+} \mathrm{C}$. The protainerich tration (intermad hey laper) war collacted and centrfuged $* 12000 \mathrm{~g}$ for $10 \mathrm{mh}$ * 4 ¿ $\mathrm{C}$, the supernatant (thtty byer) was discarded, and the infanatant wascolected. Proteh concentration wrx determined with a BCA protein quantica. toon kit (Piarce, II, US.A), with Bovine sarum abumin (BS.A) $x$ a referance. 5 mples containing $30 \mu g$ protwh weresepanatind by dectrophoresk in $10 \%$ Tridine SDS-PAGE. Protdins were then transterred of PVDF membranes at $25 \mathrm{~V}$ for $40 \mathrm{~min}$ (Trans Blot Tubo Blotth g Sytem, Bio-Rx) in trancter butter, condaling of $20 \mathrm{~mm}$ Tts, $150 \mathrm{~mm}$ Gydine, and $10 \%$ Mathanol. PVDF mambanes were then blodked in TRS containing $0.1 \%$ Tween 20 and $5 \%$ sldmmed milk, for $1 \mathrm{~h}$. Atter three washes with TBS plus 0.1\% Tween 29 the PVDF membranes were incubatad with pitmary antbodies against IL-15) (Sinta Cun, SC-1251, Goat), p65 (Cell slgnaling, C2BA4, Rabbit) Mydes (5anta Crun, SC-11356). TNFr1 (5anta Crun, SC-1070 Mouse) p50 (5arta Crun, SC8414) GAPDH (5/gma, G9545, Rabbit). HRPconjugatad secondary antbody antlabbit and

Tale 1 Ditmer le

\begin{tabular}{|c|c|}
\hline Gane (upaciax) & Serpource $5^{\prime} 3$ \\
\hline 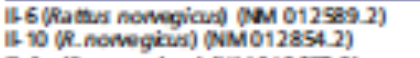 & $\begin{array}{l}\text { Fw: GAA GCT GAA GAC CCT CTG GA RNE TAA GCC TCG GAC TTG TGA AGT GGT } \\
\text { Fw: AAG GCA TTC TICACC TGC TC REV CCA AGC TGA GAA CCA AGA CC }\end{array}$ \\
\hline 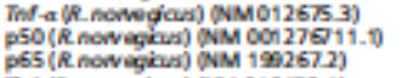 & 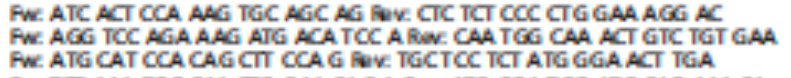 \\
\hline 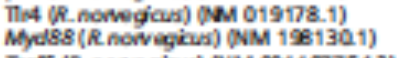 & 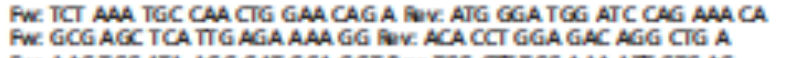 \\
\hline 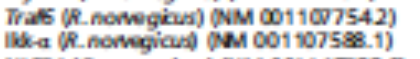 & $\begin{array}{l}\text { PW: AAG TCC ATA AGG GAT GCA GGT Rav: TCG CTI TCC AAA ATT GTC AG } \\
\text { RW: TCA AGA TGT TGG TGG GAA GAT A Rav: CTCTGG GCC CAA ATA CTG TAA }\end{array}$ \\
\hline 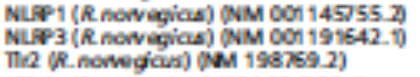 & 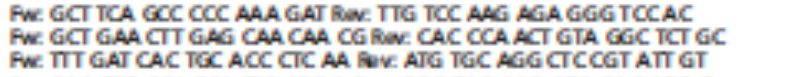 \\
\hline 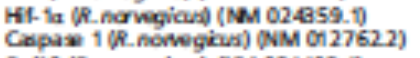 & 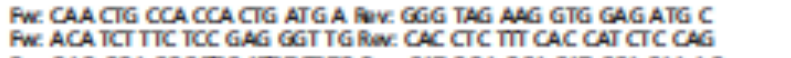 \\
\hline 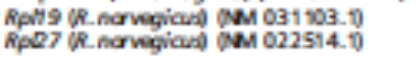 & $\begin{array}{l}\text { Fw: GAG GGA CGC TIC ATT TCT TG Rav: CAT GGA GCA CAT CCA CAA AC } \\
\text { FW: CCT CAT GCC CAC AAG GTACT WEV CTG TCT TGT ATC CCT CCT CAAA }\end{array}$ \\
\hline
\end{tabular}


ant-mouse (Cell signaing MA, USA), and rntligat (Abcam ab 6885 UM for $2 \mathrm{~h} \neq \mathrm{f}$ room temperature. The resulting bands were datectad by ECL (Amesham, UK). GAPDH was emplbyed as loading control, and the bibts wore stripped and incubated wth a GAPDH antbody (Sgm2, G9545, Rabbit) -Qurntification of antgen-antbody comploxes wax performed wth the Image

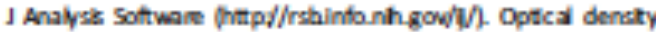
units weere obtained $\mathbf{x}$ pheis for fold target protein/oontrol protain.

\section{Statistical analysis}

Data are expresed as mean values and standand erros of the means. Differences concarning the studied groups (TO, $T 7$, and T14) were analyped with GraphPads software (GraphPad, San Diqgo, CA US.A), and statetical slgnificance was determines performing one way ANCWA with post hoc Tukey's twst, for comprison among grouph, for each different adipose pad. Comparison among pads was not parformed. For the results regarding body and tzsue mass in Cxhectic $(\pi, \pi)$, and T14) and control (C7 and C14) rimsis, we amployed ANOVA two-way, followed by Tulaey's post west. $P<0.05$ was condid. ered significant.

\section{Results}

Fourteen days after tumour cell injection, experimental can cer cachesla induced a reduction in body welght (10.6\%; $P<005)$ and in WAT mass $(42.5 \% \mathrm{~h}$ MEAT and $40.2 \%$ in RPAT, $P<0.05$ ) (Table 2l, companed with animals of the control group. Termind cachexla (T14) was accompanied by increased concentrations of nonestarified faty add, high deneity lipoprotain, and tifghoerides in the plama (Table 3).

White adipose tissue inflammation in experimental cancer cachexia

Mesenteric adipose tixue

In MEAT, increased tumour necroels factor dipha (TNF-a) gone exprescion wr. found in T7 and in T14 (23.7 and

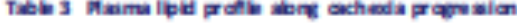

\begin{tabular}{|c|c|c|c|}
\hline & TO & 77 & T14 \\
\hline Gycar ol (miglei) & $0.14 \pm 0.00$ & $0.09 \pm 0.02$ & $0.11 \pm 0.04$ \\
\hline $\begin{array}{l}\text { NÉFA (mblent) } \\
\text { HOL (mglal) }\end{array}$ & $\begin{aligned} 0.75 & \pm 0.03 \\
48.73 & \pm 2.24\end{aligned}$ & $\begin{aligned} 0.80 & \pm 0.03 \\
46.80 & \pm 4.54\end{aligned}$ & $\begin{aligned} 1.25 & =0.22^{*} \\
52.12 & \pm 1.15\end{aligned}$ \\
\hline TG (mplas) & $2.95 \pm 5.38$ & $114.81 \pm 29.00$ & $15130 \pm 50.18^{*}$ \\
\hline
\end{tabular}
Tuteles) $\quad 295 \pm 53811481 \pm 29.0015130 \pm 50$

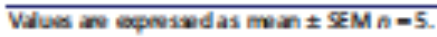

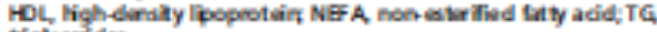
tiglyeiridas.

$*<0.05$ w. dilgrapi.

$P<0.05$ v To.

15.5.fold, respectively; $P$ <0.05) (Figure 1Bl, $\mathbf{x}$ companed with TO. Interleuldn $1 \mathrm{~b}(\mathrm{ML}-1 \mathrm{1})$ protain content was increased (5.7fold; $P<0.05$ ) in T14 (Figure 26) in relation to TO.

Aetroper itoneal a dipose tissue

Changes in proinflammatory cytoidne gene expreselon in this pad could only be detactad at the end stage (T4) of cachexla when interleuldn 6 (N-G) and TNF- $(P<0.5)$ (Figure 1A,B) mRNA levels were incieased. Proten epresclon, on the other hand, was smlar to the pattarns found in MEAT, as IILA protwin expreselion wry higher in RPAT in T14 ( $D$. - fold; $P<0$ 0. 05) (Figure 2G). Intedeuldn 10, the only antilinflammatory cyoidne examined, showed incresed gone expression in TH, despite no slgniticnt modification of protain content of the cyokine in this depot.

Epiditymal adipose tissue

In this fat pad, proinflammatooy cyoilne mRNA epres ston (UL-6 and TNF-a) was hereased only in T14 $(P<0.05)$ (Figure 1A,B). Protain espresslon of TNF-e and IL-1/P wax also hereased in T14 (3.7fold and 203 fold, respectively, $P<0.05)$ (Flgure 1E,G), whencompared with TO. The gene ex presclion of $11-10$ wrx found to be increased in $T 7(P<0.05)$ and an evan more consplouous inciement was observed in $\pi 4(P<0.01)$ in relation to both $\mathrm{TO}$ and $\pi 7$.

White adipose tissue alls inflammation in experimental cancer cachexio

AG WAT $k$ composed of vartous cells types, exh potantlally contributing to inflammation, we imastigted whether

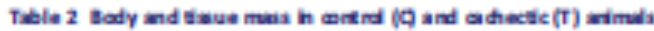

\begin{tabular}{|c|c|c|c|c|c|c|c|c|}
\hline & \multirow{2}{*}{ Inify } & \multirow[b]{2}{*}{$a$} & \multirow[b]{2}{*}{$\pi 7$} & \multirow[b]{2}{*}{$\mathrm{C14}$} & \multirow[b]{2}{*}{$\mathrm{T14}$} & \multicolumn{3}{|c|}{ Two way ANCNA Pwabes } \\
\hline & & & & & & Time & Tumber & Thmeftumbear \\
\hline $\begin{array}{l}\operatorname{BM} T(\rho) \\
\mathrm{TM}(\rho)\end{array}$ & $2208 \pm 18.4$ & $264.4 \pm 21.4$ & $\begin{array}{r}2478 \pm 178 \\
44 \pm 29\end{array}$ & $285.4 \pm 197$ & $\begin{array}{l}255.1 \pm 21.4^{*} \\
12.05 \pm 6.43\end{array}$ & ma & $7 p<0.05$ & $" P<001$ \\
\hline $\begin{array}{l}\operatorname{MEAT}(g) \\
\operatorname{BAT}(g)\end{array}$ & $\begin{array}{l}1.03 \pm 0.33 \\
1.52 \pm 0.38\end{array}$ & $\begin{array}{l}1.82 \pm 0.47 \\
215 \pm 0.34\end{array}$ & $\begin{array}{l}137 \pm 0.32 \\
2.04 \pm 0.41\end{array}$ & $\begin{array}{l}2.54 \pm 0.43^{+6} \\
3.46 \pm 0.40\end{array}$ & $\begin{array}{l}1.46 \pm 0.22^{20} \\
2.83 \pm 0.45\end{array}$ & "P< $p<0.05$ & 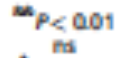 & ${ }^{*} P<001$ \\
\hline ROAT (g) & $0.87 \pm 0.38$ & $212 \pm 0.35$ & $1.39 \pm 0.40$ & $3.45 \pm 0.48$ & $2.05 \pm 0.46^{*}$ & "P<0.0S & ${ }^{*} p<0.05$ & $P<0 D 1$ \\
\hline
\end{tabular}

Vabas as expresiad as maan \pm 1 tandred entor of the maan $\mathbf{- 5}$.

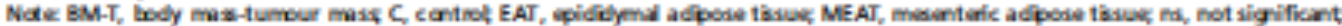

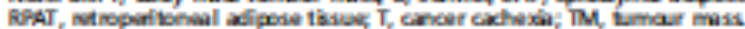




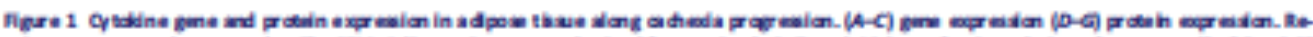

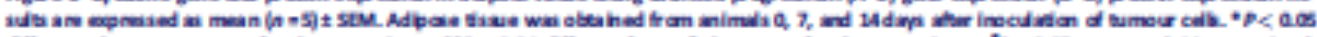

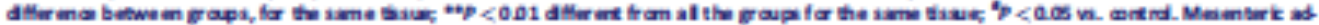

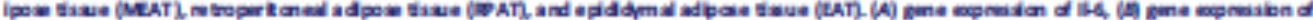

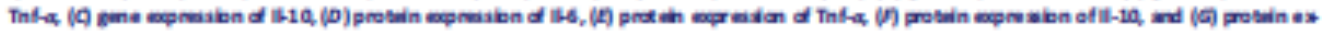
gradion diti-19
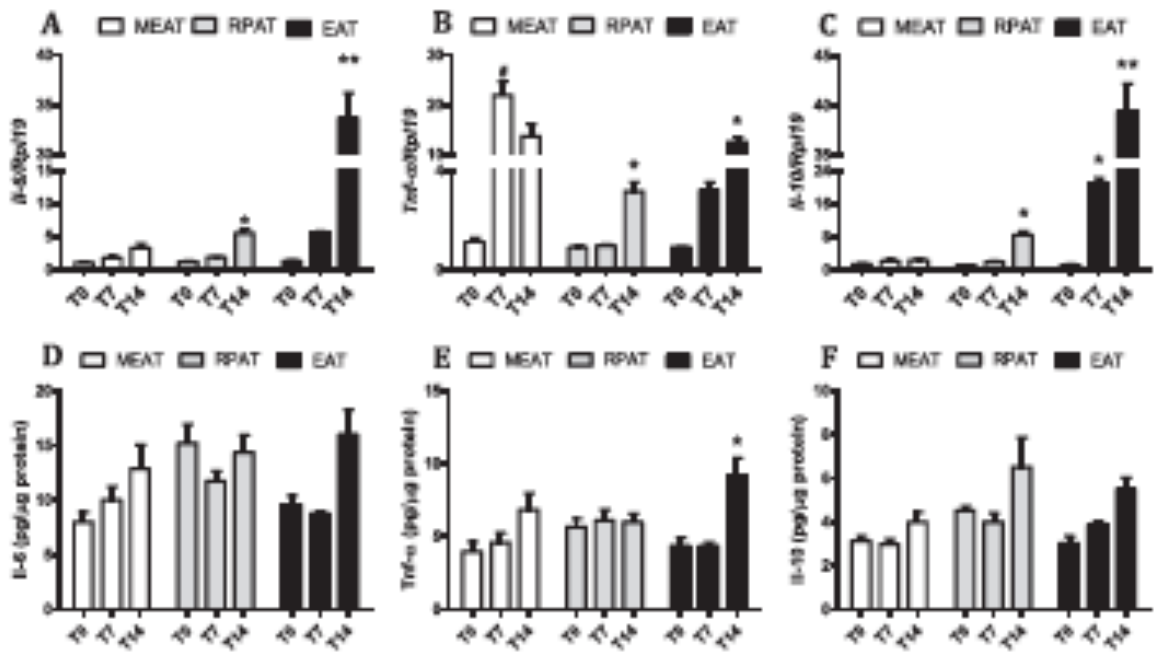

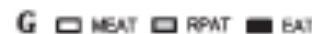

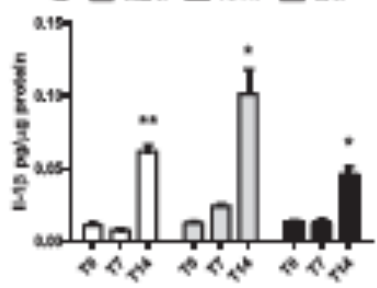

adipocpes per se would be relevant to local and, poselbly, to syzemic inflammation.

Mesenteric adipocytes

In the lsolatnd adipocytes (MEa), gone exprescion wax solely increaed for TNF a (Flgue 2Bl. despite the obsarved in. crease in protein eseresclion of all pro and antilinflammatory proteins in advanced cahexla ( 74 ) in this pad (Flguve 2D-6). II. 1 p protain combent increased in a simila proportion to that found in the whole mesenteric adpose depot. We thus spec. ulate that the increase in the expescibn of other cyokines wa houffident to affect whole tisoue values.

Retroperitonal adipocyts

In the adipocytes isolisted from the retropertioneal pad (RPa), geneespresclion of TNF aincreased in T14 in comprison with TO $(P<005)$ (Figure 2B). Such increase was parallel to the whencement of gene cereselon level found in whole retro. paritoned tsoue $\mathrm{h}$ the same group (T14). it $\mathbf{k}$ posolble that the higher valus observed for 11.10 gre expescion in 74 In RPa (Rguve 2C) are a consequence of the increase of TNF-2

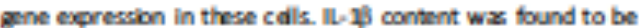
ncreased in whole RPAT, but nat in RP2, and therdore, we poshilate a possible contribution of the stromal vasoula frac ton, compitsed by the non-adipocyte celula components of the tasove. The high II.6 and TNF-a (Rguve 2D,A protdin content in adpocytes obtahed from animals with tarmind cachoxh was not reflactind in the whole tlissue, exen though gene expexsion wry increaced in TH, as compared with TO.

Epididymal adipocytes

In the cells bohted from this pad (Ea), we observed an in.

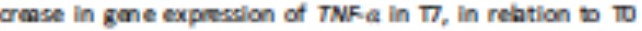




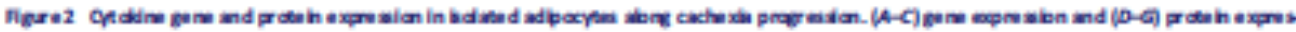

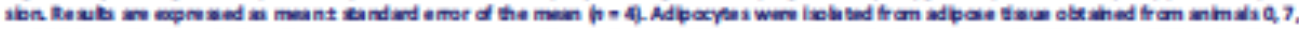

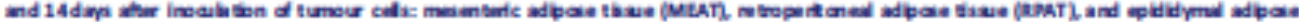

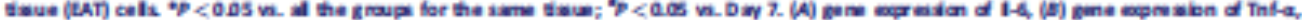

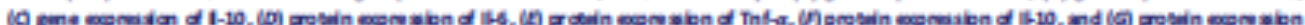
ditia
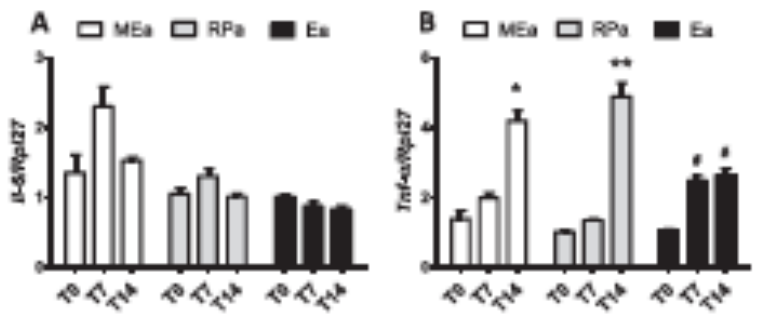

C 口MEa $\square$ RPa $\square$ Ea
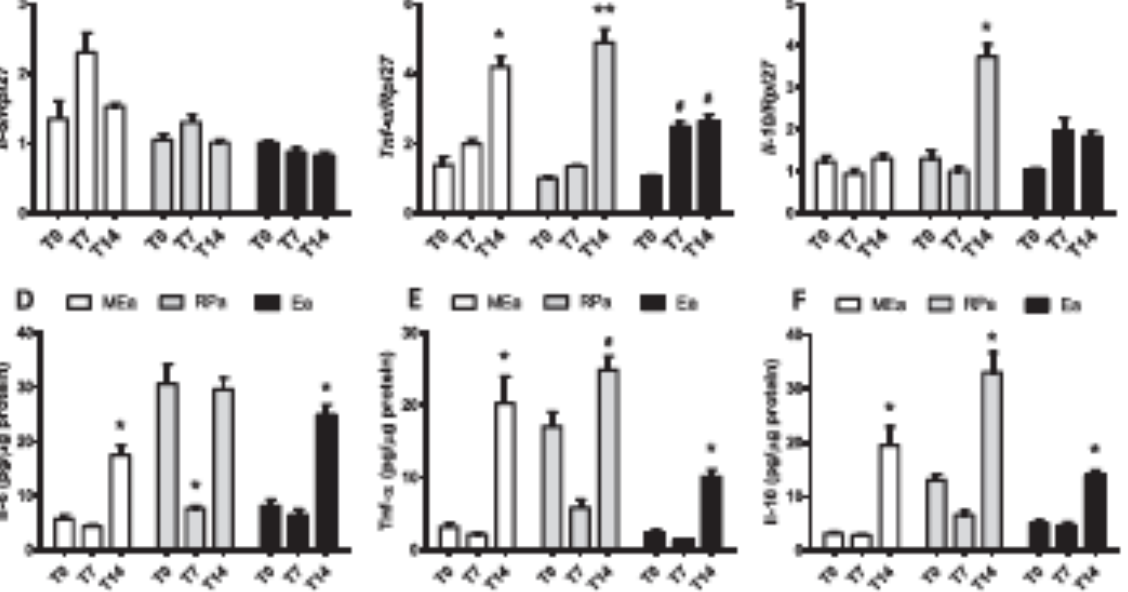

G

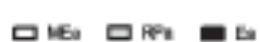

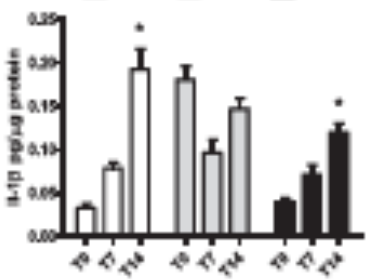

(Figue 2B). This might be the cause for the higher eqrescibn of all analyeed cyolines we mport in the adipocytes in termi nal cxhoxla (74) (Rigure 2D-G) and benrs coriespondance with the enhanced contant of TNF-a and IL.1P $n$ the whole EAT. This tissue showed a progresalve increace of II. 10 gene expreselon levels batwaen $T 7$ and $T 14$, maybe $n$ an attempt to coun terbalance increasing inflammation.

Pathways related with the induction of pro-inflammatory cytokines in adipocytes

In MBi, all genes relatud with the shudied transociption fxtors wore increased in T14: nuder hator kappa B sbunts p5O

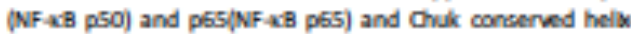
loophelix ubliqutous knase (kkel) $(P<005)$ (Rgure $3, A-C$ )

Toll hike recetor 2 (Tr2) gene eprescion wax up-reguhtod in the same group (Fgure 3E), as wel as myebid dfferenthtion pitmany response 88 (Mydsg) and TNF recepton zosodatnd the

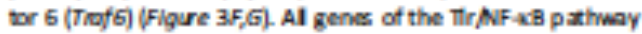
were thus shown to be regulatud by cachesin. Wrh ragard to protdin expreselion, the results of NF 18 p65 and Mydes prallekd the gene expession dxa, being increased only in turm hal cacheda (T4) $(P<0.05)$ (Flgure $5 B$.

Similady to what was observed in MEa, the changs re. parding TL.Rg/NF xB pathway in RPa cocured solely at the ff nd stage of cxhexla when p50, p65, like, TLR2, Mydsg, and Trofts gene expreselon was anhanced $(P<0.05)$ (Figure $3.4-D$. F.G. Howerer, in contrast with the protdin expression result: eported for ME2, pSO protein content inareased, pE protain content decreased, and Mydsg protein espreselon wx. un. changed $\mathrm{h}$ RPa in T14 (Rgure 5A-C). 


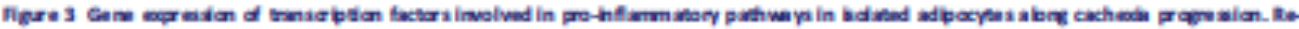

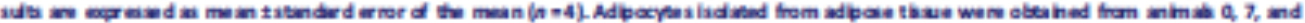

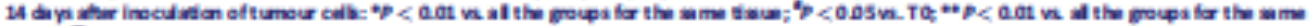

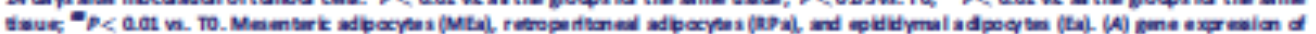

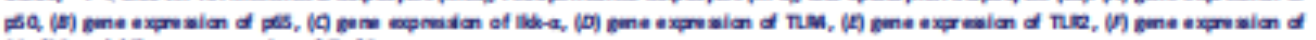

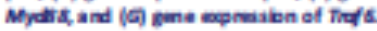

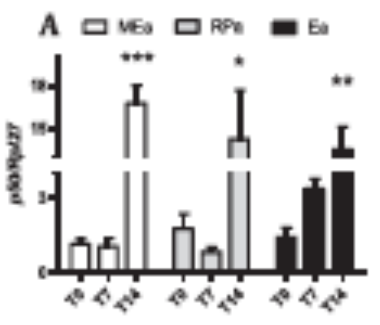

$$
\text { B D }
$$

C $\square$ Mes $\square$ RPe $=$ Ee

D 口 VEa 口Pr
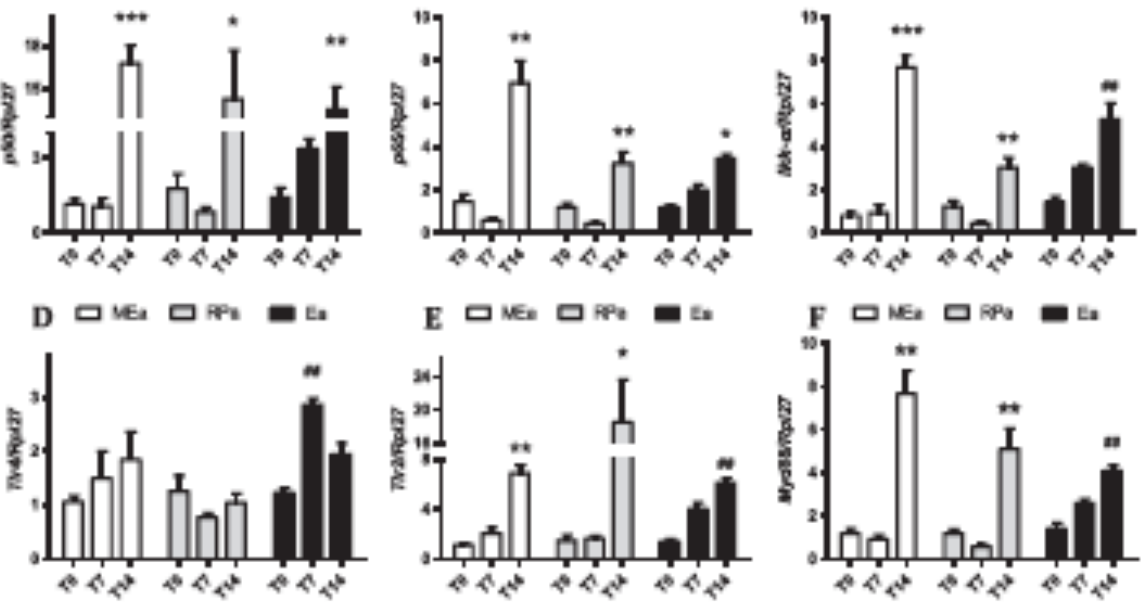

ロ Ma ロ

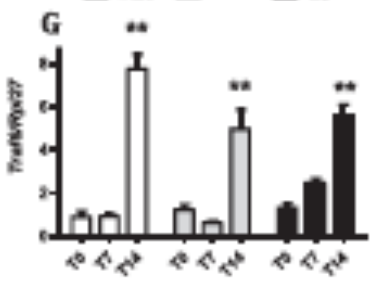

Epididpma adipocytes once again showed simibrty with the result found for MEa: P5O, p65, lkke, TLR2, Mydeg, and Trats gene exprexsion hereased in $74 \quad(P<005)$ (Figure 3A-D,FG). TLRA gane levels were increased alrendy in $T 7$ (Rgure 3E) while in $\mathrm{T14}$, the levels ware similar to TO. pSO, pफ, and Mydeg protain eereselon increased in tarminal cachexla (T14) (Rigure 5B-DL, in eplididpmal adipocytes.

\section{inflammasome pat hway}

In MEa, the exprescion of genes related wth the activity of the inflamm roome pathway was hcieseed for the NIR tamily pyrin domah containing 1 and 3 (NLRP1 and NLRP3), and Cxpase 1 on Day 14 (Figure 4.4-C). These results were accompanied by an increased desvage of Il.1\% to its active form (Rigure SF).
In RPa, only NLRP3 gone expresalion was higher in 74 (Rgure 4B). in E2, NLRP1, and NL RP3 gane eerexdion hciex ed in T14, as compared with T7 (Figure 4:A B); howerer, we ob. sarved no changes $n$ the contant of deaved lil. 1 ( Rigure 5F).

\section{Discussion}

Cxhesla is chanacterbed by progreselve locs of lean and ad: pose tsoue, siz accompanied by deruption of the blochmical protle in assodistion with pathological increase of pro inflammatory cyobilines in cancer pationts and expentmenta

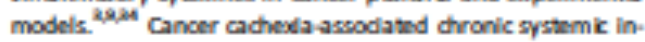
flrmmition presents a relevant contrbutton from the WAT, $x$ we and others have previously shown. is is-ie 


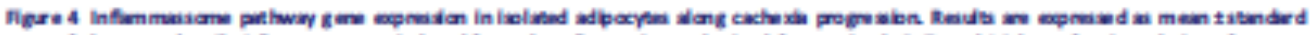

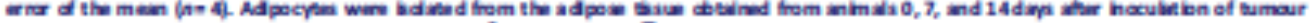

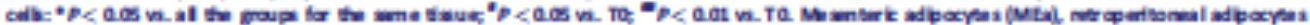

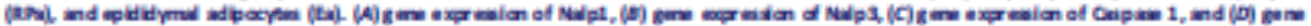
comianen of Mil-1a.
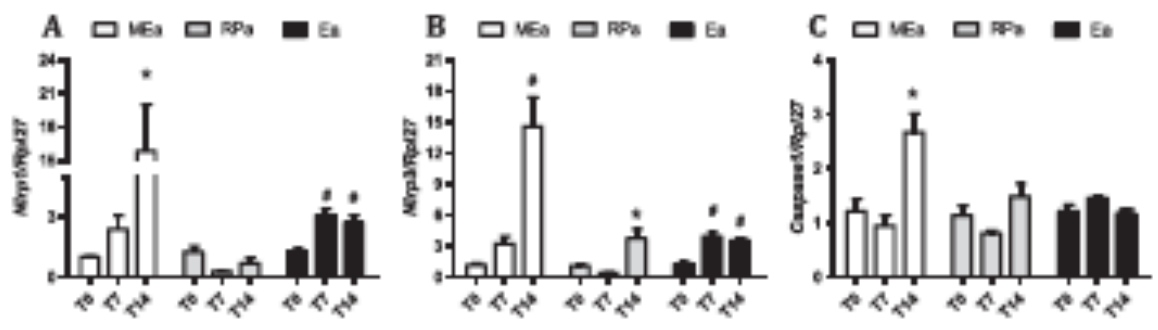

D

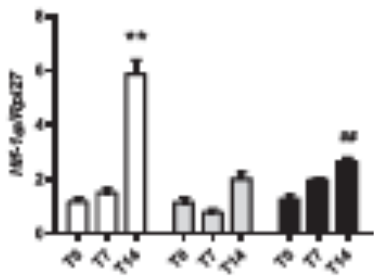

Two main questions were addressed in the present study: (1) is there heterogen aty regrding anstomical locilization of WAT in concem to inflammation caadity during the proges: slon of cahesla? and (2) What is the contribution of adpo crtes $p e r$ se to adpose tsoue inflammition? To eluclidste these appects, we studied cach exla progrexsion $n$ the rodent Waker 256 cardinosarcoma model.

All the eamined (mesenteric, retropertoneal, and eqidid. $\mathrm{mal}$ ) tht pads showed increased gane expression of inflam matory cyolidnes in advanced cahesela (T14). Ket, only Ill-1p protain combent was condistenty augmantad in all the depots. TNF-a proteh levels were shown to be higher solely in EAT of T14 almals. Adpose twoue depots from difterent $n$ atomical mgions show maked heterogeneity in microana tomical arganinzion, metabolem, and physiological and molecular aspects. ${ }^{16 j e}$ One such heterogeneity can also be noticed during cachedi, $\mathbf{x}$ we (Bxisth et al) $)^{20}$ have demon strated that the suboutaneous adipose tsoue of ancer pa tients rexponds in a precoclous manner to the onset of the diseces, with enhanced inflammatory cytoilne secretion, as compared with the meson tark depot.

Among rodent veceeral depots, BAT is the one that w sponds more rapidy to cachexla by becoming inflamed. Therefore, is dex that the different vacera adipose pads present distinct dpamics in response to the syndrome. Neverthdess, what is the contribution of the adpose cell per $s e$ in this scenaito? WAT comprises sevenal cell types, and shudies carried out with obese patents mport a great prticiparion of inflitrating immune cells in tripgeiting tsoue inflamm xtion. ${ }^{12,12,17}$

Adpocytes lisolated from RPAT displayed an ant. Inflammatory profle, with a high protain content of II. $\mathbf{D}$, and unaltered proten content of liL-1/p in tarminal cahoxla. Thus, it apears that RPa attompts to counterbalance bed in. flammation caused by the high concentration of II-1/pproteh, poxsibly syntheelined by the stroma vasoula fraction, as sug. gested by the high total tisoue concentration of this cytoline in the dopot in contrast, lisolatind adpocyes from the mesentwric and eplididpmal pads showed a clear pro-nflamm xtory profle. Ea secretes cytoitnes alrmoly at an eariy stage, while MEa inflammition was found in adanced cachexla. However. adpocytes from both of these depots contribute condistantly to local inflammation at the terminal phre of cachexa and may be relevant to the onset of spatamk inflammation. Such differences confirm the heterogeneity of adipocyass obtained trom particula depots; while MEa and Ea exhb ted a proges: sve proinflammatocy pattern, RPa increased the protein ex. presclon of Ill 10. A recent study showed that different alpose pads detive from detinct embryonik oridins." We may thus suggest that perhap, the haterogeneous response deplayed by the bolated cells trom the depots may be relatud with intrinsic diversity of these cells. 


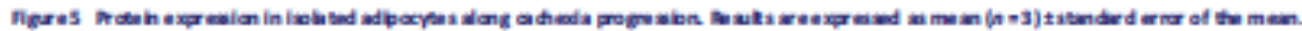

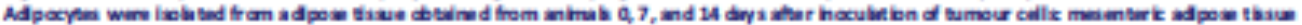

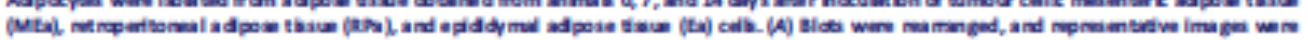

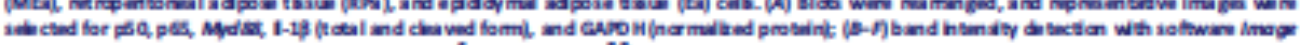

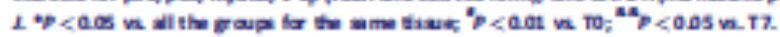

A

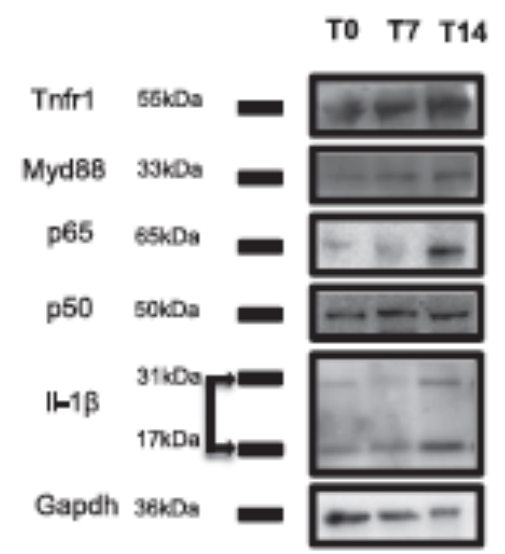

$\mathrm{RPa}$

Ea
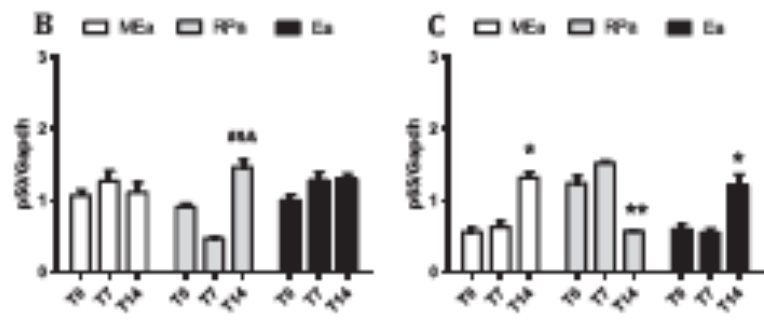

T0 $\mathrm{T7}$ T14
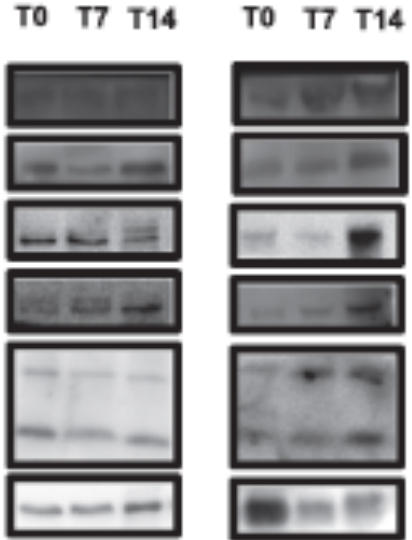
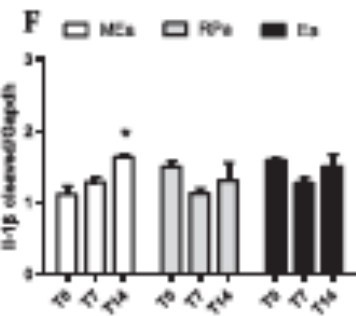

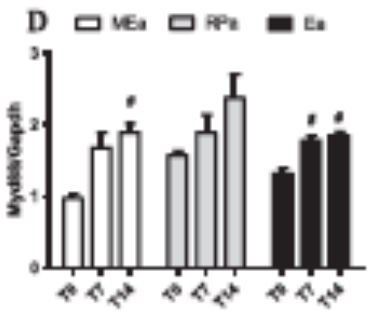

G 口 vea

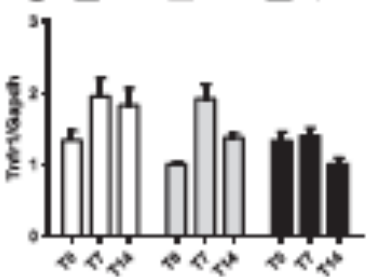

Afar examining inflamm zxory cyolitne production by cdls from the diflerent padk, we iwe:sightad the intracelular path ways thit cauld be asoodixed with the modulation of adpo cyat inflammation. Firsti, we analysed the dxcelc pathway in

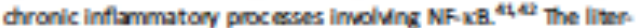
ature provides detalled evidence that the NFaB patwway in

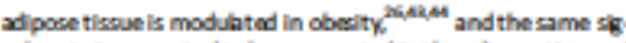
na route is sugrested to be augmented in the adipose tisave of

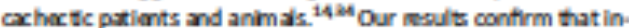
ateased pro-inflammatory cycokine content in the adipose ts. oye was accomminied by higher exprescion of transifiption tators key protaina, such as NF 48 B p6s. Mydeg protain content 
wry increased both in MEa and Ea and, in both cel popula tione, assodisted with incessed NFaB proteh expession. These findings indicate that the adpocyte NF-AB patwway is modulated during the progression of the syndrome, espedaliy at its end point in obesity, increased NFaB $x$ twity has been attributhd to infitating immune celk, rather than to adiporyes. "sil? To our best knowledge, this is the fiat report of adpocye NF-AB imoolvement in WAT inflammation in creshas.

We report increased ILIP proten comtent in all WAT pads and in two different lisolatad adipocyte populations. An in. arease of the deaved, blaxtive lli, ip form was found to be

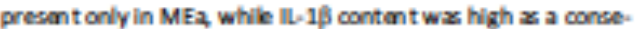
quence of cachexh, in the whole adpose pads studied. IIL If is one of the man tragets of the inflammzoome pathway. Therefore, in addilion to showing that the NFxB pathway is modulated in the alpocyter of WAT during cachese, the results indicate that cachoxia was able to modulste the inflammasome patwway in the cdils. in obesity, increased inflammasome xtvity is rdated with disexe progess. The protains NLRP 3 and Caspase 1 play an important role in this patwway. Caspase 1 found the rimals to be resktant to obesity ftur being subm thad to a high bit diet. These rimals also showed improved insulins aneitivety ather the high fax det protocol as compred with controls. show a modulation of the inflammasome patiways in alipocyas duiting cach oxila

In summry, our revilts indcate a haterogeneous moponse of the differont white adpocytes to cachexs and a role in the modulation of alpose tikge inflammation. While MEa and Ea show a dex proinflammatory response duting the dovebomant of the syndrome, the ifflammatoy tactors we found to be inciex od in cachese $\mathrm{h}$ the ratiopertoneal tisaye re probatly produced by the stromal vasoularfaction Add. tonaly, we demonstate, for the fiat time, that the inflammasome pathway may be imolved in alpose inflamma. Ion $\mathrm{h}$ cancer cachext 2 Taken together, the results sugrest that the inflammasome patiway could bea target for pharmxolog. cal teatment in cxhexh.

\section{Acknowledgements}

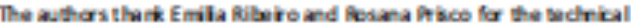

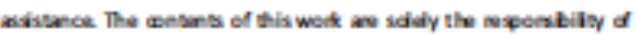

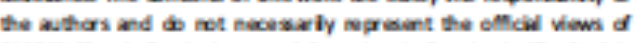

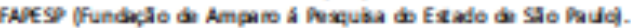
Theauliex of thb pees cently the they comply with the ethical

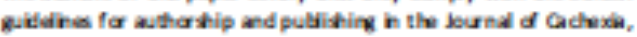

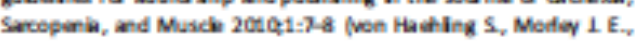
Govis. 1, and Ackers. a.

\section{Funding}

FAPES gants numbars 2019/51078-1 (M.LB.Jc) and 2012/ 500790 (MS.) and CAPES (Coordenaçlo de Apartelicoamento de Nivd Suparion).

\section{Conflict of interest}

None dedaned.

\section{References}

1. Tadile ML, Mabeve TM, Taberoy $\pi_{*}$

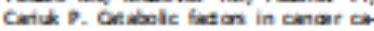

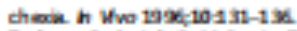

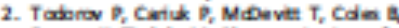

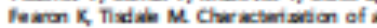

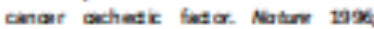
3n:-39-342

3. Tadila MI Conar celboix mabaic ab

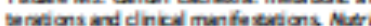
tim 10n7-19-1-7.

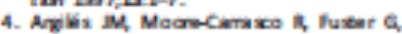

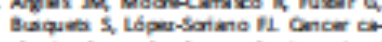
cherk: the mdecier mechensms int

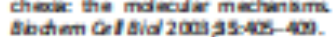

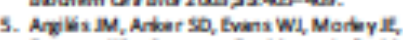
lewen NC, Strour 1, Musorbal M

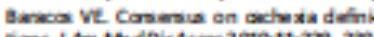

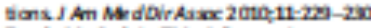
6. Zayda M, Sading TM. Adpose tsase mac-

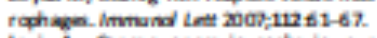

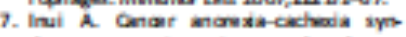
dromecurest isum in mesech and men.

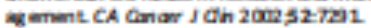

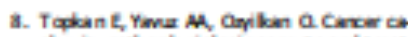

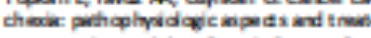
mert aptons Avan par J Conar Am 2007 ant $45-451$.

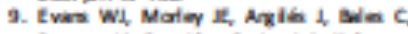

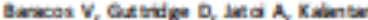
Zadih K, Lachx M, Mentavient G. Merlo D. Mish We, Muxceitsi M, Nepend A

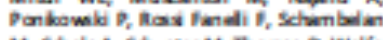
$M$, schis $A$ shuaser $M$, Thame $D$, wdile

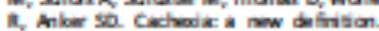

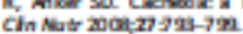

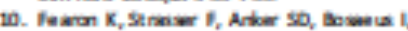

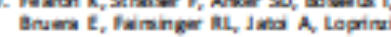

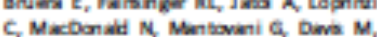

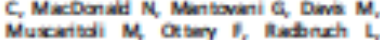

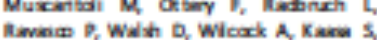

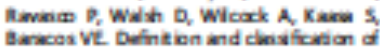
anseas Ve, befintien ind chasforion of

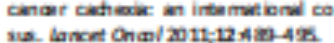

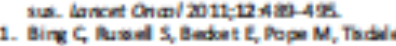

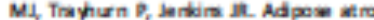

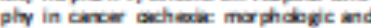

molecule milpos of edpow sue in tumaubleiting mian. A I Cancer 2006; Sima-1an.

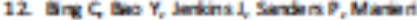
$M$ Cintis, Todile Mi, Trimpum D. Ino

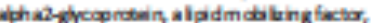

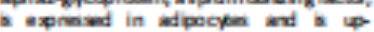

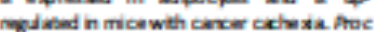

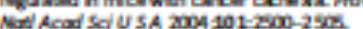

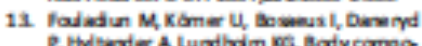

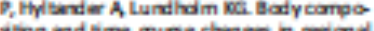

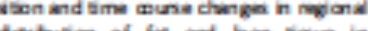

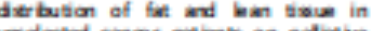
undecied conort pirims an pialwive

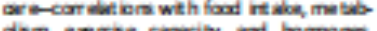

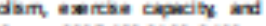

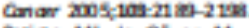

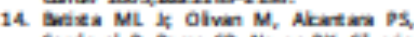

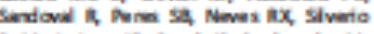
4. Maximieno 10 , Otach $D$, Sedender $M$. Adpose tiouederived lation in posertid.

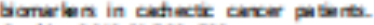

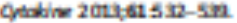




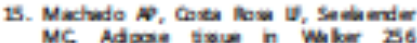

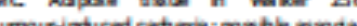

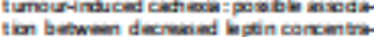

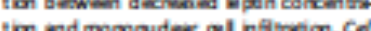
tion and manonudere ail mil

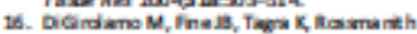

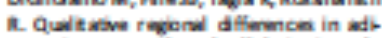

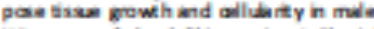
Wiser no fed of Ibium. Am I Thyabi

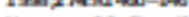

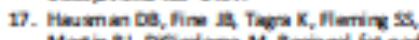

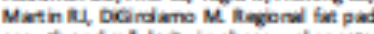

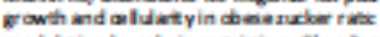

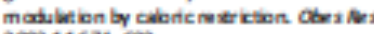
2anij $11574-602$

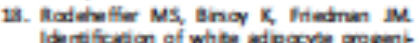
whe dipara prokn

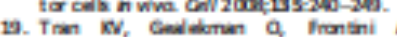

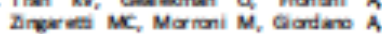

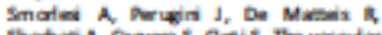

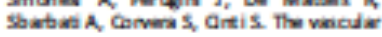
endethilum of the edpere tous geves ras bo both whita and brown fat colb. Call Mrab 2012-15-222-22?

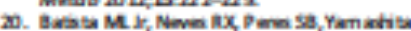

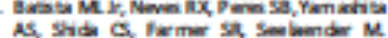
AS, shid C, fermer St, Sembendr M.

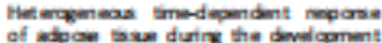

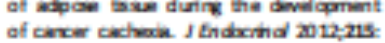
af cancer

21. Bentivelo is, Seliender MC Hebroge

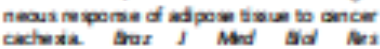
$20 \mathrm{an} 341$ 161-1106?

22. Eour N, Lhomme L, De llower A, Kolmen

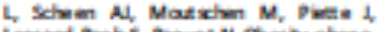
Lofind-hobs, hequet N Cbenty phono

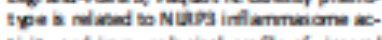
tivity ind immumbircd polle of vixena!

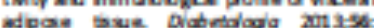
24⿴囗十) 2 2 7 .

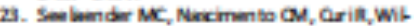

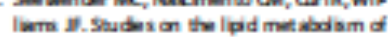

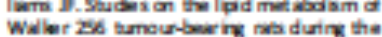

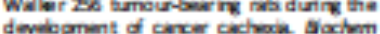

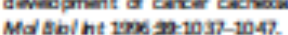

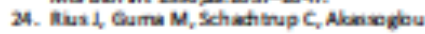
$X$, Znkembel AS, Nat $X$ Jdmen ita.

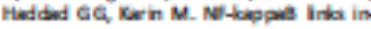
nase immunty to the hpoic mporse

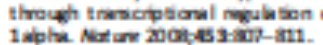

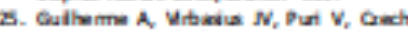
MD. Adporye dyturesers intang deaty to insilin mostre and tros 2 deber

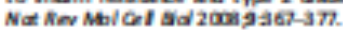

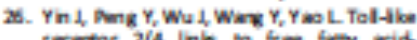
racepter 2/4 link bo from lent acid tion. J louke tid 2as4as-47-52

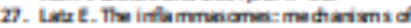
cetivesion indfunction. Gurr Opin mmenol 20ton 2223-31

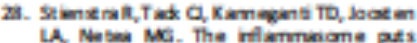

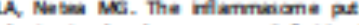
abexity in the

2. Leppon Metsusion of inflammiomex in idpase beve of women with gassiand 74-ai

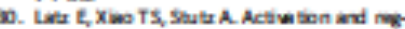

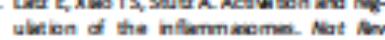
Ammenol 2014-19-207-4t

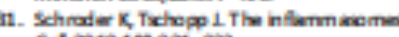

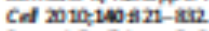

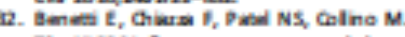

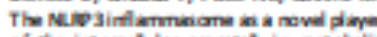

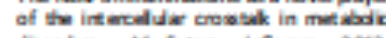

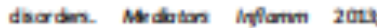

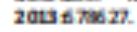

13. Sedander MC, Curi it, Celiquhain A

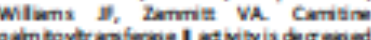

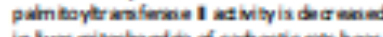

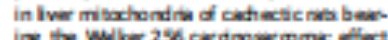

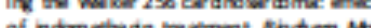

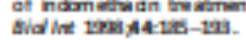

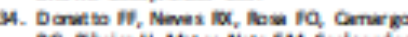

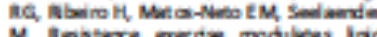
M. Mlasince coerdis madiusas ip plinima profil and cyelente cortert in tim

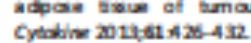

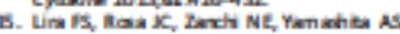
Lope ib, Lope AC, lisas M.

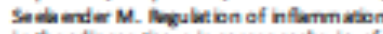

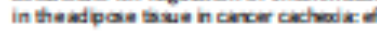

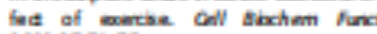
$200272 n-75$

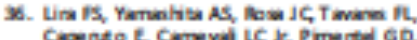

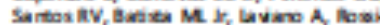

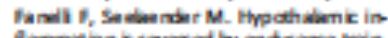
flammeten a revened by endariace train. ing in menctio-oechects na. Netr Matab (2and) 2ariation.

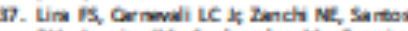

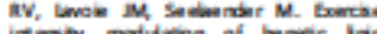

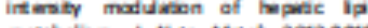
mexasm I Net Matal 20022012

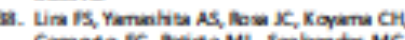

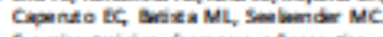

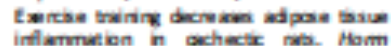
inflammien in oechex.

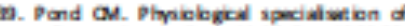

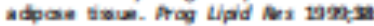
2Z-25i

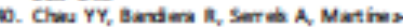

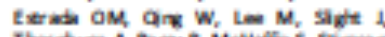

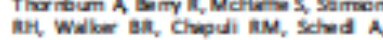

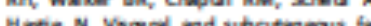

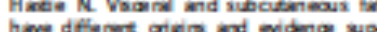

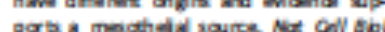
pas a mactide

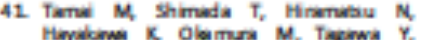

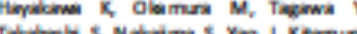

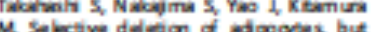

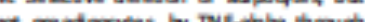
ax peidpryas by TN1-apha through Cres- and bolkemme-medisad sup prias-1m.

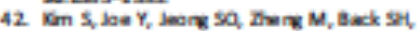

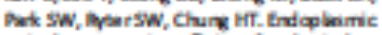

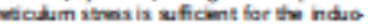

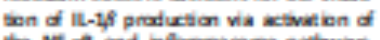

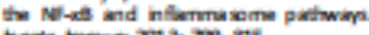

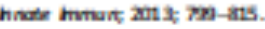

Nov, Q, Shipirg M, Ovidia, M, Tamovids, T,

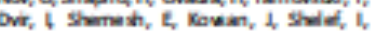

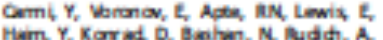

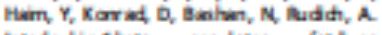

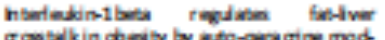

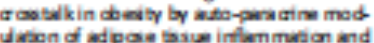

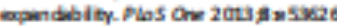

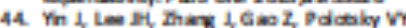

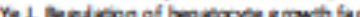

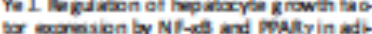
pas asice. Am I hivaid Endarinal

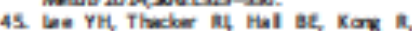

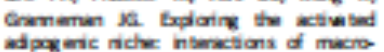
tha gen ind ad porye prowertion. Call Qp de man $41013-120$

46. lae AC lae 1 Collular and molecule dimpen in adpase bese inflemmation in to developmert of chesty-nduad irsu

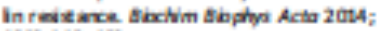
1302 *46-402

47. Mhmin SW, leswe AC, Choudhury M, Sequero KC, Abens IMM, de la Hawaves

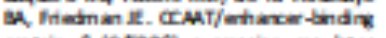

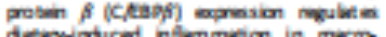
chaks and afore touse in mice $J$ tabl

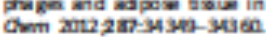

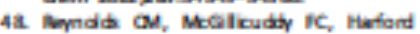

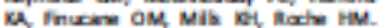

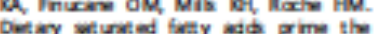

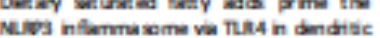

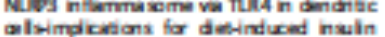
alsimpicens to desnduced meitn mastince 1227

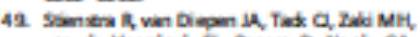

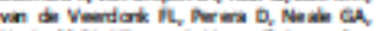

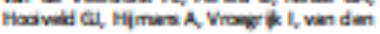

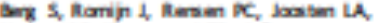

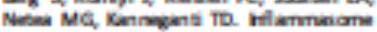
a acentod pimperin the indxtion of absity and indin masterce froc Not Aad ded US

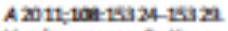

Sa. Uendenmigie a Youm M, Imasin A

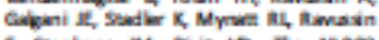

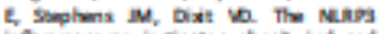

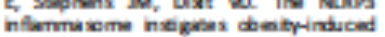

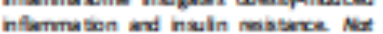
Mnd and and ind ins 
ANEXO 2 - Artigo enviado a publicação 


\section{Cachexia causes time-dependent activation of the inflammasome in the liver}

${ }^{1}$ Rodrigo X. Neves, ${ }^{2}$ José Cesar Rosa-Neto, ${ }^{3}$ Alex S. Yamashita, ${ }^{1}$ Daniela M. R. Riccardi, ${ }^{1}$ Rodolfo G. Camoargo. ${ }^{4}$ Nelson I. Neto, ${ }^{5}$ Felipe H. Santos, ${ }^{5}$ Miguel L. Batista jr, ${ }^{6}$ Janina E. E. Tirnitz-Parker ${ }^{1}$ Marília Seelaender

${ }^{1}$ Cancer Metabolism Research Group. Department of Cell and Developmental Biology, Institute of Biomedical Sciences, University of São Paulo, São Paulo, Brazil. ${ }^{2}$ Immunometabolism Research Group. Department of Cell and Developmental Biology, Institute of Biomedical Sciences, University of São Paulo, São Paulo, Brazil. ${ }^{3}$ Department of Physiology and Biophysics, Institute of Biomedical Sciences, University of Sao Paulo, São Paulo, Brazil. ${ }^{4}$ Department of Physiology, Federal University of São Paulo, São Paulo, Brazil. ${ }^{5}$ Laboratory of Adipose Tissue Biology, Center for Integrated Biotechnology, University of Mogi das Cruzes, Mogi das Cruzes, São Paulo, Brazil. ${ }^{6}$ Liver Disease and Regeneration Laboratory, School of Biomedical Sciences and Curtin Health Innovation Research Institute, Curtin University, Bentley WA, Australia

Running Head: Liver, inflammasome pathway and cachexia progression.

Correspondence to: Marília Cerqueira Leite Seelaender

Department of Cell and Developmental Biology, Institute of Biomedical Sciences, University of São Paulo, Brazil.

Address: Av. Professor Lineu Prestes, 1524, CEP 05508-900, Butantã, São Paulo, SP, Brazil.

Phone / Fax-number: 55-011-3091 7225

E-mail: seelaend@icb.usp.br

Key words: Cancer cachexia, liver, macrophage, inflammasome, and inflammation. 


\begin{abstract}
Background: Cachexia is a systemic syndrome leading to body wasting, systemic inflammation and metabolic chaos. It is a progressive condition and little is known about its dynamics. Detection of the early signs of the disease may contribute to the effective attenuation of associated symptoms. Aim: To investigate the activation of inflammasome-regulating inflammatory pathways in rat livers during the development of cachexia induced by Walker 256 carcinosarcoma. Methods: Eightweek old, male rats were subcutaneously inoculated with a Walker 256 carcinosarcoma cell suspension $\left(2 \times 10^{7}\right.$ cells in $1.0 \mathrm{~mL}$; tumour-bearing, $\mathrm{T}$; or PBS control, C). The liver was excised on days 0,7 and 14 after tumor cell injection. Results: Macrophage numbers were progressively increased in the liver of cachectic animals. In terminal cachexia, NFkBp65, Jnk and inflammasome pathways were also increased and accompanied by enhanced IL-1 $\beta$ cleavage. Conclusion: Our data show that cancer cachexia causes an increase in macrophage numbers and modulates the hepatic inflammasome pathway to augment IL-1 $1 \beta$ cleavage.
\end{abstract}




\section{Background}

Cancer cachexia is a devastating syndrome, which severely reduces the quality of the life and overall survival in cancer patients $(2,27)$. It affects around $80 \%$ of cancer patients and approximately $20 \%$ of those do not survive $(1,10,26)$. In general, cancer cachexia has been characterized as total weight loss and both adipose tissue depletion and muscle wasting.

Cachectic patients present systemic chronic inflammation, however is not clear who starts release pro-inflammatory cytokines if is tumor or host organs (4). Many studies have shown that visceral organs are able to maintain and increase pro-inflammatory cytokine levels $(3,25)$.

The liver is the central organ in the control of nutrient supply to the organism and governs the systemic metabolic rate as transport, storage, breakdown and utilization of glucose, fat and protein $(11,16)$. Cancer cachexia is speculated to contribute to disease progression through energy imbalance, possibly caused by reduction of oxidative phosphorylation levels in liver mitochondria $(9,11)$. The main liver cell types are represented by hepatocytes, biliary epithelial cells and immune cells such as liver-resident macrophages or Kupffer cells, the latter representing about $10 \%$ of total liver cells (21). In accord Martignoni et al. 2009 (15) CD68 protein increased in the liver of cachectic patients compared non cachectic and it was correlated with more aggressive tumor in those patients.

The systemic chronic inflammatory state in cachectic patients has been welldiscussed, and several studies have shown the contribution of some organs to inflammatory cytokine levels (meu e (13), but it is not totally clear. Further, the liver is also known to synthesize some inflammatory proteins, such as acute phase proteins (APPs) (17). In this study, we investigated the role of the inflammasome pathway in 
the liver of cachectic rats.

Inflammasomes are multiprotein complexes that have a major role in activating the pro-inflammatory cytokines IL-1 $\beta$ and IL-18. These are produced as immature cytokines and require inflammasome-regulated cleavage of pro-IL-1 $\beta$ in the cytoplasm into mature IL-1 $\beta$ prior to its release $(12,20)$. Several proteins constitute the inflammasome pathway, such as the NOD-like receptor (NLR) family (NLRP1, NLRP2, NLRP3, NLRP6, NLRC4, and NLRP12), and the pyrin and HIN200 (hematopoietic interferon-inducible nuclear antigens) domain-containing protein (PYHIN) family (5). The NLRP3 inflammasome pathway is a key player since studies have shown that mice with a genetic knockout of NLP3 and Caspase 1 were demonstrated to be resistant to obesity development when submitted to a high fat diet, compared to wildtype mice $(23,28)$.

Therefore, the main aim of the present study was to investigate the inflammasome pathway associated with the increase of macrophage numbers in the liver and their activation with aggravation of the syndrome. 


\section{Materials and Methods}

\section{Animals}

Male adult Wistar rats (270-300 g), obtained from the Institute of Biomedical Sciences, University of São Paulo, were maintained in metabolic cages, under a $12 \mathrm{~h}$ light/12h dark cycle and controlled temperature conditions $\left(23 \pm 1^{\circ} \mathrm{C}\right)$, receiving water and food (commercial chow; Nuvilab, Nuvital, Brazil) ad libitum. The Biomedical Sciences Institute/USP Ethical Committee for Animal Research approved all the adopted procedures (050/102 ECAR), which were carried out in accordance with the ethical principles stated by the Brazilian College of Animal Experimentation. Walker 256 tumor cells $\left(2 \times 10^{7}\right.$ cells $)$ were injected subcutaneously into the right flank of the animals (40). Control rats received saline injections on the same day of tumor inoculation. The experiments were carried out as a time course study, and the rats were sacrificed by decapitation on days 0,7 and 14 post-inoculation ( $n=5 /$ group) after $12 \mathrm{~h}$ fasting.

\section{Liver collection}

The livers were removed, weighed, snap-frozen in liquid nitrogen and stored at $-80^{\circ} \mathrm{C}$

\section{Immunohistochemistry}

The livers were placed into plastic cassettes, and mounted with OCT compound medium (Sakura Finetek Japan Co., Ltd., Tokyo, Japan) and frozen by liquid nitrogen. Frozen sections were cut at $7 \mu \mathrm{m}$ and used for hematoxylin and eosin evaluation of liver histology as well as further immunohistochemical analyses. Liver 
sections were fixed with methanol/acetone (1:1), permeabilized with $0.02 \%$ Tween 20 in PBS (PBS-T) and blocked with 5\% goat serum in PBS-T. Tissue sections were incubated with anti-CD68 (Abcam, ab 31630, rabbit) to detect liver macrophages at 1:200 overnight at $4^{\circ} \mathrm{C}$. Antibody detection was performed using a horseradish peroxidase-conjugated secondary antibody (goat anti-rabbit IgG H\&L (Biotin) ab97049, 1/500) and the Vecta stain ABC Kit (Vector Laboratories) and Sigma Fast 3,3-diaminobenzidine as substrate (Sigma, St. Louis, MO). Sections were counterstained with hematoxylin.

\section{Real-time PCR}

Total RNA was isolated from the tissues and cells with Trizol (Invitrogen, Carlsbad, CA), following the manufacturer's recommendations. The first strand of cDNA was generated from $2 \mu \mathrm{g}$ of total RNA, using a commercially available kit (High Capacity cDNA Reverse Transcription Kits, Invitrogen, Foster City, CA, United State America). Polymerase chain reaction (PCR) amplification was performed in duplicates with SYBR Green PCR Master Mix (Applied Biosystems, Foster City, CA) in the QuantStudio 12K Flex Real Time PCR (Applied Biosystems), using the primers listed in Table 1. Gene expression was normalized to Rpl27 reference genes. Data were calculated using the 2- $\Delta \Delta \mathrm{CT}$ method, and are presented as fold changes in gene expression relative to control samples.

\section{Liver cytokine levels}

Rat livers $(0.05-0.08 \mathrm{~g})$ were homogenized in RIPA buffer $(0.625 \%$ Nonidet P40, 0.625\% Sodium Deoxycholate, $6.25 \mathrm{mM}$ Sodium Phosphate, and $1 \mathrm{mM}$ Ethylenediaminetetraacetic acid, at $\mathrm{pH}$ 7.4), containing a protease inhibitor-cocktail 
(proteinase and phosphatase inhibitors, Roche). Homogenates were centrifuged at $15.000 \times \mathrm{g}$ for $30 \mathrm{~min}$ at $4{ }^{\circ} \mathrm{C}$. The supernatant was collected, and protein concentration was determined with a BCA protein quantification kit (Pierce, Rockford, IL, USA), with bovine serum albumin as a reference. Liver samples were quantitatively assessed for interleukin 6, IL-6 (DuoSet, DY506), tumor necrosis factor, TNF-a (DuoSet, DY510), interleukin -10, IL-10 (DuoSet, DY522), and interleukin $1 \beta, I L-1 \beta$ (DuoSet, DY501). Protein concentrations were measured by ELISA (DuoSet ELISA, R\&D Systems, Minneapolis, MN). Assay sensitivities were determined to be $8.000 \mathrm{pg} / \mathrm{ml}$ in the range of $125-8000 \mathrm{pg} / \mathrm{ml}$ for IL-6, and 4.000 $\mathrm{pg} / \mathrm{ml}$ in the range of $62.5-4000 \mathrm{pg} / \mathrm{ml}$ for TNF- $\alpha, \mathrm{IL}-10$, and IL-1 $\beta$. All samples were run as duplicates and the mean value was reported. The results were normalized to total protein.

\section{Western blotting}

Frozen livers were homogenized in RIPA buffer $(0.625 \%$ Nonidet P-40, 0.625\% Sodium Deoxycholate, $6.25 \mathrm{mM}$ Sodium Phosphate, and $1 \mathrm{mM}$ Ethylenediaminetetracetic acid at, $\mathrm{pH} 7.4$ with proteinase and phosphatase inhibitors, Roche). Homogenates were centrifuged at $15.000 \times \mathrm{g}$ for $30 \mathrm{~min}$ at $4^{\circ} \mathrm{C}$; the supernatant was collected, and protein concentrations were determined with a BCA protein quantification kit (Pierce, Rockford, IL), with BSA as a reference. Samples containing $50 \mathrm{mg}$ protein were separated by electrophoresis in 10\% Tricine SDS-PAGE. Proteins were then transferred to PVDF membranes at $25 \mathrm{~V}$ for $40 \mathrm{~min}$ (Trans-Blot Turbo Blotting System, Bio-Rad) in transfer buffer, consisting of $20 \mathrm{mM}$ Tris, $150 \mathrm{mM}$

Glycine and 10\% Methanol. PVDF membranes were then blocked in TBS containing $0.1 \%$ Tween 20 and skimmed $5 \%$ milk for $1 \mathrm{~h}$. After three washes with TBS $0.1 \%$ 
Tween, the PVDF membranes were incubated with primary antibodies against p-JNK (Santa Cruz, SC-6254 mouse), TLR4 (Santa Cruz, SC-30002 rabbit), p-NFkBp65 (Cell Signaling 93h1 rabbit), IL-1 (Santa Cruz, SC-1251 goat) and Gapdh (Santa Cruz, SC-25778 rabbit). HRP-conjugated secondary antibody (anti-rabbit and antimouse Cell Signaling and anti-goat Abcam ab 6885-1 UK) for $2 \mathrm{~h}$ at room temperature and bands were detected by ECL (Amersham, Little Chalfont, UK). The blots were stripped and incubated with anti-Gapdh (Santa Cruz, SC-25778 rabbit) as a loading control. Quantification of antigen-antibody complexes was performed using Image J Analysis Software (http://rsb.info.nih.gov/ij/). Optical density units were given in pixels for fold target protein/control protein.

\section{Statistical analysis}

Data are expressed as mean values and S.E.M. Differences concerning the studied groups (T0, T7 and T14) were analyzed with GraphPad5 software (GraphPad, San Diego, CA, USA) and statistical significance was determined performing One-Way ANOVA with post-hoc Tukey's test for comparison among groups. Body and tissue mass in cachectic rats on day 14 for control (C14) and tumor (T14) were analysed using Student's t-test. A value of $p<0.05$ was considered significant. 


\section{Results}

After 14 days tumor cell injection, experimental cancer cachexia induced a reduction in body weight gain $(10.6 \% ; p<0.05)$ compared with control animals of the same age. In addition, a higher level of IL-1 $\beta$ was found in the liver $(p<0.05)$ also the concentration of macrophage-marker protein and mRNA profile that characterize the presence of macrophage increased in the end of cachexia stage $(p<0.01)$.

In liver, gene expression of TIr4, TIr2, and Cc/2 increased on day $14(p<0.01)$ (Figure $1 \mathrm{~A}, \mathrm{E}$ and $\mathrm{F}$ ) and $/ \mathrm{l}-1 \beta$ gene expression increased on T7 until T14 day $(p<0.01)$ (Figure $1 \mathrm{G})$. On the other hand, gene expression of $N F K B p 65, M y d 88$, and Traf6 did not change.

Next, we sought to determine the increase of macrophages in the liver, and whether it is time-dependent during development of cachexia. We found that macrophage cells infiltrated increased on T7 and increased more in terminal cachexia (Figure $2 \mathrm{D}-\mathrm{F}$ ), so these infiltrated are time-dependent during the development cachexia and their contributed to cytokines gene expression release in the liver with positive correlation (Supplementary fig. 1, 2 and 3)

To explore the role of the liver physiological system, we evaluated some cytokines, yet only II-1b protein content augmented on 14 day $(p<0.01)$ (Figure 3 A), but other cytokines such as Tnf- $\alpha$, II-6 and II-10 did not change. Then we analysed the II-1 $\beta$ cleavage protein content and it also increased on T14 $(p<0.05)$ (Figure 4 C). We analysed the possible pathways that transcript II-1 $\beta$ gene. We found increased $p-$ NF-KBp65 and p-Jnk protein content $(p<0.05)$ (Figure 4 A and B) in the end of cachexia, but these transcription factors seems won't be activated by TIr4, because it did not change the protein content. 
Despite of, we were look at genes of inflammasome pathway could is being changed, once we found II-1 $\beta$ protein cleavage content increased. NLRP1 and 3 genes levels increased on T7 day until on T14 day $(p<0.01)$ (Figure 5 A and B), Caspase 1 gene expression increased in terminal cachexia $(p<0.001)$ (Figure 5 F), and Nod2 gene expression increased only on T7 day and returned basal levels on T14 day $(p<0.01)$ (Figure $5 \mathrm{E})$, whereas Hif-1a gene expression did not change during the development of the cachexia.

Finally, we found increased II-1 $\beta$ protein in the serum on day $14(p<0.01)$ (Figure 6), and all the results suggested that the liver is contributing to inflammation state during the development of the cachexia.

\section{Discussion}

For decades, cancer cachexia has been considered a multifactorial syndrome with the poor prognostic of life. Many studies have described the behavior of tumour and host in the cachexia progression such as chronic systemic inflammation $(1,26)$. We determined that the liver contributes to chronic systemic inflammation during the development cancer cachexia in rats with Walker 256 carcinosarcoma.

In the liver there are many different cells, like hepatocyte and leukocyte cells, which the last is represent for bigger amount of Kupffer cells, well-known like macrophages (24). These cells can alter their concentration in the liver from some diseases such as obesity and diabetes $(6,22)$. In the present study, we found a linear increase of macrophages amount during the cachexia progress and also mRNA related macrophage presence. It seems be clear that cancer cachexia regulated liver tissue to immune cells presence (15). 
The liver plays an important role in the government metabolic pathways (11), and in some diseases, as well as cachexia, it maybe present an imbalance in metabolic pathway, suggesting that the motivator to metabolic chaos $(19,21)$. In our study, we verified that IL-1 $\beta$ gene expression increased in the cachexia progression, and also important inflammatory proteins, such as NF-kBp65 and JNK. Cancer cachexia managed to change the macrophage and inflammatory profile in the liver.

Cachexia patients have reported inflammatory chronic systemic response (3), and infiltrated immune cells in the adipose tissue as well as adipocytes have been suggested as responsible for maintaining the systemic inflammatory state (14) in print). Further, we showed that the increase of macrophages infiltrated in the liver during the cachexia progress might be responsible for increase of IL-1 $\beta$ cleavage and as a consequence provoke the local inflammation. We verified also cancer cachexia has modulated the inflammasome pathway.

The inflammasome pathway has been studied in different diseases $(5,18)$, and it has been shown to be extremely important for local or systemic inflammation, mainly in its activity during the cleavage of $I I-1 \beta$, which has been described as a potent pro-inflammatory cytokine $(8,30)$. In the liver, we found higher gene expression of any important proteins related to the inflammasome complex, supporting the evidence of the II-1 $\beta$ cleavage higher.

The contribution to systemic inflammation by host in cancer cachexia has been seen in many studies $(3,7,29)$, and our findings show that the liver may contribute to systemic inflammation in the end cancer cachexia state, when we found higher concentrations of $\mathrm{II}-1 \beta$ in the serum in those animals.

In conclusion, our results suggest that the liver is deeply affected by cancer cachexia during of the disease's development, and it is tightly suggested by 
macrophages infiltrated in the liver that produce a higher amount of $I-1 \beta$ resulting in the both local and systemic inflammation.

\section{Reference}

1. Argilés JM, Anker SD, Evans WJ, Morley JE, Fearon KC, Strasser F, Muscaritoli M, and Baracos VE. Consensus on cachexia definitions. J Am Med Dir Assoc 11: 229-230, 2010.

2. Argilés JM, Busquets S, Stemmler B, and López-Soriano FJ. Cancer cachexia: understanding the molecular basis. Nat Rev Cancer 14: 754-762, 2014.

3. Batista ML, Jr., Olivan M, Alcantara PS, Sandoval R, Peres SB, Neves RX, Silverio R, Maximiano LF, Otoch JP, and Seelaender M. Adipose tissue-derived factors as potential biomarkers in cachectic cancer patients. Cytokine 61: 532-539, 2013.

4. Beluzi M, Peres SB, Henriques FS, Sertié RA, Franco FO, Santos KB, Knobl P, Andreotti S, Shida CS, Neves RX, Farmer SR, Seelaender M, Lima FB, and Batista ML. Pioglitazone treatment increases survival and prevents body weight loss in tumor-bearing animals: possible anti-cachectic effect. PLoS One 10: e0122660, 2015.

5. Benetti E, Chiazza F, Patel NS, and Collino M. The NLRP3 Inflammasome as a novel player of the intercellular crosstalk in metabolic disorders. Mediators Inflamm 2013: 678627, 2013.

6. Bertola A, Bonnafous S, Anty R, Patouraux S, Saint-Paul MC, Iannelli A, Gugenheim J, Barr J, Mato JM, Le Marchand-Brustel Y, Tran A, and Gual P. Hepatic expression patterns of inflammatory and immune response genes associated with obesity and NASH in morbidly obese patients. PLoS One 5: e13577, 2010.

7. Bilir C, Engin H, Can M, Temi YB, and Demirtas D. The prognostic role of inflammation and hormones in patients with metastatic cancer with cachexia. Med Oncol 32: $56,2015$.

8. Drexler SK and Yazdi AS. Complex roles of inflammasomes in carcinogenesis. Cancer J 19: 468-472, 2013.

9. Dumas JF, Goupille C, Julienne CM, Pinault M, Chevalier S, Bougnoux P, Servais S, and Couet $\mathbf{C}$. Efficiency of oxidative phosphorylation in liver mitochondria is decreased in a rat model of peritoneal carcinosis. J Hepatol 54: 320-327, 2011.

10. Inui A. Cancer anorexia-cachexia syndrome: current issues in research and management. CA Cancer J Clin 52: 72-91, 2002.

11. Kazantzis M and Seelaender MC. Cancer cachexia modifies the zonal distribution of lipid metabolism-related proteins in rat liver. Cell Tissue Res 321: 419-427, 2005.

12. Latz E, Xiao TS, and Stutz A. Activation and regulation of the inflammasomes. Nat Rev Immunol 13: 397-411, 2013.

13. Lira FS, Yamashita AS, Rosa JC, Tavares FL, Caperuto E, Carnevali LC, Jr., Pimentel GD, Santos RV, Batista ML, Jr., Laviano A, Rossi-Fanelli F, and Seelaender M. Hypothalamic inflammation is reversed by endurance training in anorecticcachectic rats. Nutr Metab (Lond) 8: 60, 2011. 
14. Machado AP, Costa Rosa LF, and Seelaender MC. Adipose tissue in Walker 256 tumour-induced cachexia: possible association between decreased leptin concentration and mononuclear cell infiltration. Cell Tissue Res 318: 503-514, 2004.

15. Martignoni ME, Dimitriu C, Bachmann J, Krakowski-Rosen H, Ketterer $\mathbf{K}$, Kinscherf R, and Friess $\mathbf{H}$. Liver macrophages contribute to pancreatic cancer-related cachexia. Oncol Rep 21: 363-369, 2009.

16. Narsale AA, Enos RT, Puppa MJ, Chatterjee S, Murphy EA, Fayad R, Pena MO, Durstine JL, and Carson JA. Liver Inflammation and Metabolic Signaling in ApcMin/+ Mice: The Role of Cachexia Progression. PLoS One 10: e0119888, 2015.

17. Preston T, Slater C, McMillan DC, Falconer JS, Shenkin A, and Fearon KC. Fibrinogen synthesis is elevated in fasting cancer patients with an acute phase response. J Nutr 128: 1355-1360, 1998.

18. Reynolds CM, McGillicuddy FC, Harford KA, Finucane OM, Mills KH, and Roche HM. Dietary saturated fatty acids prime the NLRP3 inflammasome via TLR4 in dendritic cells-implications for diet-induced insulin resistance. Mol Nutr Food Res 56: 1212$1222,2012$.

19. Rosa LF, Kazantzis M, and Seelaender MC. The effect of Walker-256 tumour development upon Kupffer cell metabolism. Cell Biochem Funct 16: 195-202, 1998.

20. Schroder K and Tschopp J. The inflammasomes. Cell 140: 821-832, 2010.

21. Seelaender MC, Kazantzis M, and Costa Rosa LF. The effect of adrenaline and Walker-256 tumour-induced cachexia upon Kupffer cell metabolism. Cell Biochem Funct 17: 151-156, 1999.

22. Sica A, Invernizzi $\mathbf{P}$, and Mantovani A. Macrophage plasticity and polarization in liver homeostasis and pathology. Hepatology 59: 2034-2042, 2014.

23. Stienstra R, van Diepen JA, Tack CJ, Zaki MH, van de Veerdonk FL, Perera D, Neale GA, Hooiveld GJ, Hijmans A, Vroegrijk I, van den Berg S, Romijn J, Rensen PC, Joosten LA, Netea MG, and Kanneganti TD. Inflammasome is a central player in the induction of obesity and insulin resistance. Proc Natl Acad Sci U S 108: 15324-15329, 2011.

24. Takezawa R, Watanabe $\mathbf{Y}$, and Akaike T. Direct evidence of macrophage differentiation from bone marrow cells in the liver: a possible origin of Kupffer cells. $J$ Biochem 118: 1175-1183, 1995.

25. Tisdale MJ. Mechanisms of cancer cachexia. Physiol Rev 89: 381-410, 2009.

26. Topkan E, Yavuz AA, and Ozyilkan O. Cancer cachexia: pathophysiologic aspects and treatment options. Asian Pac J Cancer Prev 8: 445-451, 2007.

27. Tsoli $\mathbf{M}$ and Robertson G. Cancer cachexia: malignant inflammation, tumorkines, and metabolic mayhem. Trends Endocrinol Metab 24: 174-183, 2013.

28. Vandanmagsar B, Youm YH, Ravussin A, Galgani JE, Stadler K, Mynatt RL, Ravussin E, Stephens JM, and Dixit VD. The NLRP3 inflammasome instigates obesity-induced inflammation and insulin resistance. Nat Med 17: 179-188, 2011.

29. Watanabe T, Shibata M, Nishiyama H, Soeda S, Furukawa S, Gonda K, Takenoshita S, and Fujimori K. Serum levels of rapid turnover proteins are decreased and related to systemic inflammation in patients with ovarian cancer. Oncol Lett 7: 373-377, 2014.

30. Zitvogel L, Kepp O, Galluzzi L, and Kroemer G. Inflammasomes in carcinogenesis and anticancer immune responses. Nat Immunol 13: 343-351, 2012. 
Figures 1.

A

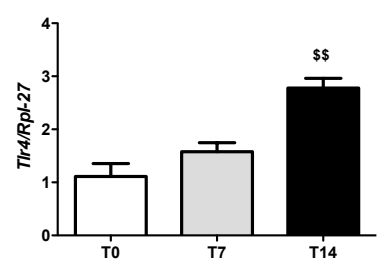

D

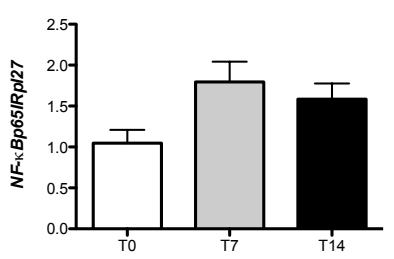

G

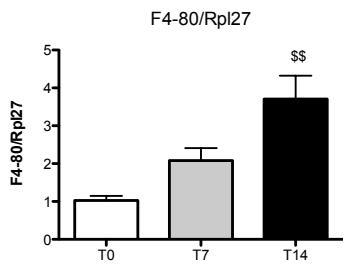

B

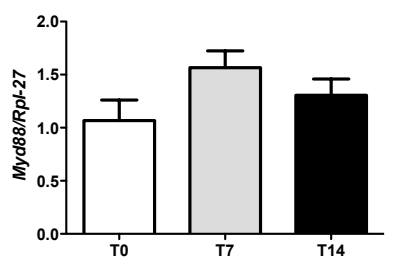

E

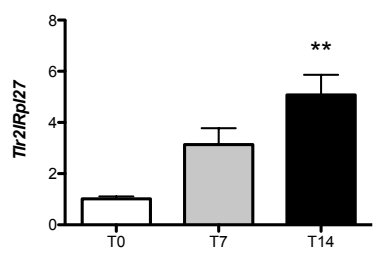

H

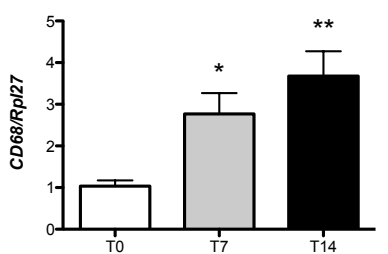

C

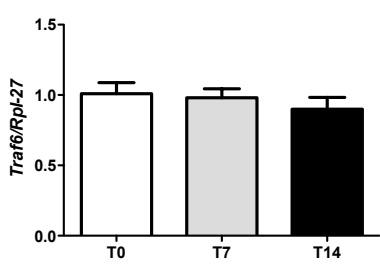

F

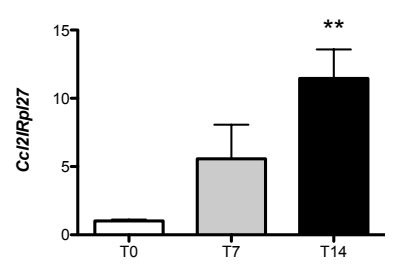

I

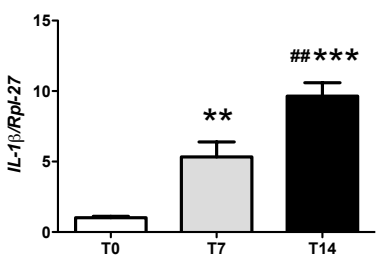

Figure 1. Gene expression from inflammatory pathway in the liver along cachexia progression. Results are expressed as mean $(n=5) \pm$ S.E.M. The liver was collected at time points $(0,7$ th and 14 th day after inoculation of tumour cells). ${ }^{*} p<0,05$ vs T0; ${ }^{* *} p<0,001$ vs T0; ${ }^{* * *} p<0,0001$ vs T0; \#\#p<0,001 vs T7; $\$ \$ p<0,001$ vs all the times points. A- gene expression of TIr4. B- gene expression of Myd88. Cgene expression Traf6. D- gene expression of NF- KBp65. E- gene expression of TIr2. F- gene expression of $\mathrm{Ccl} 2$. G- gene expression of CD68. H- gene expression of F4/80. I- gene expression of $\|-1 \beta$. 
Figure 2.

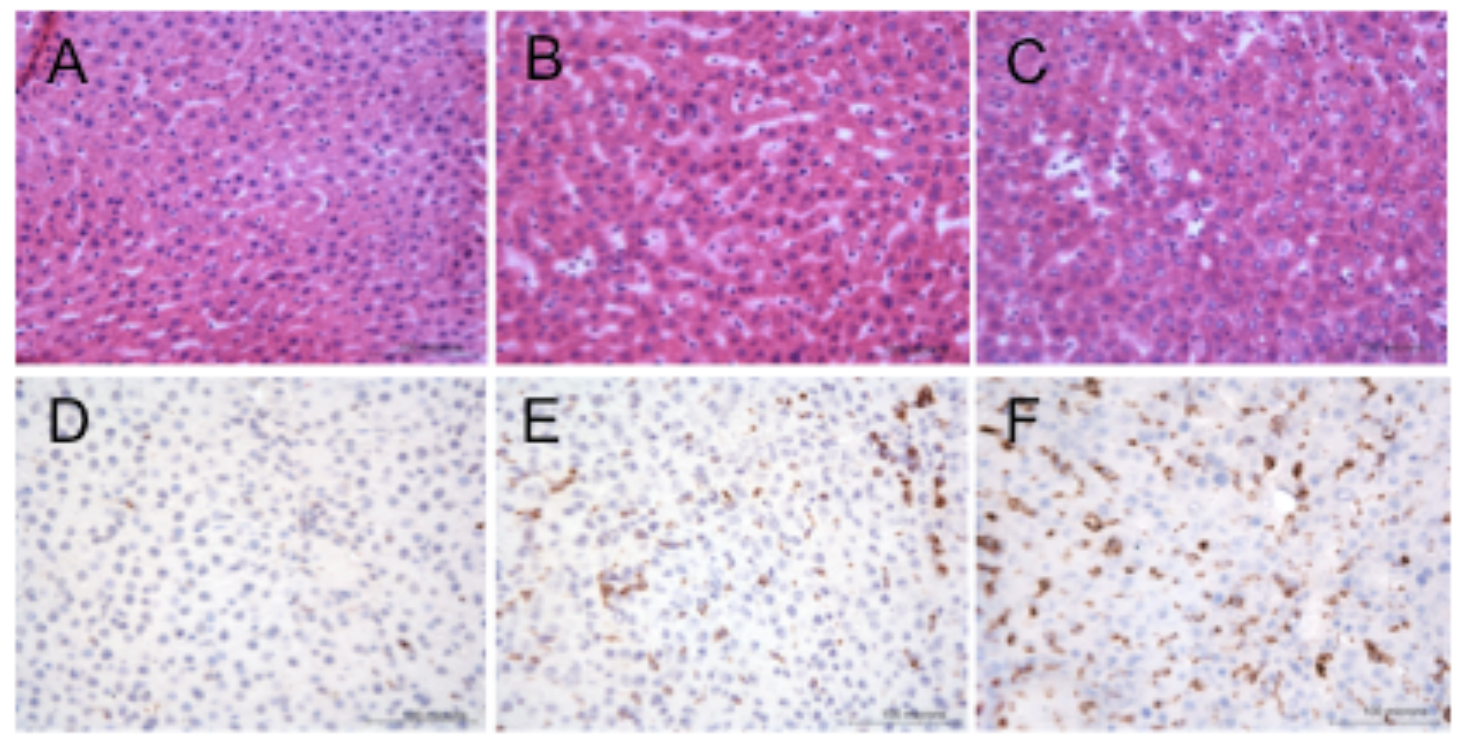

Figure 2. H\&E staining and immunohistochemistry to CD68. A- T0 stained with H\&E. B- T7 stained with H\&E. C- T14 stained with H\&E. D- T0 immunostaining to CD68 antibody. E- T7 immunostaining to CD68 antibody. F- T14 immunostaining to CD68 antibody. 
Figure 3.

A

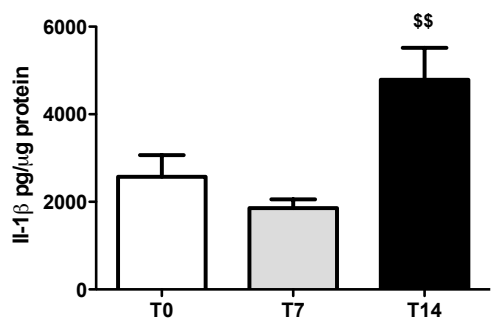

C

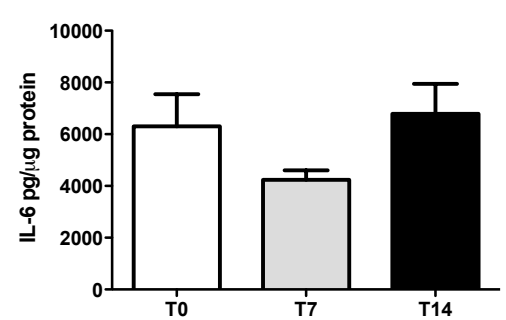

B

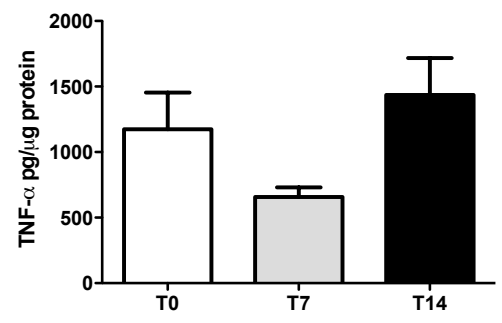

D

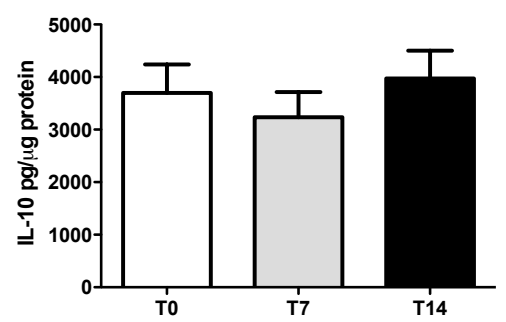

Figure 3. Protein expression from inflammatory cytokine in the liver along cachexia progression. Results are expressed as mean $(n=5) \pm$ S.E.M. The liver was collected at time points $(0$, 7 th and 14th day after inoculation of tumour cells). $\$ \$ p<0,001$ vs all the times points. A- protein expression of total II-1 $\beta$. B- protein expression Tnf- $\alpha$. C- protein expression of II-6. D- protein expression of lk-10. 
Figure 4.

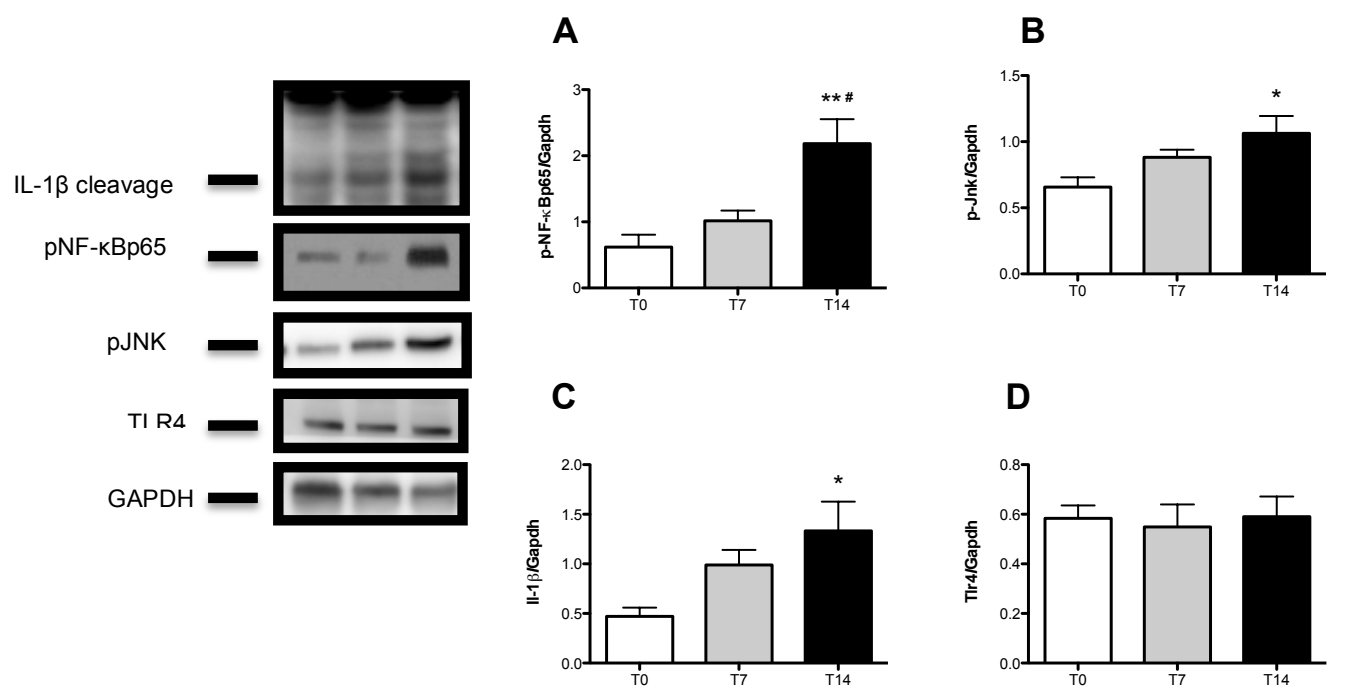

Figure 4. Protein expression from transcription factor in the liver along cachexia progression. Results are expressed as mean $(n=4) \pm$ S.E.M. The liver was collected at time points $(0,7$ th and 14 th day after inoculation of tumour cells). ${ }^{*} p<0,05$ vs $T 0 ;{ }^{* *} p<0,001$ vs $\mathrm{TO} ; \# p<0,05$ vs T7. A- protein expression of $p-N F k b p 65$. B- protein expression of $p$-Jnk. C- protein expression of cleavage II-1ß. Dprotein expression of TIr4. 
Figure 5.

A

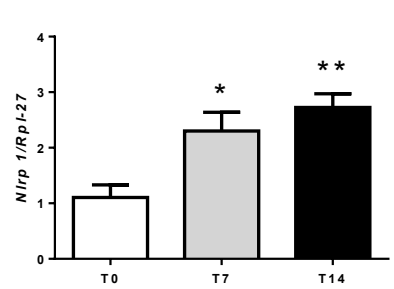

D

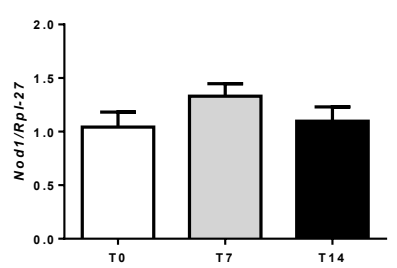

B

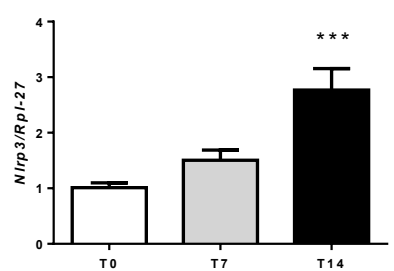

E

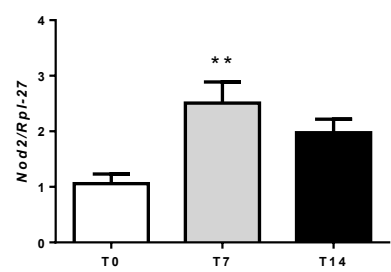

C

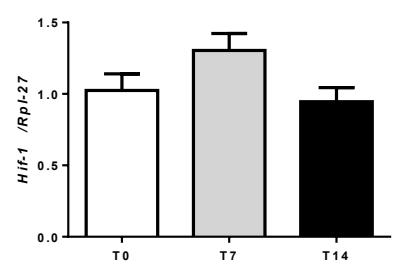

$\mathbf{F}$

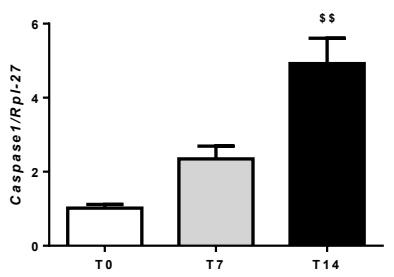

Figure 5. Gene expression from inflammasome pathway in the liver along cachexia progression. Results are expressed as mean $(n=5) \pm$ S.E.M. The liver was collected at time points $(0,7$ th and 14 th day after inoculation of tumour cells). ${ }^{*} p<0,05$ vs T0; ${ }^{* *} p<0,001$ vs T0; ${ }^{* * *} p<0,0001$ vs T0; $\$ \$ p<0,001$ vs all the times points. A- gene expression of NIrp1. B- gene expression of Nlrp3. C- gene expression Hif-1a. D- gene expression of Nod1. E- gene expression of Nod2. F- gene expression of Caspase 1. 
Figure 6.

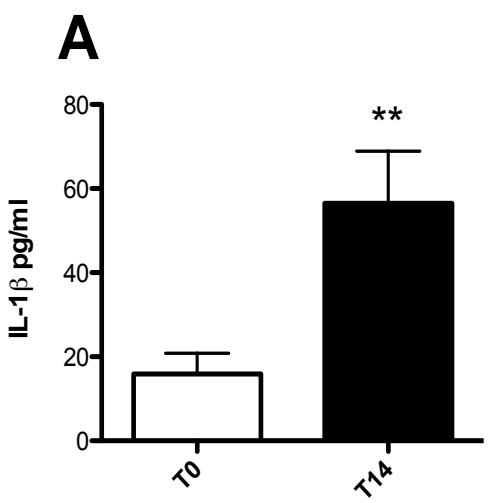

B

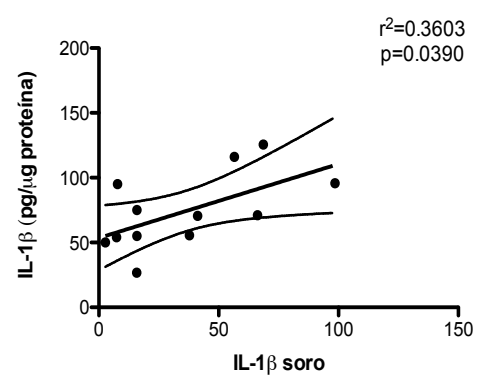

Figure 6. IL-1 $\beta$ protein in the serum along cachexia progression. A- Results are expressed as mean $(n=5) \pm$ S.E.M. The serum was collected at time points ( 0 and 14 th day after inoculation of tumour cells). ${ }^{*} \mathrm{p}<0,01$ vs T0. B- Correlation between IL-1 $\beta$ protein from serum and liver. 
Table 1. Primer list

\begin{tabular}{|c|c|}
\hline Gene (Species) & Sequence $5^{`} \rightarrow 3^{\prime}$ \\
\hline $\begin{array}{l}\text { p65 (Rattus norvegicus) } \\
\text { (NM 199267.2) }\end{array}$ & $\begin{array}{l}\text { Fw: ATG CAT CCA CAG CTT CCA G } \\
\text { Rev: TGC TCC TCT ATG GGA ACT TGA }\end{array}$ \\
\hline $\begin{array}{l}\text { TIr4 (Rattus norvegicus) } \\
\text { (NM 019178.1) }\end{array}$ & $\begin{array}{l}\text { Fw: TCT AAA TGC CAA CTG GAA CAG A } \\
\text { Rev: ATG GGA TGG ATC CAG AAA CA }\end{array}$ \\
\hline $\begin{array}{l}\text { Myd88 (Rattus norvegicus) } \\
\text { (NM 198130.1) }\end{array}$ & $\begin{array}{l}\text { Fw: GCG AGC TCA TTG AGA AAA GG } \\
\text { Rev: ACA CCT GGA GAC AGG CTG A }\end{array}$ \\
\hline $\begin{array}{l}\text { Traf6 (Rattus norvegicus) } \\
\text { (NM 001107754.2) }\end{array}$ & $\begin{array}{l}\text { Fw: AAG TCC ATA AGG GAT GCA GGT } \\
\text { Rev: TCG CTT TGC AAA ATT GTC AG }\end{array}$ \\
\hline $\begin{array}{l}\text { NIrp1 (Rattus norvegicus) } \\
\text { (NM 001145755.2) }\end{array}$ & $\begin{array}{l}\text { Fw: GCT TCA GCC CCC AAA GAT } \\
\text { Rev: TTG TCC AAG AGA GGG TCC AC }\end{array}$ \\
\hline $\begin{array}{l}\text { NIrp3 (Rattus norvegicus) } \\
\text { (NM 001191642.1) }\end{array}$ & $\begin{array}{l}\text { Fw: GCT GAA CTT GAG CAA CAA CG } \\
\text { Rev: CAC CCA ACT GTA GGC TCT GC }\end{array}$ \\
\hline $\begin{array}{l}\text { TIr2 (Rattus norvegicus) } \\
\text { (NM 198769.2) }\end{array}$ & $\begin{array}{l}\text { Fw: TTT GAT CAC TGC ACC CTC AA } \\
\text { Rev: ATG TGC AGG CTC CGT ATT GT }\end{array}$ \\
\hline $\begin{array}{l}\text { Hif1a (Rattus norvegicus) } \\
\text { (NM 024359.1) }\end{array}$ & $\begin{array}{l}\text { Fw: CAA CTG CCA CCA CTG ATG A } \\
\text { Rev: GGG TAG AAG GTG GAG ATG C }\end{array}$ \\
\hline $\begin{array}{l}\text { Caspase1 (Rattus } \\
\text { norvegicus) (NM 012762.2) }\end{array}$ & $\begin{array}{l}\text { Fw: ACA TCT TTC TCC GAG GGT TG } \\
\text { Rev: CAC CTC TTT CAC CAT CTC CAG }\end{array}$ \\
\hline $\begin{array}{l}\text { Nod1 (Rattus norvegicus) } \\
\text { (NM 001109236.1) }\end{array}$ & $\begin{array}{l}\text { Fw: TGC ATT CAA TGG CAT CTC G } \\
\text { Rev: TGG TCA GCC AGA TTA TTG TGA }\end{array}$ \\
\hline $\begin{array}{l}\text { Nod2 (Rattus norvegicus) } \\
\text { (NM 001106172.1) }\end{array}$ & $\begin{array}{l}\text { Fw: CAT CCC AGA GGG CAA GAA AA } \\
\text { Rev: GCC TCG TAA GGC AGA GAC AGT }\end{array}$ \\
\hline $\begin{array}{l}\text { II-1 } \beta \text { (Rattus norvegicus) } \\
\text { (NM 031512.2) }\end{array}$ & $\begin{array}{l}\text { Fw: GCA GCT TTC GAC AGT GAG G } \\
\text { Rev: TCA AGG GCT TGG AAG CAA }\end{array}$ \\
\hline $\begin{array}{l}\text { Rp/27 (Rattus norvegicus) } \\
\text { (NM 022514.1) }\end{array}$ & $\begin{array}{l}\text { Fw: CCT CAT GCC CAC AAG GTA CT } \\
\text { Rev: CTG TCT TGT ATC GCT CCT CAA A }\end{array}$ \\
\hline
\end{tabular}


Table 2. Body and tissue mass in Control (C) and Cachectic ( $\mathrm{T}$ ) animals

\begin{tabular}{lcccccccccccc}
\hline & \multicolumn{3}{c}{ T0 } & \multicolumn{3}{c}{ T7 } & \multicolumn{3}{c}{ C14 } & \multicolumn{3}{c}{ T14 } \\
\hline BM-TM (g) & 266,3 & \pm & 17,1 & 278,97 & \pm & 8,79 & 328,20 & \pm & 9,12 & 296,61 & \pm & $10,56^{*}$ \\
TM (g) & & & & 5,23 & & 2,35 & & & & 19,19 & \pm & 4,70 \\
Liver (g) & 6.32 & \pm & 0.72 & 8,60 & \pm & 0,71 & 11,03 & \pm & 1,13 & 11,17 & \pm & 1,56 \\
MEAT (g) & 1,10 & \pm & 0,56 & 1,47 & \pm & 0,22 & 1,60 & \pm & 0,23 & 1,24 & \pm & 0,34 \\
RPAT (g) & 0,97 & \pm & 0,4 & 2,11 & \pm & 0,75 & 2,79 & \pm & 1,30 & 2,17 & \pm & 0,75 \\
EAT (g) & 1,74 & \pm & 0,54 & 3,06 & \pm & 0,78 & 3,39 & \pm & 0,85 & 3,26 & \pm & 0,82 \\
\hline
\end{tabular}
Note: C (Control), T (Cancer-cachexia), BM - TM (Body Mass - Tumour mass), TM (Tumour Mass), MEAT (Mesenteric adipose tissue), RPAT (Retroperitoneal adipose tissue) and EAT (Epididymal adipose tissue). Values are expressed as mean \pm S.E.M. $n=5 .{ }^{*} p<0.05$. 
Supplementary figures
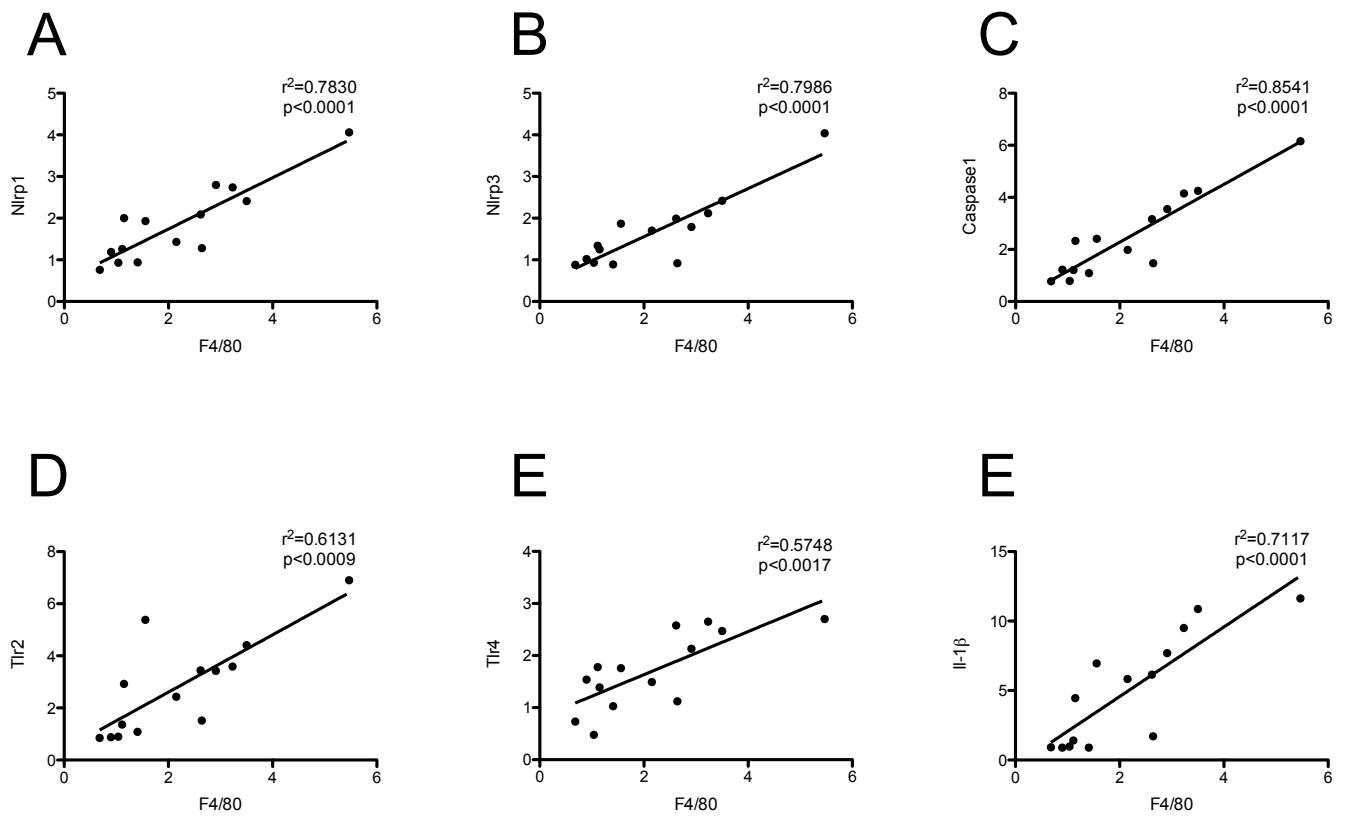

Supplementary Figure 1. Correlation with gene expression of F4/80 in the liver. A- Nlrp1. B-Nlrp3. C- Caspase1. D- Tlr2. E- Tlr4. F- Il-1ß. 

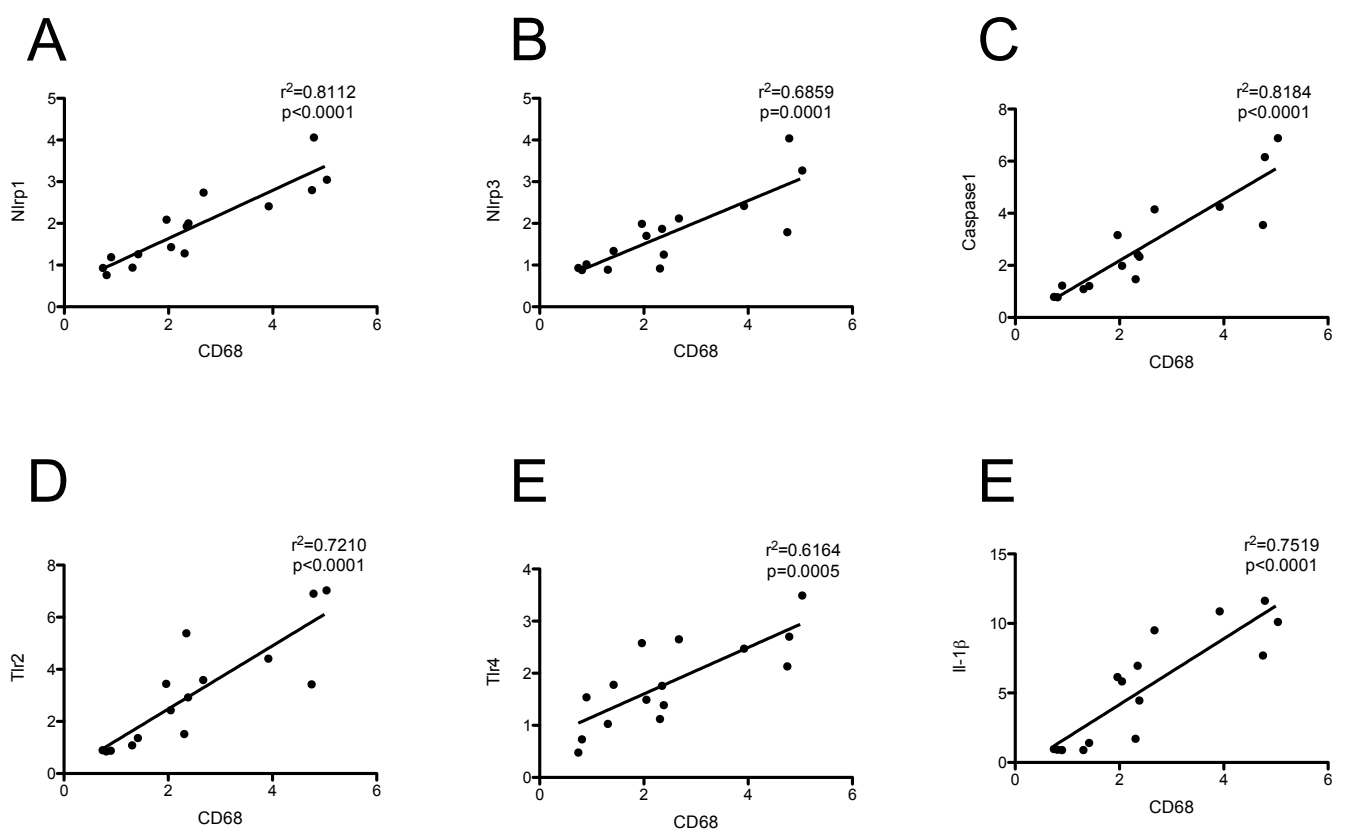

Supplementary Figure 2. Correlation with gene expression of CD68 in the liver. A- Nlrp1. B-Nlrp3. C- Caspase1. D- Tlr2. E- Tlr4. F- Il-1ß. 

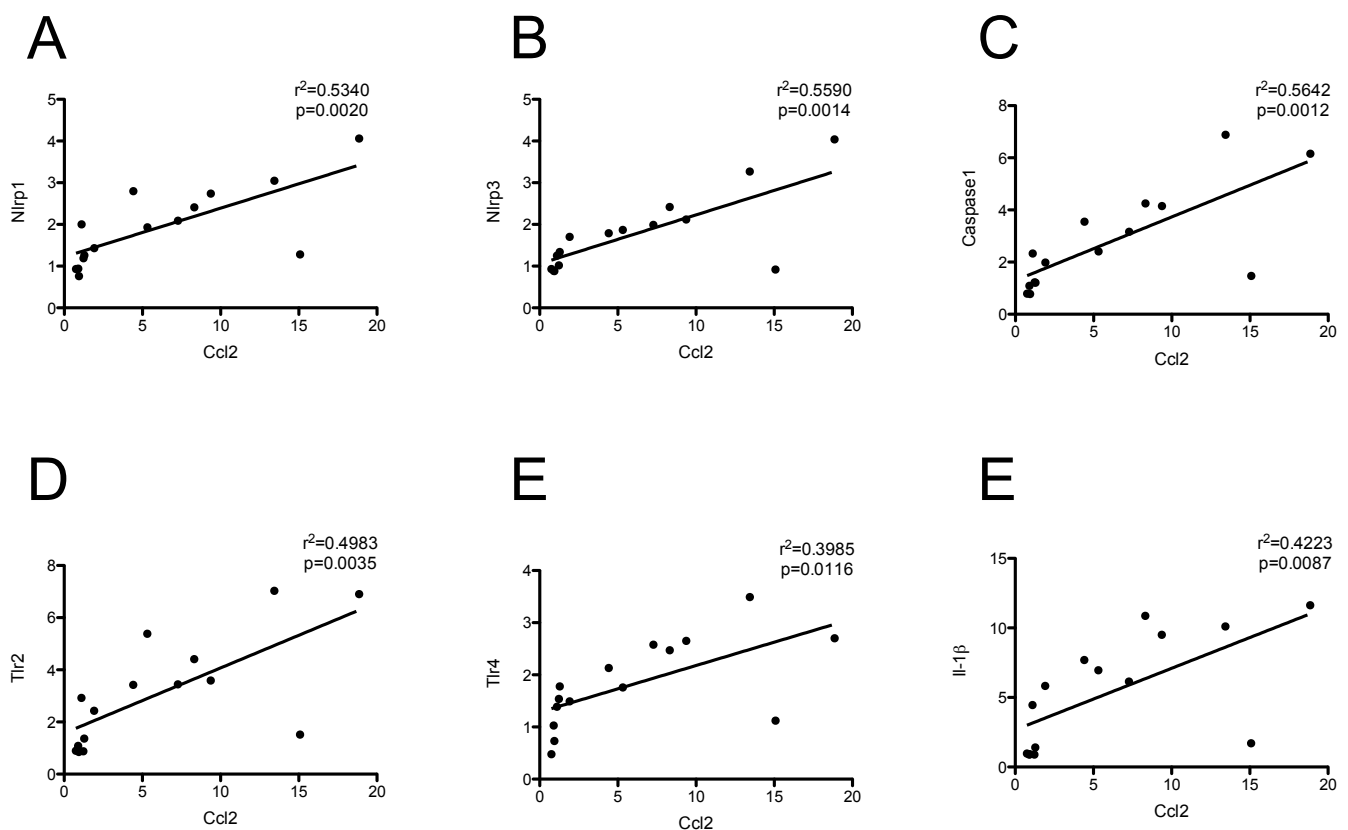

Supplementary Figure 3. Correlation with gene expression of Ccl2 in the liver. A- Nlrp1. B-Nlrp3. C- Caspase1. D- Tlr2. E- Tlr4. F- Il-1ß. 